NBER WORKING PAPER SERIES

\title{
THE LIFE-CYCLE DYNAMICS OF EXPORTERS AND MULTINATIONAL FIRMS
}

\author{
Anna Gumpert \\ Haishi Li \\ Andreas Moxnes \\ Natalia Ramondo \\ Felix Tintelnot \\ Working Paper 24013 \\ http://www.nber.org/papers/w24013 \\ NATIONAL BUREAU OF ECONOMIC RESEARCH \\ 1050 Massachusetts Avenue \\ Cambridge, MA 02138 \\ November 2017, Revised November 2019
}

We thank the editor, Stephen Yeaple, and two anonymous referees for their comments. We benefited from comments at various seminars. We would like to specially thank Jonathan Vogel for his insightful comments on an early version of the paper. We also thank Costas Arkolakis, Kerem Cosar, Javier Cravino, Stefania Garetto, Pinelopi Goldberg, Eduardo Morales, Veronica Rappoport, Andrés Rodríguez-Clare, and Mu-Jeung Yang for their comments and suggestions. We greatly thank Julien Martin for his help with the French data. Zhida Gui and Xiao Ma provided outstanding research assistance. This project has received funding from the European Research Council (ERC) under the European Union's Horizon 2020 research and innovation programme (grant agreement No 715147) and from the French National Research Agency (ANR) as part of the "Investissements d'avenir" program (reference: ANR-10-EQPX-17-Centre d'accès sécurisé aux données-CASD). The empirical analysis with the German data was conducted during visits to the research center of the Deutsche Bundesbank. We gratefully acknowledge the hospitality of the Bundesbank and the access to its Micro-database Direct investment (MiDi). Anna Gumpert gratefully acknowledges the financial support from the Deutsche Forschungsgemeinschaft through CRC TR 190. All errors are our own. The views expressed herein are those of the authors and do not necessarily reflect the views of the National Bureau of Economic Research.

NBER working papers are circulated for discussion and comment purposes. They have not been peer-reviewed or been subject to the review by the NBER Board of Directors that accompanies official NBER publications.

(C) 2017 by Anna Gumpert, Haishi Li, Andreas Moxnes, Natalia Ramondo, and Felix Tintelnot. All rights reserved. Short sections of text, not to exceed two paragraphs, may be quoted without explicit permission provided that full credit, including $(\subset$ notice, is given to the source. 
The Life-Cycle Dynamics of Exporters and Multinational Firms

Anna Gumpert, Haishi Li, Andreas Moxnes, Natalia Ramondo, and Felix Tintelnot

NBER Working Paper No. 24013

November 2017, Revised November 2019

JEL No. F1,F23

\title{
ABSTRACT
}

This paper studies the life-cycle dynamics of exporters and multinational enterprises (MNEs). Using rich firm-level data, we document a comprehensive set of facts on entry, exit, and growth of new exporters and new MNEs. Guided by these facts, we build a model based on the standard proximity-concentration trade-off extended to incorporate time-varying firm productivity and sunk costs of MNE entry. The calibrated version of the model goes far in matching crosssectional and dynamic moments of the data on exporters and MNEs. We show that including the choice to become an MNE affects the predicted export dynamics after trade liberalization. The different dynamics in a model with and without MNEs hinge on the right truncation of fastgrowing exporters induced by the inclusion of the MNE choice.

\author{
Anna Gumpert \\ Department of Economics \\ LMU Munich \\ Akademiestr. 1/III \\ D-80799 Munich, Germany \\ https://annagumpert.wordpress.com/ \\ anna.gumpert@econ.lmu.de \\ Haishi Li \\ University of Chicago \\ Kenneth C. Griffin Department of Economics \\ Saieh Hall \\ 5757 S University Ave \\ Chicago, IL 60637 \\ haishi@uchicago.edu \\ Andreas Moxnes \\ Department of Economics \\ University of Oslo \\ P.O box 1095 Blindern \\ 0317 OSLO \\ NORWAY \\ and CEPR \\ andreamo@econ.uio.no
}

\author{
Natalia Ramondo \\ School of Int'l Relations and Pacific Studies \\ University of California at San Diego \\ 9500 Gilman Drive, MC 0519 \\ La Jolla, CA 92093 \\ and NBER \\ nramondo@ucsd.edu \\ Felix Tintelnot \\ Kenneth C. Griffin Department of Economics \\ University of Chicago \\ 5757 South University Avenue \\ Chicago, IL 60637 \\ and NBER \\ tintelnot@uchicago.edu
}




\section{Introduction}

Exporters' life-cycle dynamics are important to understand the long-term and short-term effects of economic shocks and trade policy changes. In consequence, they have been extensively studied. However, exporting is only one possibility for firms to serve a foreign market. Firms may also choose to become multinational enterprises (henceforth, MNEs). Despite the overwhelming importance of these firms in the data, we know comparatively little about the life-cycle dynamics of MNEs and their possible interaction with exporter dynamics. ${ }^{1}$

This paper studies the life-cycle dynamics of exporters and MNEs. Using rich firm-level data, we first provide a comprehensive set of facts on the life-cycle dynamics of new exporters and new MNEs. We exploit data on domestic firms, exporters, and MNEs from France and Norway and complement them with data on MNEs from Germany. First, new exporters in a foreign market have two to three times higher exit rates than new affiliates of MNEs in the same market. Second, average sales growth is similar for new exporters and new MNEs. However, export growth profiles of exporters that switch to serving the market as MNEs are steeper than those of exporters that do not switch to MNE status. Finally, exit rates of exporters at age one exhibit gravity-they are strongly correlated negatively with foreign market size and positively with distance-whereas those of young MNE affiliates are uncorrelated with these foreign country characteristics. In contrast, entry rates do not present stark differences in their gravity patterns between the two groups. Our findings are strikingly very similar across the three economies under study, despite their different size and structure.

Guided by the facts, we develop a dynamic model of trade and foreign direct investment (FDI) based on the static model of the proximity-concentration trade-off in Helpman et al. (2004, henceforth, HMY). We introduce dynamics into the model by assuming that firm productivity evolves according to a Markov process and that MNE activities face a sunk entry cost. The model preserves the ranking of the export and MNE choice from the static model: The most productive firms become MNEs; firms with intermediate productivity levels become exporters; and the least productive firms serve only their home market. The sunk costs of MNE activities lead to a band of inaction, a range of productivity levels where existing MNEs do not exit a market, but non-MNEs with the same productivity do not enter. We show that our model is rich enough to qualitatively capture the facts we document.

\footnotetext{
${ }^{1}$ MNE affiliates' global sales are twice as large as global exports, and they account for disproportionally large shares of aggregate output and employment in many countries (Antrás and Yeaple, 2014).
} 
In the calibrated version of the model, we incorporate sunk export costs, as in the dynamic model of exporting in Roberts and Tybout (1997), and assume that fixed and sunk costs for both MNE and export activities are heterogenous at the firm-destination level. We evaluate this quantitative version of the model in which Helpman et al. (2004) is coupled with dynamics features of Roberts and Tybout (1997). Although we do not target the life-cycle exit and growth profiles of exporters and MNEs, the calibrated model captures quite well the patterns observed in the data.

Finally, we evaluate the predictions of our calibrated model with both exporters and MNEs regarding life-cycle and aggregate dynamics after a hypothetical trade-liberalization episode. We compare the predictions of our model with both exporters and MNEs to a calibrated version of the model with only exporters. Enriching the canonical dynamic model of trade to include MNEs-a first-order feature of the data-has consequences for the life-cycle and aggregate dynamic behavior of exporters. One source of the different responses of exporters between the two models hinges on the right truncation of fastgrowing exporters induced by the inclusion of the MNE choice. Without the MNE choice, the most productive firms are exporters, as in the static model in Melitz (2003); with the MNE choice, the most productive firms become MNEs, as in HMY. In a dynamic setup, including the MNE choice not only truncates the exporters' distribution of productivity levels, but also induces a truncation to-the-right of the distribution of growth rates. The fastest-growing exporters stop exporting and become MNEs when that option is allowed, while the slowest-growing exporters remain exporters. Those exporters with the highest productivity growth do not contribute to the average growth rate of exporters in the model with MNEs-because they change status—but they do so in the model where the MNE option is not included. ${ }^{2}$

Our paper contributes to several strands of literature. First, we contribute to the small, but growing, literature that studies the joint behavior of exporters and MNEs using dynamic models. Ramondo et al. (2013), Fillat and Garetto (2015), and Conconi et al. (2016), among others, document and study different implications of the proximity-concentration tradeoff in dynamic setups. We present new evidence and study implications related to the joint life-cycle behavior of exporters and MNEs. ${ }^{3}$

\footnotetext{
${ }^{2}$ This mechanism hinges on the assumption that exporters that become MNE abandon exports to serve a foreign market. We find that exports relative to total sales in a foreign destination decrease sharply after MNE entry, consistent with the evidence documented by Belderbos and Sleuwaegen (1998), Bloningen (2001), and Head and Ries (2001), which use detailed firm- and product-level data.

${ }^{3}$ Ramondo et al. (2013) include aggregate uncertainty into a two-period model of trade and FDI to analyze how the properties of the international business cycle affect the choice of the entry mode into foreign markets. Fillat and Garetto (2015) include aggregate uncertainty and sunk entry cost to study the consequences for asset pricing. Conconi et al. (2016) include a learning mechanism to explain that most firms enter foreign markets as exporters before opening an affiliate there. Early work by Rob and Vettas
} 
Second, we complement the extensive literature that studies exporters' dynamics. Early work by Baldwin (1989), Baldwin and Krugman (1989), and Dixit (1989), followed by Roberts and Tybout (1997), Ghironi and Melitz (2005), Das et al. (2007), Alessandria and Choi (2007), and Impullitti et al. (2013), point to the importance of the hysteresis created by sunk investments for understanding the effects of temporary and permanent shocks on aggregate trade flows and exchange rate movements. Our model combines elements of this rich dynamic literature on exporters with the canonical model of trade and FDI in Helpman et al. (2004).

Our paper is also closely related to Ruhl and Willis (2017) who document a set of lifecycle dynamics facts for Colombian exporters. We document a similar (sub-)set of facts for new French and Norwegian exporters, but also include life-cycle facts for MNEs. We find, as they do, that matching the observed patterns of survival and growth of new exporters requires very low sunk export costs, but this is not the case for MNEs. Whereas they include demand-side frictions in the model to match the observed exit and growth patterns, we include MNEs, a first-order feature of the data. We evaluate how far the model goes in matching the data and whether the presence of MNEs changes the dynamic behavior of exporters after a hypothetical trade-liberalization episode. ${ }^{4}$

The paper proceeds as follows: Section 2 describes the data; Section 3 documents the facts; Section 4 describes the model; Section 5 presents the calibration; Section 6 presents the counterfactual exercises; and Section 7 concludes.

\section{Data}

Our empirical analysis is based on rich firm-level panel data sets from France, Norway, and Germany. The French and the Norwegian data contain information on domestic firms, exporters, and MNEs in varying levels of detail. In contrast, the German data

(2003) features demand uncertainty together with capacity constraints to study the mechanism behind the choice of firms to simultaneously export to and maintain affiliates in the same market.

4 The literature on the life-cycle of domestic firms (summarized by Haltiwanger et al., 2013) and exporters find that models with a AR(1) firm-level productivity process, as in Hopenhayn (1992), deliver new firms that grow too large too quickly. Both literatures have resorted to demand frictions to slow down firm growth (see Foster et al. (2016) for domestic firms). In relation to exporters' growth driven by demand factors, papers such as Albornoz et al. (2012), Eaton et al. (2014), and Morales et al. (2017), focus on the dynamics of trade associated with learning. Arkolakis (2016) includes the cost of building a customer base in a dynamic model of trade. Fitzgerald et al. (2017) evaluate the importance of demand-learning firm growth versus customer-based firm growth to explain the life-cycle dynamics of firm export quantities and export prices. Araujo et al. (2016) document that in markets with better contracting institutions new exporters start bigger but grow slower (conditional on survival). They propose a framework in which imperfect contract enforcement, together with imperfect information (and previous export experience in other foreign markets) interact to match the observed pattern of exporter growth and survival. 
contain extremely detailed information on the foreign affiliates of German MNEs, but do not provide any information on exporters and domestic firms. Our analysis exploits the strengths of each of the three data sources, all of which cover a period of more than ten years.

France. The data span the years 1999-2011 and combine information from several sources. Information on a firm's domestic sales is from FICUS (1999-2007) and FARE (2008-2011); the export data are from the French customs; information on ownership links between firms in France and between firms in France and abroad are from LiFi; and information on foreign affiliate sales is from OFATs $(2007,2009-2011)$. We restrict the sample to firms that are subject to the BRN-taxation regime and, for some of the analysis, to the sub-period 1999-2007. ${ }^{5}$

The data contain information on each firm's domestic sales and export sales by destination, as well as the location of foreign affiliates of French MNEs. Information on foreign affiliate sales is available only for a subset of large MNEs and for some (non-consecutive) years. ${ }^{6}$ While affiliate sales are recorded annually, exports are recorded monthly. Following Kleinert et al. (2015), we consolidate the information on domestic activities, exports and foreign affiliates to the level of the French group (i.e., if firms A and B belong to firm C, we consolidate all three firms). We keep a consolidated firm in the sample if at least one of its domestic members is active in the manufacturing sector in at least one year. ${ }^{7}$ For independent firms, we focus on those that operate in the manufacturing sector in at least one year. Our sample contains only firms headquartered in France and excludes French affiliates of foreign MNEs.

We consider MNE-country pairs and exporter-country pairs with multiple entry and exit over the sample period. ${ }^{8}$ We restrict our attention to majority-owned affiliates of French MNEs, which account for around 80 percent of all affiliates of French MNEs. We aggregate both exports and FDI at the parent firm-foreign destination-year level. We end up with a sample of 963,375 firm-year observations. The upper panel of Table E.1 shows that 1.6 percent of firms in our sample are MNEs and 28.7 percent are non-MNE exporters.

\footnotetext{
${ }^{5}$ The FICUS/FARE databases provide balance sheet data on virtually all French firms. The principal data source is firms' tax statements. The BRN regime applies to larger firms. We conducted our analysis also including all firms. As small firms rarely export or conduct FDI, results are very similar. The period restriction is made in order to avoid structural breaks in the time series, as both the industry classification and the definition of the domestic sales variable changed in 2008.

${ }^{6}$ OFATS is a survey of French MNEs with affiliates outside of the European Union. The sample is biased towards large MNEs, as a comparison of domestic sales for MNEs in OFATs and the other sources reveals.

7 This consolidation implies that wholesale firms in France may be part of our sample, which is important because large French groups often channel exports through wholesale affiliates.

${ }^{8}$ Restricting the sample to MNE-country and exporter-country pairs with a single entry and exit over the sample period yields very similar results.
} 
French MNEs account for almost 60 percent of employment in our sample, while nonMNE exporters account for more than 30 percent. The median (mean) French MNE operates in two (five) markets, with a handful of MNEs serving more than 81 markets, while the median (mean) exporter serves four (ten) markets, with some exporters serving more than 178 markets (top-coded to preserve confidentiality).

Norway. The data, which span the years 1996-2006, include information on each firm's domestic sales, as well as export and foreign affiliate sales by destination country. The data nest balance sheet information on firms in the Norwegian manufacturing sector from Statistics Norway's Capital Database; information on exporters from customs declarations; and data on firms' foreign operations from the Directorate of Taxes' Foreign Company Report. The coverage is comprehensive: All foreign affiliates of Norwegian firms in the manufacturing sector, as well as 90 percent of Norwegian manufacturing revenues, are included; firms in the oil sector are excluded.

We consider MNE-country pairs and exporter-country pairs with multiple entry and exit over the sample period. We include both majority- and minority-owned foreign affiliates of Norwegian parents and adjust the affiliate sales by the parent's ownership share. ${ }^{9}$ Our sample consists of 89,018 firm-year observations. As the lower panel of Table E.1 shows, only 1.5 percent of Norwegian firms have affiliates abroad, and 36.4 percent are non-MNE exporters. Norwegian MNEs represent more than 13 percent of total manufacturing employment in Norway, while exporters represent 63 percent. The median (mean) Norwegian MNE operates in two (four) markets, with a maximum at 37 markets, while the median (mean) exporter serves three (seven) markets, with a maximum of 122 markets.

Germany. The data, which span the years 1999-2011, contain detailed balance sheet information about foreign affiliates of German MNEs. The main data source is the Microdatabase Direct investment (MiDi, see Schild and Walter, 2015). Information about parent firms is limited; for instance, it is not possible to distinguish between domestic and export sales of the parent.

We consolidate the information on direct and indirect ownership shares and restrict our attention to majority-owned affiliates, which represent 95 percent of foreign affiliates of German MNEs, and affiliates whose parent operates in the manufacturing sector, or whose parent is a holding company belonging to a corporate group in the manufacturing sector, in at least one year. ${ }^{10}$ We consolidate affiliates at the parent firm-foreign destination-

\footnotetext{
${ }^{9}$ A 20 percent ownership threshold, not ten percent, is used to distinguish direct from portfolio investment. The ownership shares considered for Norway are lower than the ones for France (20 versus 50 percent) in order to gain observations.

10 Reporting foreign investments to the German central bank is compulsory, but the reporting
} 
year level, and end up with a sample of 37,843 parent-year observations. Only 0.21 percent of German firms have affiliates abroad, but they account for 27 percent of total sales in Germany (Buch et al., 2005). The median (mean) German MNE operates in one (three) country(ies), with some parents operating in more than 27 markets (top-coded to preserve confidentiality).

\section{Facts on the life-cycle dynamics of exporters and MNEs}

We document three novel facts about the life-cycle dynamics of MNEs and exporters. First, we show life-cycle patterns of exit rates. Second, we present evidence on life-cycle growth. Third, we document the relation between exit and entry rates across destination markets and characteristics of those markets. Taken together, these facts are informative about the features to be included in a dynamic model of exports and FDI- we explain this connection in more detail below.

We study the behavior of new firms that start exporting to-or open an affiliate ina foreign country. We focus on the firm's main mode of international operation and distinguish between non-MNE exporters and MNEs. That is, only firms that are not MNEs are considered exporters to a foreign destination, while firms with foreign operations in a market are considered MNEs whether they export or not contemporaneously to the same foreign destination. This distinction is motivated by the observation that FDI is the dominant mode of serving the foreign market after MNE entry. Appendix Figure D.1 shows that the average export-to-foreign sales ratio decreases to around ten percent when a firm opens an affiliate in a market, and that around ten percent of MNEs with exports to that market before MNE entry completely discontinue exporting once they switch to FDI.

Our facts are based on observations at the firm-destination-year level. For expositional purposes, in the body of the paper, we present figures that show averages across the destinations, weighted by each destination's share of export (MNE) firms. Appendix Table E. 2 contains the results of Ordinary-Least- Squares (OLS) regressions that include a battery of fixed effects and additional controls.

requirements change over time. We adjust the sample to unify thresholds: We include only affiliates with either a participation of ten percent and revenues of at least ten million DM (Euro equivalent), or with participation of at least 50 percent and revenues of at least three million Euro. We consolidate ownership shares and restrict the sample to majority-owned affiliates only after unifying the reporting threshold. 
Figure 1: Exit rates by age.

(a) France

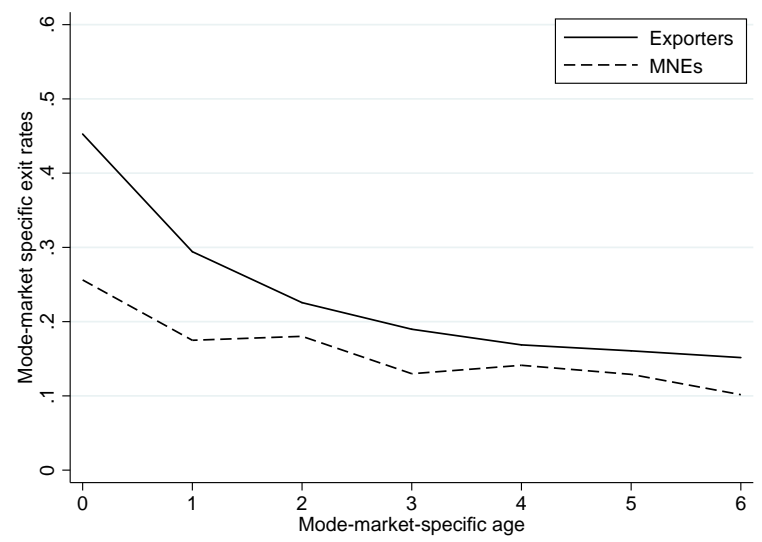

(b) Norway

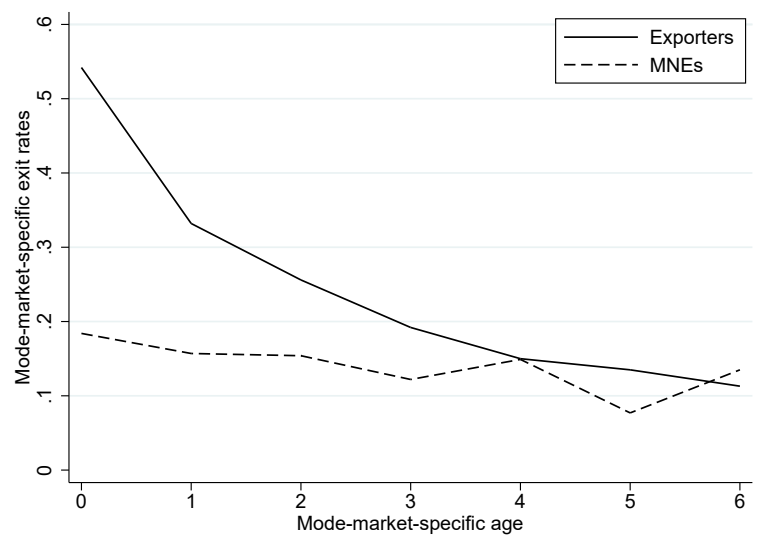

Notes: Number of exits from a mode-market relative to the number of firms active in a mode-market, by mode-market-specific age, for exporters and MNEs. Observations are at the firm-destination-year level. We show averages across destinations weighted by each destination's share of export (MNE) firms. Exporters refers to non-MNE exporters.

\subsection{Exit rates}

We first study the exit patterns of new exporters and new MNEs. We focus on exit from the current mode of international operation and a foreign country.

Figure 1 plots the exit rates of exporters and MNEs at the firm-destination level by age. Exit rates are calculated as the number of MNEs (exporters) that exit a given destination relative to the number of active MNEs (exporters) in that destination at each age. Age refers to the number of years after entry in a given market-mode, with age in the entry year equal to zero. The figure presents averages across all firm-destination pairs.

On average, MNEs in a foreign market have between one third and one half of the exit rates of exporters in the same foreign country in their first year of life. For both modes of internationalization, exit rates are declining with age, though more drastically for exporters. It is remarkable that results are qualitatively and quantitatively similar between France and Norway. ${ }^{11}$

A formal test confirms that French exporters are around 15 percentage points more likely to exit than foreign affiliates of French MNEs in the first two years after entry, but the difference disappears later in life. For Norway, the difference in exit rates between exporters

\footnotetext{
${ }^{11}$ Eaton et al. (2008) document similar exit rates for new Colombian exporters at the firm-destination level. In unreported evidence, we find that the exit patterns of new MNEs from Germany are also remarkably similar to the patterns found for French and Norwegian MNEs.
} 
Figure 2: Exit rates by age: experienced versus non-experienced MNEs.

(a) France

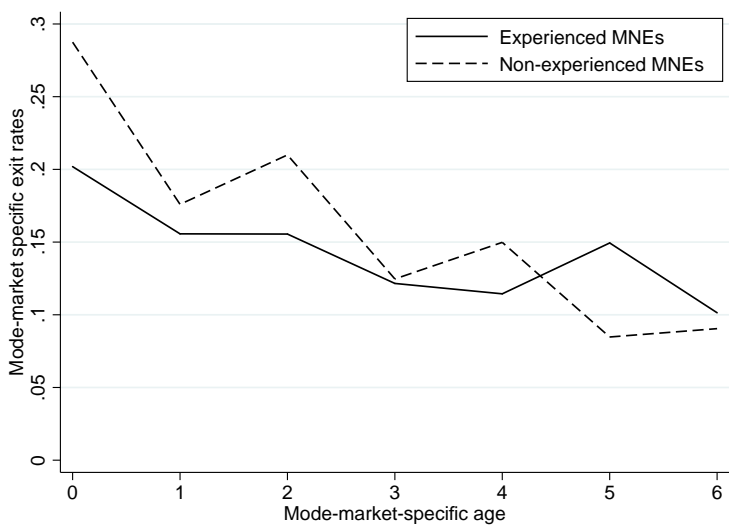

(b) Norway

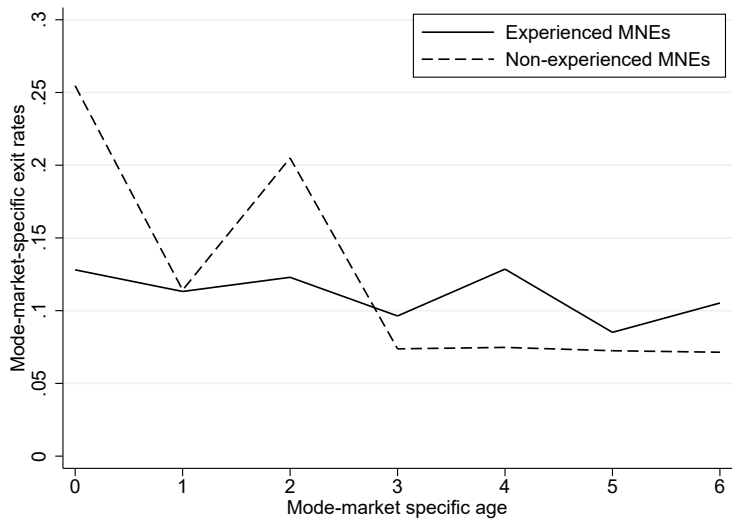

Notes: Number of exits from a mode-market relative to the number of firms active in a mode-market, by mode-market-specific age. Experienced MNEs are new affiliates of MNEs that exported to a foreign market for one or more years before opening an affiliate there. Observations are at the firm-destination-year level. We show averages across destinations weighted by each destination's share of MNE firms.

and MNEs is 30 percentage points at entry, but, after two years, the difference is not statistically different from zero. This finding is summarized in Appendix Figure D.2.

It is reasonable to conjecture that having experienced a destination market as an exporter before entering with an MNE affiliate has an effect on the chances of survival in that market. We explore this evidence in Figure 2. We define "experienced MNE" an MNE that exported to a given destination market in any year before opening a foreign affiliate there. ${ }^{12}$ Experienced MNEs have an almost 10-percentage point lower exit rate, on average, in the first year after entry than new affiliates without export experience. However, this advantage disappears later in life (see also Appendix Figure D.3).

We conclude that:

Fact 1. New MNEs in a foreign destination have lower exit rates than new exporters in that destination. MNEs with previous export experience in a market have lower exit rates at entry than MNEs without that experience.

The large difference between exit rates of exporters and MNEs suggests the presence of sunk costs of MNEs that are much larger than sunk costs of exporting. Additionally, the co-existence of experienced and non-experienced MNEs supports a HMY-type model with an $\mathrm{AR}(1)$ process for firm productivity.

Robustness. One may be concerned that the differences in exit rates documented in

\footnotetext{
${ }^{12}$ Experienced MNEs represent almost 60 percent of new MNEs for France (47 percent for Norway).
} 
Figure 1 are not due to differences between the two modes of internationalization, but that they are artifacts of definitions of age and exit. Firms may switch between modes so that exporters become MNEs, and MNEs become exporters, for example. To exclude such patterns from driving our results, we present two robustness results using the French data. First, we recompute age as the number of years that the firm is active in a market, regardless of its international mode of operation; that is, we compute market-specific, rather than mode-market specific, age. Second, we redefine exit as complete exit from the market rather than as exit from either exporting or MNE activities in a market. Baseline results still hold, as columns 3 and 4 in Appendix Table E. 2 show. Additionally, one may be concerned that the entry mode of FDI plays a role: If MNEs enter a market through Merger and Acquisition (M\&A), they take over pre-existing domestic firms, whereas Greenfield affiliates are, by definition, brand-new firms. Using the data from Germany, Appendix Figure D.5a shows that there is no difference in exit rates between the two modes of entry of foreign affiliates of German MNEs. ${ }^{13}$

\subsection{Sales growth}

Figure 3 shows the sales growth of exporters and MNE affiliates by age. We focus on firms that survive for at least four years in a mode-market and demean the firm-destination observations by industry, year, and destination fixed effects. We normalize sales with respect to one-year after entry because the entry year may be contaminated, particularly for exporters, by the so-called "partial-year effects"-artificially high first-year growth rates due to firms that start operations in the middle of the calendar year (see Bernard et al., 2017). Columns 5 and 6 in Appendix Table E. 2 show the OLS results.

Figure 3 shows that foreign sales grow at similar rates for French exporters, Norwegian exporters, and Norwegian MNEs, conditional on surviving for at least four years in the market. Growth rates are markedly different only between age zero and age one, but as outlined, this difference is likely attributable to partial-year effects. ${ }^{14}$

Lumping together exporters that eventually become MNE with the ones that never do may mask substantial heterogeneity. Figure 4 shows that, in the French data, the group

\footnotetext{
${ }^{13}$ In unreported results for France, we find that our baseline results are robust to: splitting the sample into European Single Market (ESM) and non-ESM countries to address concerns about the different reporting thresholds for exports to EU and non-EU members; using the unconsolidated rather than the consolidated data; splitting the sample into the 1999-2005 and 2006-2011 periods; including cohort, rather than year, fixed effects; and correcting for partial-year effects. Additionally, results at the firm level are very similar to results at the firm-destination level.

${ }^{14}$ Unreported evidence for Germany shows that sales profiles of German MNEs are quite similar to the ones of Norwegian MNEs.
} 
Figure 3: Sales growth by age.

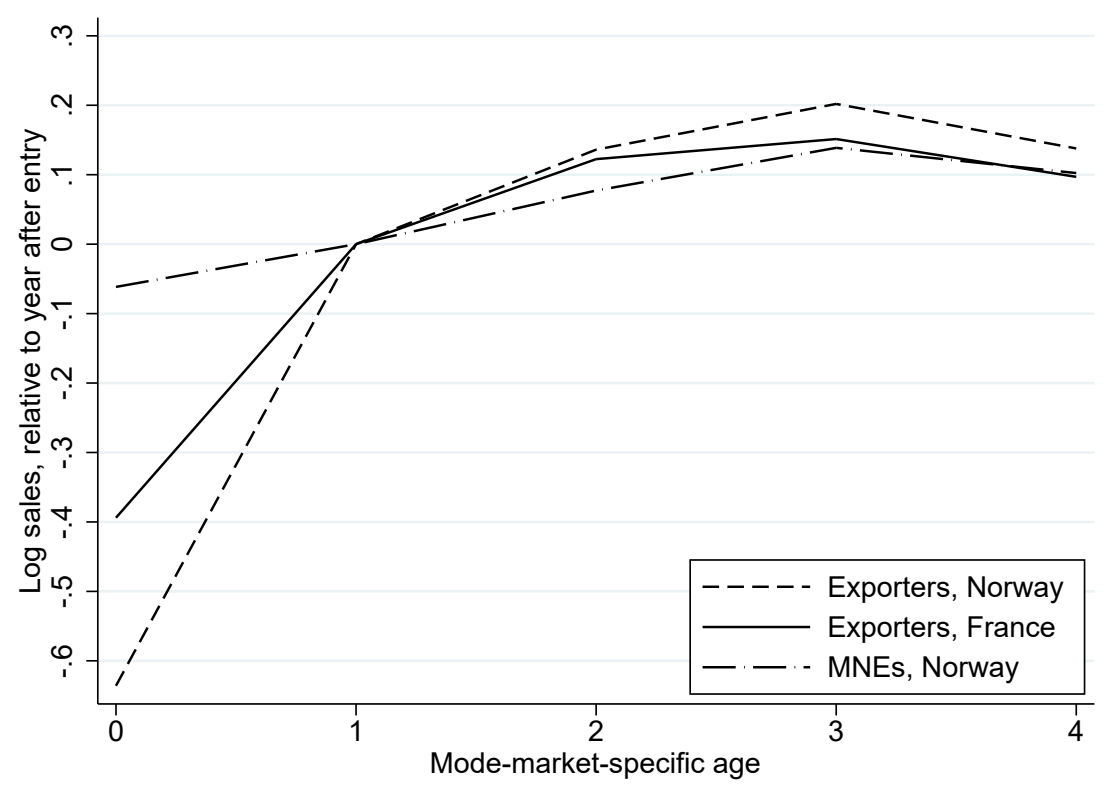

Notes: Log of firm-destination export (affiliate) sales with respect to firm-destination export (affiliate) sales in the year after entry. Firms with five or more years in the market. Observations are at the firm-destinationyear level. We show averages across destinations weighted by each destination's share of export (MNE) firms. Log of sales first demeaned by industry, year, and destination fixed effects. Exporters refers to nonMNE exporters.

of exporters that switch to FDI to serve a given market ("ever-MNE" exporters) clearly grow faster, in terms of exports, in the years previous to MNE entry, than the exporters that never become MNE ("never-MNE" exporters). In the Norwegian data, the difference is less marked, but the number of observations also decreases substantially.

We conclude that:

Fact 2. Average life-cycle sales growth is similar for exporters and MNEs. However, everMNE exporters grow, on average, much faster before MNE entry than do never-MNE exporters.

The similarity of export and affiliate sales growth suggests that productivity evolves in a similar way for exporters, parents and affiliates of MNEs. The higher export sales growth of ever-MNEs than never-MNEs supports a strong role for self-selection of firms into the different modes of internationalization, as in HMY.

Robustness. One may be concerned that normalizing sales growth by the year after entry is not sufficient to adequately account for partial-year effects. As the French data contain monthly export sales, we can correct for partial-year effects by calculating 12month growth rates (as also done by Bernard et al. 2017). A comparison of columns 5 and 
Figure 4: Exporters' sales growth by age and type.

(a) France

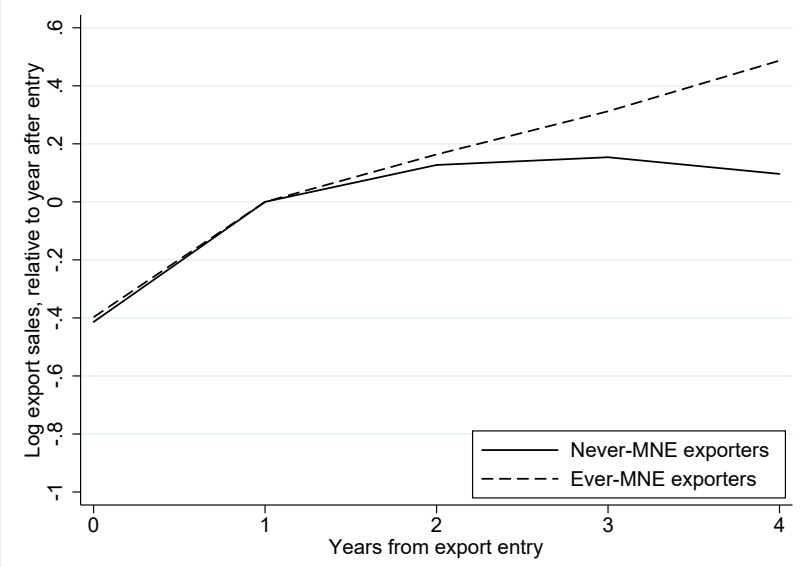

(b) Norway

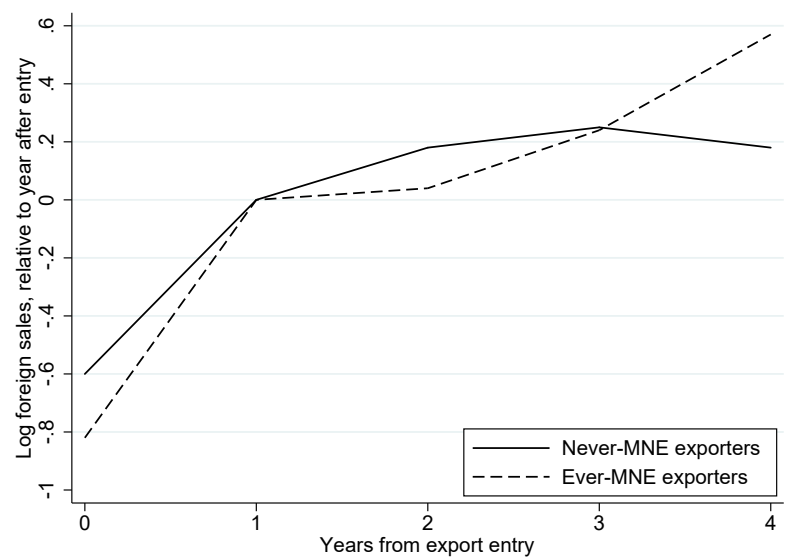

Notes: Log of firm-destination export sales with respect to firm-destination export sales in the year after export entry, for firms with five or more years in the market as exporters. Observations are at the firm-destinationyear level. We show averages across destinations weighted by each destination's share of export firms. Log of sales are first demeaned by industry, year, and destination fixed effects. Never-MNE exporters are exporters that, in our sample period, do not change to MNE status. Ever-MNE exporters are exporters that become MNEs after export entry. Exports for ever-MNE exporters are computed for the years before MNE entry, for exporters that enter MNE status after exporting for four years into a given market.

7 in Appendix Table E.2 confirms that the entry year does seem contaminated by these effects: Growth at age one is much higher for the calendar-year data than for the adjusted data; for subsequent ages, growth rates are quite similar, which supports the age-one normalization in Figure 3.

To document the selection induced by non-random survival, Appendix Figure D.4 shows growth profiles by tenure in the market. As expected, firms that survive longer grow faster. The differences are less pronounced for MNEs, but for all tenure lengths, exports from age one onwards grow at a similar rates as MNE sales.

Finally, one may be rightly concerned that sales growth rates of new MNEs differ between new MNE affiliates that enter the market through M\&A versus Greenfield FDI. One may expect that, as brand-new firms, affiliates created through Greenfield FDI grow faster than affiliates created through M\&As, which are older. ${ }^{15}$ Using the German data, Appendix Figure D.5b shows that, as expected, MNEs that enter through M\&A grow less than MNEs that enter a market with a Greenfield project. Nonetheless, the differences are not large if one disregards the entry year, again supporting our normalization choice in Figure 3.

\footnotetext{
${ }^{15}$ Part of the higher growth rate may be due to partial-year-effects for MNEs because some affiliates may not start operating in January, but later in the year.
} 


\subsection{Entry, exit, and gravity}

The previous two facts pool firms across different destination countries. Country characteristics, however, may be an important determinant of a firm's development over its life-cycle. To explore this issue, we study the correlation between first-year exit rates and entry rates of exporters and MNEs, and two country characteristics that are prominent in the international trade literature: the size of the destination country, as measured by GDP; and the distance of the destination country from the firm's home country. Our finding is that:

Fact 3. First-year exit rates of exporters exhibit gravity, whereas those of MNEs do not. Both entry rates for exporters and MNEs exhibit gravity.

Figure 5 shows scatter plots of first-year exit rates against market size (upper panels), and distance (lower panel), for France. We restrict the sample to countries with at least ten firm-destination observations. We relegate results for Norway, which are extremely similar, to Appendix Figure D.6.

The cross-country patterns of first-year exit between the two modes of international operation are strikingly different: While exporters operating in smaller and more distant markets are more likely to stop operations right after entry, it is not clear that affiliates of MNEs do. ${ }^{16}$ An OLS regression shows that the exit probability increases by almost seven percentage points when distance doubles, and it decreases by 3.4 percentage points when GDP doubles, with both coefficients significant at the one percent level. In contrast, the effects of GDP and distance on the exit rates of MNE affiliates are insignificant.

Figure 6 shows the same scatter plots for the entry rates. Unlike the exit rates, both entry rates for exporters and MNEs are correlated with country characteristics. In OLS regressions, we find that the elasticities with respect to market size are quite similar for exporters and MNEs, but the distance elasticities are three times as large for exporters. ${ }^{17}$ Appendix Figure D.7 shows that, for Norway, distance elasticities are also higher for exporter entry than for MNE entry and market size elasticities are similar across the two entry modes.

The difference of first-year exit rates between exporters and MNEs suggests that higher sunk costs of entry for exporters than for MNEs. This fact is thus key in informing

\footnotetext{
${ }^{16}$ Using data from Argentina, Albornoz et al. (2016) document a similar pattern for exporters: survival probabilities decrease with distance. They rationalize this finding with a model where sunk export costs increase with distance proportionally less than do fixed costs.

${ }^{17}$ The elasticities with respect to market size are 0.52 (s.e. 0.027 ) and 0.41 (s.e. 0.033 ) for exporters and MNEs, respectively; distance elasticities are -1.15 (s.e. 0.105 ) vs -0.36 (s.e. 0.094 ).
} 


\section{Figure 5: First-year exit rates and market characteristics, France.}

\section{Market size}

(a) Exporters

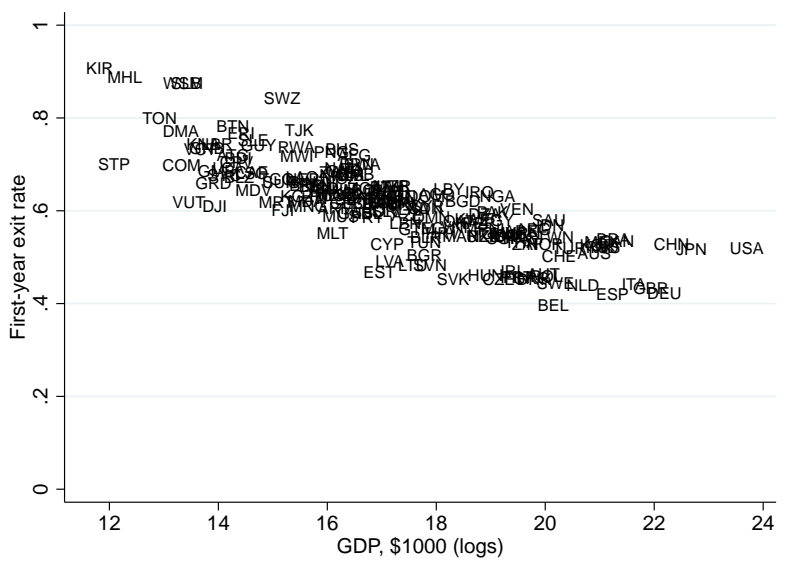

(b) MNEs

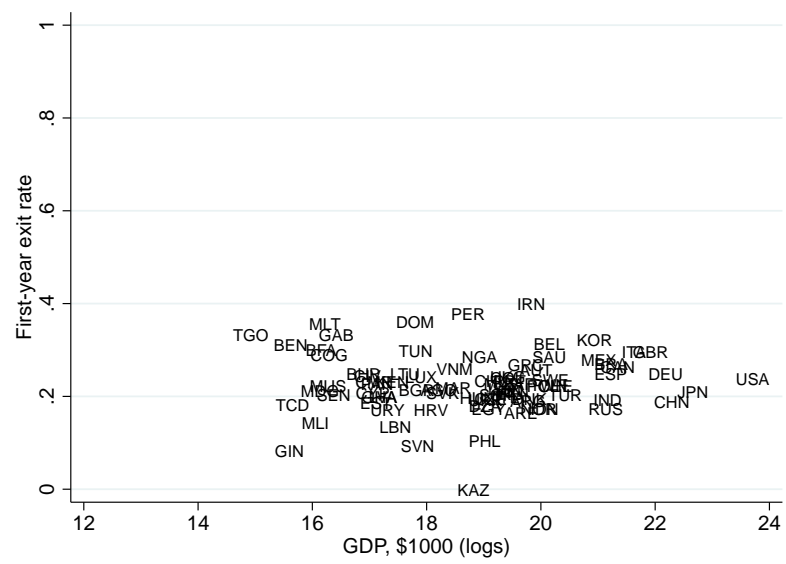

\section{Distance}

(c) Exporters

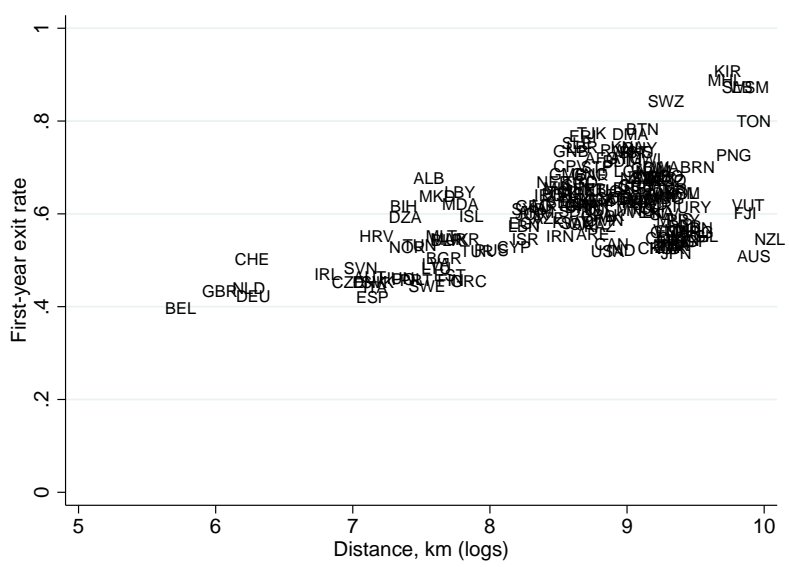

(d) MNEs

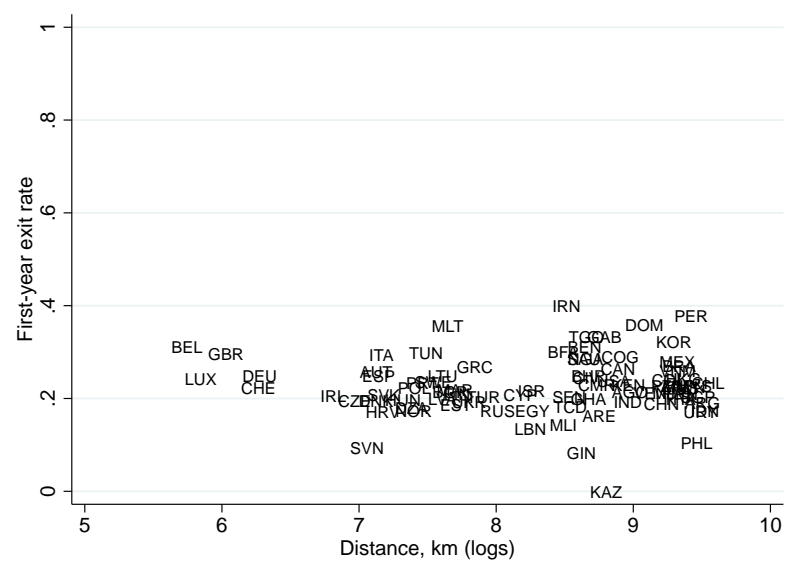

Notes: Number of exits from a mode-market relative to the number of firms active in a mode-market, for exporters and MNEs, in the first year upon mode-market entry (i.e., age zero). Destinations with ten or more firm-year observations and with available GDP data. Exporters refers to non-MNE exporters. GDP data from International Financial Statistics (IMF). Distance data from CEPII (Mayer and Zignago, 2011). 
Figure 6: Entry rates and market characteristics, France.

\section{Market size}

(a) Exporters

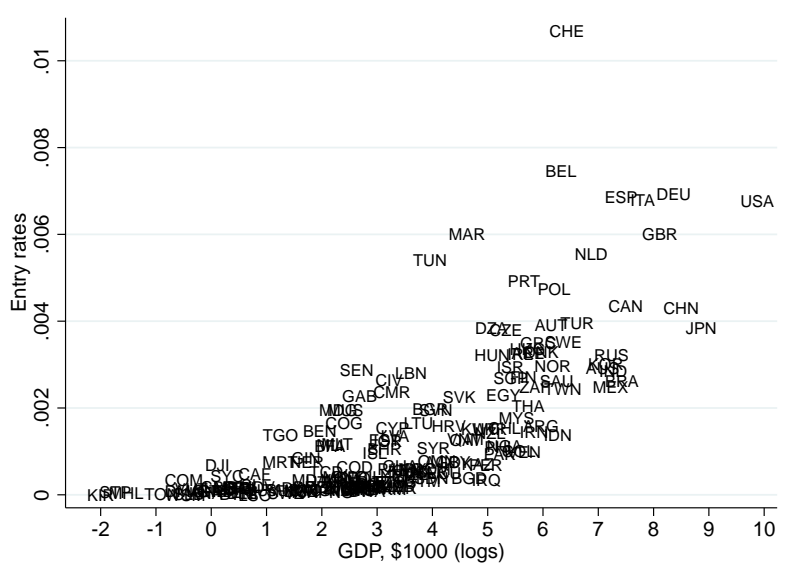

(b) MNEs

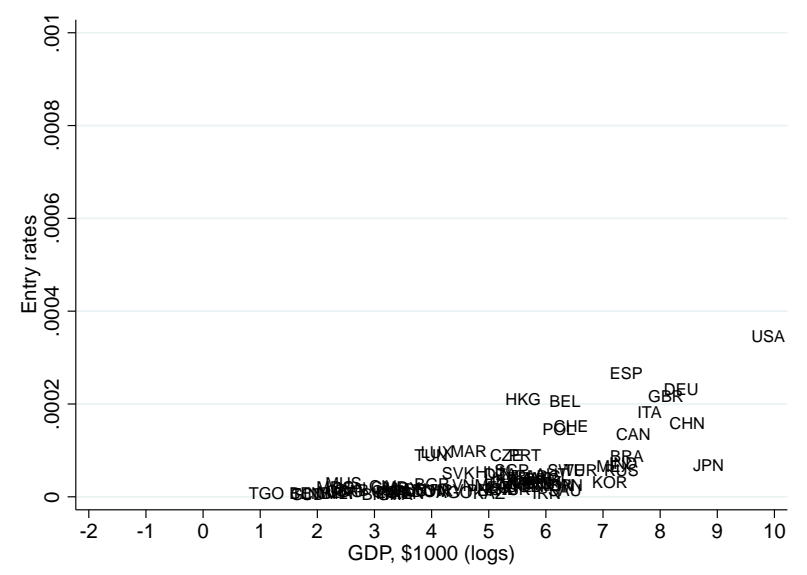

Distance

(c) Exporters

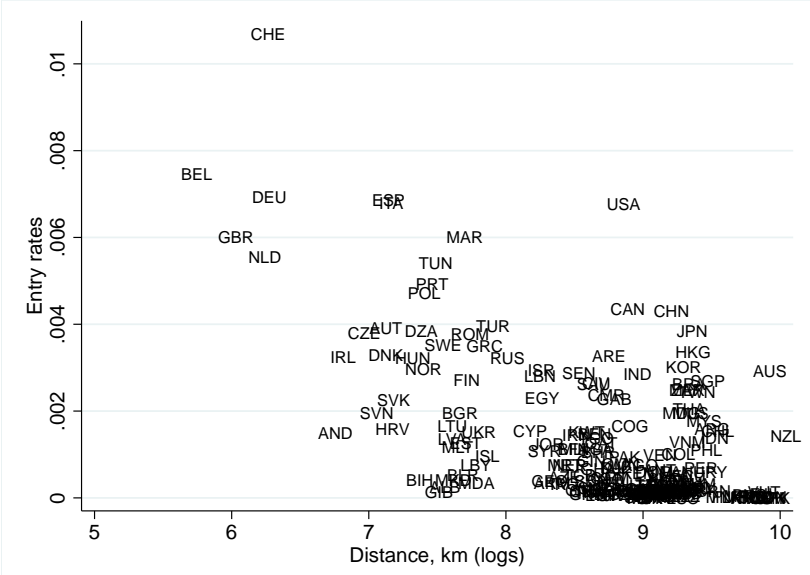

(d) MNEs

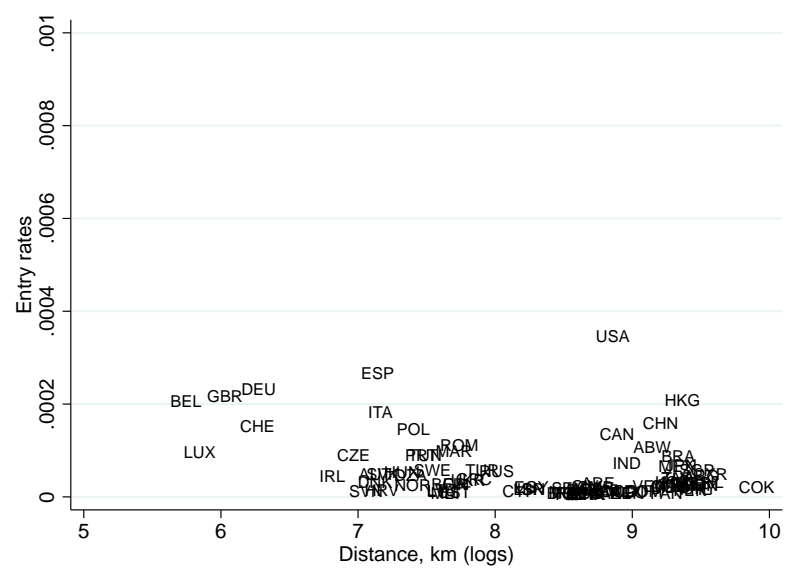

Notes: Number of entries to a mode-market relative to the number of domestic firms active in the home market. Destinations with ten or more firm-year observations and with available GDP data. Exporters refers to non-MNE exporters. GDP data from International Financial Statistics (IMF). Distance data from CEPII (Mayer and Zignago, 2011).

dynamic models of exporters and MNEs. The patterns observed for entry rates suggest that exporters face distance-dependent trade costs, whereas MNEs do not, consistent with the proximity-concentration-trade off in HMY. A static model thus suffices to capture this fact.

Robustness. Exporters and MNEs are active in different countries: Firms penetrate many more countries as exporters than as MNEs. To exclude that the difference in country 
coverage drives the results, we replicate our analysis for only those countries with both exporting and multinational activity, for France. Both the pattern of first-year exit and entry rates for exporters are less pronounced than in the full sample, but still clearly correlated with country characteristics. ${ }^{18}$ For MNEs, results are unchanged.

\section{A dynamic model of exports and MNEs}

Guided by the facts documented in the previous section, we build a dynamic model of export and MNE activities that is based on the model of the proximity-concentration trade-off with heterogeneous firms in HMY, extended to include an autoregressive process for firm productivity and sunk costs for MNE activities. We construct a model of "horizontal" FDI, i.e., affiliate sales are destined to the host market only. For simplicity, export-platforms, i.e., locating production in market $l$ and serving a third market $n$ through exports from $l$, and intrafirm trade are excluded. ${ }^{19}$ We focus on horizontal FDI instead of vertical FDI as the prior literature has found horizontal FDI to be the main form of FDI activity (see Ramondo et al., 2016).

\subsection{Set up}

We build a partial equilibrium model with two countries, Home and Foreign. Time is discrete. Labor is the only factor of production and is supplied in fixed quantity. The wage in each country is pinned down by a constant-return-to-scale freely tradable homogeneous good sector, and normalized to one, $w=1$.

Goods that are exported to the foreign country are subject to an iceberg-type trade cost, $\tau \geq 1$, while production in foreign affiliates is subject to an efficiency loss given by $\gamma \geq 1$, with $\tau>\gamma$, consistent with the empirical evidence (Antrás and Yeaple, 2014). A firm that exports incurs a per-period fixed cost, $f^{x}$, and a firm that operates an affiliate in the foreign country incurs a per-period fixed cost $f^{m}$, with $f^{m} / f^{x}>(\gamma / \tau)^{\sigma-1}$, as in HMY. Firms that decide to open an affiliate have to pay a sunk cost, $F^{m}>0$, at the time of MNE entry. Fixed and sunk costs are paid in units of labor.

A firm is characterized by a core efficiency level, $\phi \equiv \exp (z)$, that evolves over time

\footnotetext{
${ }^{18}$ Export exit elasticities with respect to GDP and distance are -0.023 (s.e. 0.003 ) and 0.046 (s.e. 0.005), while entry elasticities with respect to the same variables are 0.23 (s.e. 0.026 ) and -0.53 (s.e. 0.112 ).

${ }^{19}$ See Ramondo and Rodríguez-Clare (2013) and Tintelnot (2017) for recent models of export-platform FDI.
} 
following a first-order autoregressive AR(1) process,

$$
z^{\prime}=\rho z+\sigma_{\epsilon} \epsilon^{\prime},
$$

where $0 \leq \rho<1$ and $\epsilon^{\prime} \sim N(0,1)$. If a firm from the Home country opens an affiliate in the Foreign country, that affiliate inherits its parent's productivity process.

There exists a continuum of firms that compete monopolistically, and have access to a continuum of differentiated products. The mass of Home firms, $M$, is fixed and normalized to one. We assume Constant-Elasticity-of-Substitution (CES) preferences, with the elasticity of substitution denoted by $\sigma$. Firms optimally charge a constant mark-up, $\kappa \equiv \sigma /(\sigma-1)$, over marginal costs, so that sales follow the standard CES formula. Let $E \equiv \kappa^{1-\sigma} X / P^{1-\sigma}$ be foreign demand. We assume that the firms from the home country account only for a small fraction of the overall sales in the foreign country, so that the price index in the foreign country is taken as fixed. We normalize $E_{\text {home }}=1$ so that $E$ is the size of Foreign relative to Home.

Static profit maximization implies that domestic sales are given by $X^{d}(\phi)=\phi^{\sigma-1}$, while exports from Home are $X^{x}(\phi)=E \phi^{\sigma-1} \tau^{1-\sigma}$, and affiliate sales in Foreign are $X^{m}(\phi)=$ $E \phi^{\sigma-1} \gamma^{1-\sigma}$.

Firms have two possible states: producing in the home market for domestic consumers only and, potentially, for foreign consumers (D); or producing in the home market for domestic consumers and in the foreign market for foreign consumers (M). The value of being a multinational firm with core productivity $\phi$ is given by

$$
\begin{aligned}
V(\phi, M)=\frac{X^{d}(\phi)}{\sigma}+ & \max \left\{\frac{X^{m}(\phi)}{\sigma}-f^{m}+\beta E V\left(\phi^{\prime}, M \mid \phi\right),\right. \\
& \left.\max \left(0, \frac{X^{x}(\phi)}{\sigma}-f^{x}\right)+\beta E V\left(\phi^{\prime}, D \mid \phi\right)\right\} ;
\end{aligned}
$$

and the value of being a domestic firm with core productivity $\phi$ is given by

$$
\begin{aligned}
V(\phi, D)=\frac{X^{d}(\phi)}{\sigma}+\max \{ & \left\{\frac{X^{m}(\phi)}{\sigma}-f^{m}-F_{e}^{m}+\beta E V\left(\phi^{\prime}, M \mid \phi\right),\right. \\
& \left.\max \left(0, \frac{X^{x}(\phi)}{\sigma}-f^{x}\right)+\beta E V\left(\phi^{\prime}, D \mid \phi\right)\right\} .
\end{aligned}
$$

The optimal policy for an MNE is to discontinue the foreign investment if being domestic (state $\mathrm{D}$ ) entails larger discounted expected profits than being MNE (state M). This policy is characterized by a cutoff value of productivity $\bar{\phi}^{m}$. If productivity falls below $\bar{\phi}^{m}$, a current MNE exits the foreign market and produces only in the domestic market. If 
productivity exceeds $\bar{\phi}^{m}$, the firm remains an MNE (state M). Similarly, the optimal policy for a domestic firm is characterized by a productivity cutoff level, $\bar{\phi}_{e}^{m}$. Once the productivity level of the domestic firm exceeds $\bar{\phi}_{e}^{m}$, it becomes an MNE. It is possible to rank the two productivity cut-offs: Since the second terms in the outer maximization problem in (1) and (2), respectively, are identical, and $X^{m}$ and $V$ are increasing in $\phi$, as the expectation operator preserves monotonicity, it follows that $\bar{\phi}^{m}<\bar{\phi}_{e}^{m}$. This implies that the model delivers an "inaction" zone that exists by virtue of the sunk cost of doing FDI (Baldwin, 1989). Domestic firms with productivity $\phi \in\left[\bar{\phi}^{m}, \bar{\phi}_{e}^{m}\right]$ remain domestic, while MNEs with productivity $\phi \in\left[\bar{\phi}^{m}, \bar{\phi}_{e}^{m}\right]$ remain MNEs. The inaction zone, thus, creates persistence in the MNE status.

Without sunk MNE costs, it suffices to have $f^{m} / f^{x}>(\gamma / \tau)^{1-\sigma}$ for MNEs to have a higher exit cutoff than exporters, $\bar{\phi}^{m}>\bar{\phi}^{x}$. With sunk MNE costs, that assumption is not enough. We proceed by assuming that the MNE exit cutoff is higher than the exporter exit cutoff. ${ }^{20}$

\subsection{Model predictions}

We now explain how the model captures the facts documented in Section 3.

The model can capture Fact 1 under some conditions. The "inaction" zone created by the presence of sunk and fixed costs makes MNEs less likely to exit than in a setup with no sunk costs. That exit rates for MNEs are lower than for exporters-and by how muchdepends on the values of the model's parameters. Proposition 1 states the result.

Proposition 1. Let the entry cut-off for MNEs $\ln \left(\bar{\phi}_{e}^{m}\right)=\bar{z}_{e}^{m}$ and the entry and exit cut-off for exports $\ln \left(\bar{\phi}^{x}\right)=\bar{z}^{x}$ relate as $\bar{z}_{e}^{m}=\bar{z}^{x}+\varphi$, with $\varphi>0$. There exists $\varphi^{*}$ such that for $0 \leq \varphi<\varphi^{*}$, the exit probability upon entry is higher for an exporter than for an MNE with identical productivity before exit.

Proof. See Appendix B.1.

The effect of export experience on the exit probability of an MNE is driven by selection on productivity, as Proposition 2 shows.

Proposition 2. The probability that a new MNE exits upon entry is lower if the firm switched from export to MNE activity than from domestic to MNE activity.

\footnotetext{
${ }^{20}$ The assumption that $\bar{\phi}^{m}>\bar{\phi}^{x}$ is implicit in the way we wrote the value functions: It rules out that, for the marginal MNE, the value of producing at home for the domestic market only is higher than the value of producing at home for the domestic and foreign market. In our calibrations and simulations below, this ranking of cutoffs is never violated.
} 


\section{Proof. See Appendix B.2.}

All new MNEs have received a sufficiently good productivity shock that induces them to enter a market as MNEs. As exporters are more productive than domestic firms, firms with export experience enter MNE status with a productivity level that is higher than that of a firm with no export experience. Given that productivity follows a Markov process with log-normal distributed shocks, and the exit cutoffs are the same for MNEs with and without export experience, more productive firms at the time of entry are less likely to have a productivity draw that falls below the exit cutoff in the subsequent period. Proposition 2 is for the case of positive sunk costs of MNE entry, but the result also holds in the case of no sunk MNE costs.

Both exporters and MNEs follow the same productivity process in the model. However, this does not automatically lead to the similar sales growth rates of exporters and MNEs documented in Fact 2. The selection patterns that arise from the inclusion of fixed and sunk costs have subtle effects on the growth rates. Ultimately, how well the model can capture the similarity of exporter and MNE growth rates remains a quantitative question, which we address in Section 5. Self-selection of firms also drives the higher sales growth of ever-MNE exporters relative to never-MNE exporters.

Finally, the inclusion of sunk MNE costs allows the model to capture Fact 3: First-year exit rates of new exporters are correlated with country characteristics, while for MNEs, they are not. The following proposition shows the result.

Proposition 3. Let $\bar{z}$ be the productivity exit cutoff from a mode of international operation. The increase in the first-year exit probability when $\bar{z}$ increases is larger when sunk costs of entry into the mode are zero than when sunk costs are positive.

Proof. See Appendix B.3.

Because of MNE sunk costs, the productivity level required for MNE entry exceeds the productivity level for MNE exit, $\bar{\phi}_{e}^{m}>\bar{\phi}^{m}$. The higher the sunk costs, $F^{m}$, the higher the option value of being an MNE and, hence, the larger the zone of inaction and the less sensitive the exit behavior to differences in variable profits. ${ }^{21}$

An important implication of the model is that new exporters in an environment without the option to become MNE have different life-cycle properties than in an environment where they can self-select into MNE activities. Intuitively, including the MNE choice

\footnotetext{
${ }^{21}$ In an export-only model, Albornoz et al. (2016) show that the probability of export survival in a market increases with the ratio of sunk to fixed costs. While their result is about how export survival rates change with sunk costs, our Proposition 3 states a difference-in-difference result: How the survivalor, equivalently, exit-probability changes due to a change of market characteristics, for different levels of sunk costs.
} 
not only truncates the exporters' distribution of productivity levels, but also induces a truncation to-the-right of the distribution of productivity growth rates. Only firms with productivity above the export, but below the MNE threshold in two consecutive periods contribute to export productivity (and sales) growth. For each $z \in\left[\bar{\phi}^{x}, \bar{\phi}^{m}\right]$, there is a maximum possible increase in productivity such that an exporter remains an exporter. Exporters that receive a higher productivity shock turn into MNEs when the MNE choice is allowed. Those exporters with the highest productivity shocks and, thus, the highest sales growth, do not contribute to the average growth rate of exporters in the model with MNEs (because they change status), but they do it in the model without MNEs. In turn, because the maximum possible growth in productivity decreases with productivity levels, smaller exporters are the ones contributing to average productivity in the model without MNEs, but not in the model with MNEs (because they switch status). As a consequence, exporters in the model for which the MNE option is present have higher average productivity early in life and, hence, lower exit rates.

Proposition 4 derives this result formally for the marginal exporter. ${ }^{22}$

Proposition 4. Assume that firm productivity follows a first-order autoregressive process, $z_{t}=\rho z_{t-1}+\sigma_{\epsilon} \epsilon_{t}$, with $\epsilon_{t} \sim N(0,1)$, and $0 \leq \rho<1$, and assume that sunk costs of MNE entry are zero, $F^{m}=0$. Consider the firm with $z_{t-1}=\underline{z}$ and $z_{t}>\underline{z}$, where $\underline{z}$ denotes the productivity threshold above which firms become exporters. Define expected productivity growth in a model with only left truncation in the productivity distribution as $G^{L} \equiv \mathbb{E}\left(z_{t}-z_{t-1} \mid z_{t}>\underline{z}, z_{t-1}=\underline{z}\right)$, while in a model with left and right truncation, expected productivity growth is defined as $G^{L R} \equiv \mathbb{E}\left(z_{t}-z_{t-1} \mid \underline{z}<z_{t}<\bar{z}, z_{t-1}=\underline{z}\right)$, with $\bar{z}$ denoting the right truncation point above which the firm changes from export to MNE status. Then, there exists a value $\bar{z}^{*} \in(\underline{z}, \infty)$ such that for $\underline{z}<\bar{z}<\bar{z}^{*}, G^{L}>G^{L R}$, with equality for $\bar{z}=\bar{z}^{*}$.

Proof. See Appendix B.

We quantitatively explore the effect of including the option to become MNE by comparing calibrated versions of the model with MNEs and with only exporters in Section 6.

\section{Calibration}

We calibrate the model and analyze how well the calibrated model quantitatively captures the patterns observed in the data. We extend the model in Section 4 to include sunk

\footnotetext{
${ }^{22}$ In Appendix A.1, we show that the growth rate for the average exporter can be lower in the model with MNEs for certain parameters' values.
} 
export costs and assume that both fixed and sunk export and MNE costs are firm-specific. Appendix $C$ presents the main equations of the extended model.

Our goal is to parameterize the extended model by targeting cross-sectional features of the data, as well as the dynamics of domestic sales, and then assess how well our calibrated model accounts for new affiliate and exporter dynamics as reflected in the facts in Section 3. We perform two calibrations using moments from France and Norway to calibrate the parameters of the model. We present the calibration not only for France, but also for Norway because the information on MNE sales in the French data is very limited. We use the top 15 destination markets for exports and MNEs, plus a sixteenth country constructed as a weighted average of the rest of the world (RoW). The top 15 destinations represent more than 75 percent of export and MNE sales. ${ }^{23}$

For each destination, we calibrate the values of the iceberg trade and MNE costs, the mean and variance of the per-period export and MNE fixed costs, the mean and variance of the sunk costs of MNE and export entry, and the relative market size. Consistent with the model presented in the previous section, we abstract away from export-platforms sales, so that entry into each destination country can be solved independently. As in the model, we restrict the analysis to a partial equilibrium setting in which wages and price indices are exogenous.

\subsection{Calibration procedure}

We set the discount factor for firms $\beta=0.95$, which is consistent with an interest rate of five percent. The elasticity of substitution $\sigma$ is set to 4 , which implies a mark-up over unit cost of 33 percent and is a common value estimated for the trade elasticity.

A first set of parameters can be calibrated without solving for the firm's problem. Given $\sigma$, we use the ratio of export to domestic sales, $r_{n}^{x} \equiv\left(X_{n}^{x}(\phi) / X^{d}(\phi)\right)^{\frac{1}{1-\sigma}}=E_{n} \tau_{n}^{1-\sigma}$, for firms serving market $n$, to get an estimate of size-adjusted trade costs for market $n$. Analogously, we use the ratio of MNE to domestic sales, $r_{n}^{m} \equiv\left(X_{n}^{m}(\phi) / X^{d}(\phi)\right)^{\frac{1}{1-\sigma}}=$ $E_{n} \gamma_{n}^{1-\sigma}$, for MNE affiliates operating in market $n$, to get an estimate of size-adjusted MNE costs for market $n .^{24}$ We calculate $r_{n}^{x}$ and $r_{n}^{m}$, respectively, as a weighted average across firms serving market $n$ in each mode, with weights given by the firm's domestic sales.

\footnotetext{
${ }^{23}$ In the French data, it is not possible to distinguish exports to Belgium from exports to Luxembourg. Therefore, we aggregate Belgium-Luxembourg and the Netherlands into one country (Benelux). Due to its increasing importance, we add China to the list of foreign destination for France.

${ }^{24}$ In order to gain observations, for some destinations of French MNEs, we impute missing MNE sales using as covariates $(\log )$ domestic sales, $(\log )$ domestic employment, an interaction of the two previous variables, year and sector fixed effects, for firms surviving at least five years in a foreign destination.
} 
For exports, we restrict attention to firms that served market $n$ at least three years in a row. For MNEs, we do not limit the number of years in a market (given the low number of observations on sales for France). Appendix Table E.3 shows the values for $r_{n}^{x}$ and $r_{n}^{m}$, for each destination market.

The parameters characterizing the Markov process for firm-level productivity, $\rho$ and $\sigma_{\epsilon}$ come from estimating by OLS a first-order autoregressive process on domestic sales, using all French and Norwegian firms (i.e., unbalanced panel). The regression includes year and industry fixed effects, with standard errors clustered at the industry level. With these estimates, we directly set $\rho$ equal to the estimated sales autocorrelation coefficient, $\hat{\rho}_{\text {sales }}$, and $\sigma_{\epsilon}$ equal to $\hat{\sigma}_{\text {sales }} /(\sigma-1)$. For France, $\rho=0.960$ and $\sigma_{\epsilon}=0.197$, while for Norway, our estimates imply that $\rho=0.957$ and $\sigma_{\epsilon}=0.133{ }^{25}$

The remaining parameters of the model are jointly calibrated, for each market. We assume that sunk (fixed) costs are drawn from a log-normal distribution, are constant for each firm over time, and are independent from firm productivity. The relevant market-specific sunk and fixed cost parameters are: the mean and standard deviation of sunk export costs, $\mu_{e n}^{x}$ and $\sigma_{e n}^{x}$; the mean and variance of sunk MNE costs, $\mu_{e n}^{m}$ and $\sigma_{e n}^{m}$; the mean of per-period export costs, $\mu_{f n}^{x}$; and the mean of per-period MNE costs, $\mu_{f n}^{m}$. We pin down $\sigma_{f n}^{m}$ and $\sigma_{f n}^{x}$ by assuming the coefficient of variation in sunk and fixed cost draws for each mode is the same, i.e., $\left|\sigma_{e n}^{s} / \mu_{e n}^{s}\right|=\left|\sigma_{f n}^{s} / \mu_{f n}^{s}\right|(s \in x, m)$. We target the following six moments, for each market: the fraction of non-MNE French (Norwegian) exporters serving market $n$, relative to French (Norwegian) firms that do not serve market $n$ with exports (which includes non-exporter firms and exporters to other destinations); the fraction of French (Norwegian) MNEs serving market $n$, relative to French (Norwegian) firms that do not serve market $n$ with an affiliate (which includes non-MNE firms and MNEs to other destinations); the share of French (Norwegian) MNEs that exit at age zero (i.e., entry year) market $n$, relative to MNE stayers in market $n$; the share of French (Norwegian) exporters that exit at age zero (i.e., entry year) market $n$, relative to exporter stayers in market $n$; the average share of French (Norwegian) MNEs that exit market $n$, relative to MNE stayers in market $n$; and the average share of French (Norwegian) exporters that exit market $n$, relative to exporter stayers in market $n$. Appendix Tables E.4 and E.5 show targeted moments in the model and data, an average across destinations and by destination. Appendix Table E.6 presents the calibrated parameters by destination.

Results below are calculated from model and data observations at the firm-destinationyear level. As for the facts in Section 3, for expositional purposes, we present averages across the destinations included in our samples, weighted by each destination's share of

\footnotetext{
${ }^{25}$ Results are very similar if we estimate a Tobit model rather than a linear model.
} 
Table 1: The size of calibrated costs.

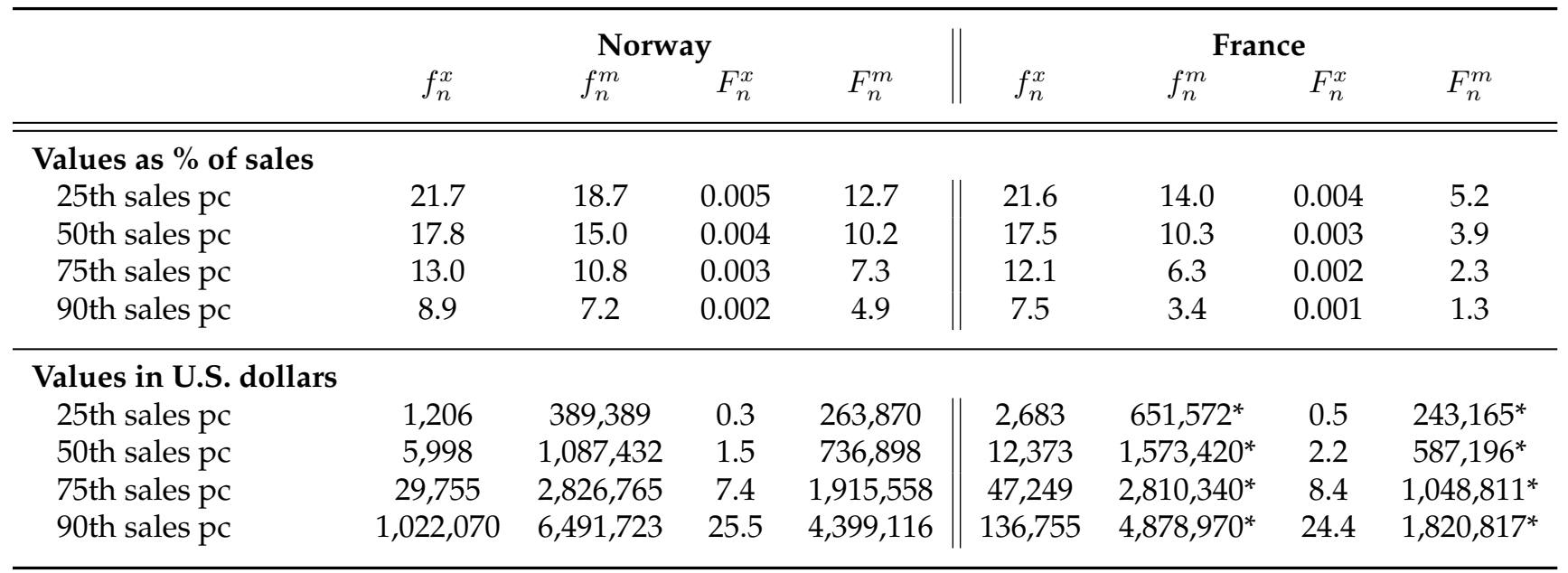

Notes: $f_{n}^{x}$ are per-period fixed export costs; $f_{n}^{m}$ are per-period fixed MNE costs; $F_{n}^{x}$ are sunk export costs; and $F_{n}^{m}$ are sunk MNE costs. Values are averages across firms' draws, conditional on a positive measure of exporters (MNEs), in each destination. Averages across destinations included in the calibration, weighted by each destination's share of export (MNE) firms. Weights are data-based (model-based), for data (model) variables. Sales percentiles are with respect to the export (MNE) sales distribution. The values in U.S. dollars for different percentiles are calculated using the values of sales in the data, transformed to U.S. dollars using an average of the annual exchange rate observed over our sample period, from Penn World Tables 9.0 (Feenstra et al., 2015). $\left(^{*}\right)$ estimated values assuming that the xth pc of the MNE sales distribution is proportional to the $x$ th pc of the export sales distribution, with the proportionality factor calculated using the ratio of export to MNE sales for each percentile, for Norway.

export (MNE) firms, relative to all export (MNE) firms in our sample. The Appendix contains the results by destination.

\subsection{Calibration results}

We evaluate the size of the calibrated per-period fixed costs and sunk entry costs, for exports and MNE activities, in terms of one year of firm sales, and in monetary values. Table 1 presents the results.

Sunk costs, particularly for exports, do not seem to be a heavy burden on firms deciding to internationalize. For MNEs, sunk costs represent around ten percent of annual sales for smaller firms and around five percent for larger firms, according to our calibration for Norway. For French MNEs, our calibration suggests that these sunk costs, in terms of sales, are half those faced by Norwegian MNEs. In monetary terms, for Norwegian MNEs, sunk costs range from less than 300,000 to almost 4.5 million U.S. dollars. In contrast, the calibrated sunk export costs are very small, around 0.2-0.5 percent of annual export sales. 
Fixed operating costs, however, are relatively much larger. Fixed costs represent around nine percent of foreign sales for large Norwegian exporters and reach more than 20 percent for small exporters; per-period MNEs costs are slightly lower in terms of sales. Our calibrated values for French exporters and MNEs entail slightly lower per-period costs, in terms of annual sales, than for Norwegian firms. In monetary terms, given the difference in size between MNEs and exporters, per-period fixed costs for exporters are around one million U.S. dollars for the 90th percentile of Norwegian exporters, but reach almost 6.5 million U.S. dollars for the largest Norwegian MNEs. Appendix Table E.7 presents results by destination market for the median exporter (MNE) in terms of sales in each destination.

\subsection{Fit of calibrated model}

We now evaluate how well our calibrated model captures the facts in Section 3. We start by comparing the exit rates of new exporters and MNEs in the data and the model. Our calibration procedure targets exit rates of MNEs and exporters at entry and on average, but not at each age. Figure 7 shows that our calibrated model does fairly well in capturing the life-cycle dynamics of exit for new MNEs and new exporters. Even though the firstyear exit rate is a targeted moment, the model underestimates how much exit is observed upon entry into a market, particularly for exporters. But the quantitative model captures well the decline in exit rates with age. Targeting the first-year exit rate is crucial to obtain this decline; when this moment is not included in the calibration, exit rates increase, rather than decrease, with age. ${ }^{26}$

Figure 8 shows the ability of the model to capture the growth profiles of MNE and export sales. We compute the geometric average across destination markets and normalize sales with respect to age one (i.e., one year after entry). The model matches the flat sales profile for MNEs remarkably well, as well as the growth profile of export sales, for Norway. The model calibrated to France, however, delivers exporters that, after age one, grow faster than in the data.

To evaluate the model's ability to quantitatively capture Fact 3 in Section 3, we estimate by OLS the elasticity of exit rates at age zero and entry rates, for exporters and MNEs, on geography-adjusted country size, $r_{n}^{x} \equiv E_{n} \tau_{n}^{1-\sigma}\left(r_{n}^{m} \equiv E_{n} \gamma_{n}^{1-\sigma}\right)$, across the destinations included in our calibration, for Norway and France. We use the observed and simulated

\footnotetext{
${ }^{26}$ This is also the case in Ruhl and Willis (2017) (see their Figure $2 b$ and $3 b$ ): When they target first-year exit rates for exporters, they obtain exit rates that decline with age; when they only target the average exit rate, they obtain exit rates that increase with age.
} 
Figure 7: Exit rates by age, model and data.

France

(a) Exporters

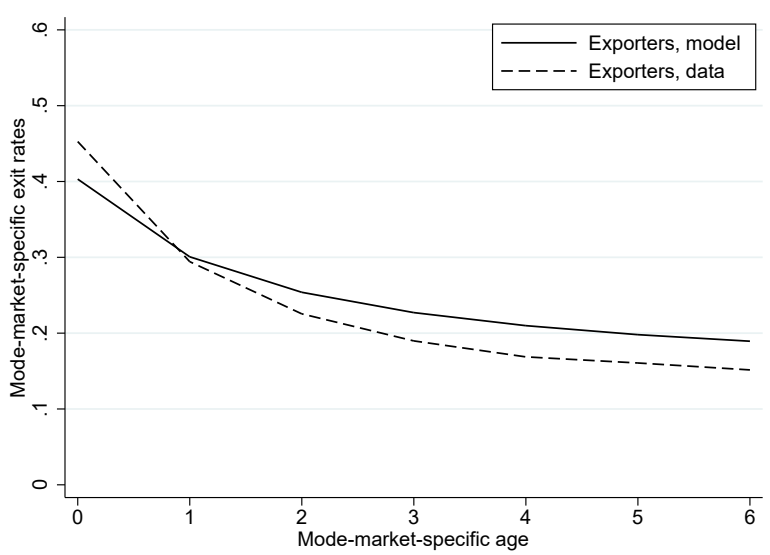

(b) MNEs

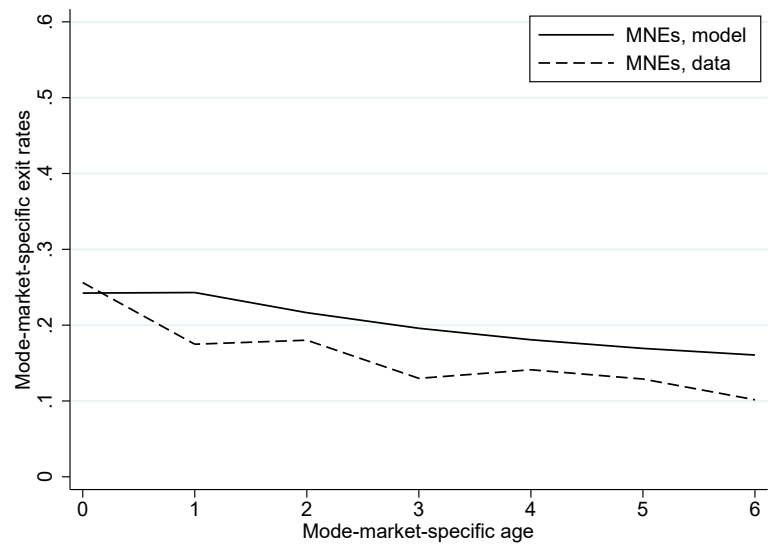

Norway

(c) Exporters

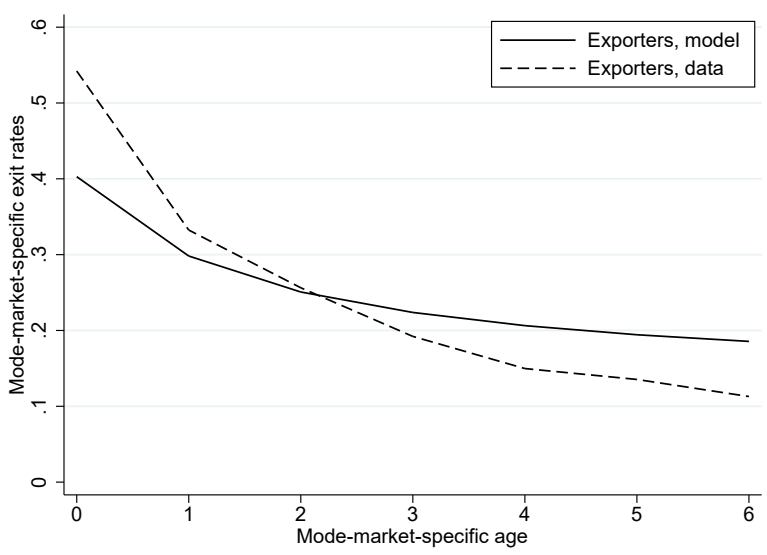

(d) MNEs

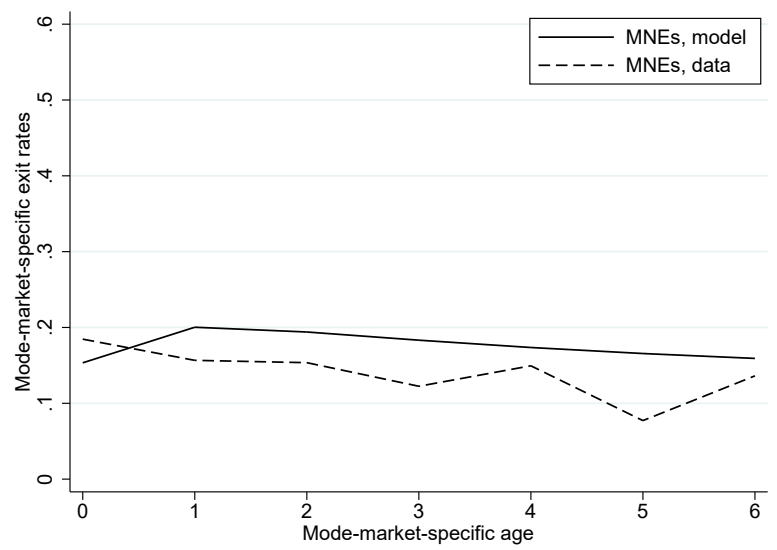

Notes: Number of exits from a mode-market relative to the number of firms active in a mode-market, by mode-market-specific age, for exporters and MNEs. Observations are at the firm-destination-year level. We show averages across destinations included in the calibration, weighted by each destination's share of export (MNE) firms. Weights are data-based and model-based, for data and model variables, respectively. Exporters in the data refers to non-MNE exporters.

data. Results are presented in the first two panels of Table 2. One has to keep in mind that these regressions have only 16 observations. Still, the model delivers sharper results for exporters exit rates than for MNEs, as the theory predicts and our third fact shows: New exporters' exit rates decrease with size-adjusted iceberg cots, while new MNEs' exit rates do not have a clear pattern. The model's implied entry rates elasticities are larger for MNEs than for exporters as observed in the data, but the model difference between the two is smaller. 
Figure 8: Sales growth by age, model and data.

(a) Exporters, France

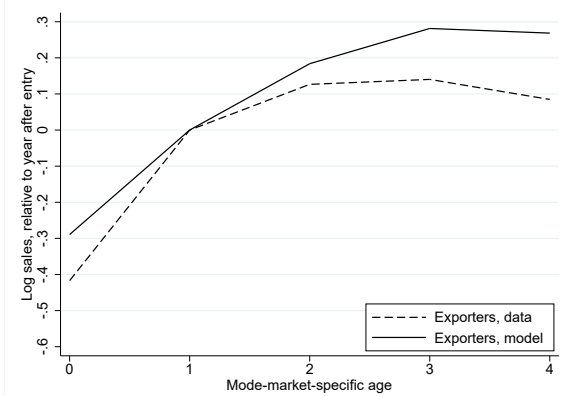

(b) Exporters, Norway

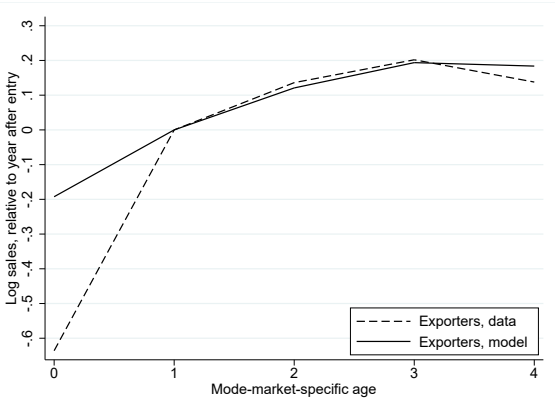

(c) MNEs, Norway

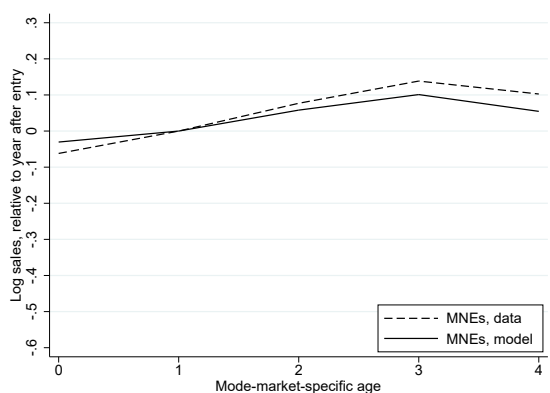

Notes: Log of firm-destination export (affiliate) sales with respect to firm-destination export (affiliate) sales in the year after entry, for firms with five or more years in the market, in each mode. Observations are at the firm-destination-year level. We show averages across destinations included in the calibration, weighted by each destination's share of export (MNE) firms. Weights are data-based and model-based, for data and model variables, respectively. In the data, log of sales are first demeaned by industry, year, and destination fixed effects. Exporters in the data refers to non-MNE exporters.

Table 2 includes comparisons for other non-targeted moments. Panel 3 shows that the calibrated model correctly captures the fact that new experienced MNEs have lower exit rates than non-experienced MNEs. Yet, the calibrated model delivers virtually zero new MNEs that were not previously exporters. Additionally, starter rates in the model are fairly closed to the ones observed in the French data. The model also captures rather accurately the transitions from/to export and domestic status, and from/to MNE and domestic status. But the model over-predicts the transition from/to MNE and export status: Too many exporters become MNEs, and too many MNEs transition into only exporters.

\subsection{Model calibration with only exporters}

The goal of our counterfactual exercises is to assess whether the option to become MNE changes the predictions of the standard export dynamics model under a trade-liberalization shock. Before turning to the counterfactual exercises, we therefore compare the goodness of fit of our calibrated model with MNEs to a calibrated model with only exporters.

The calibration of the exporter-only model targets exactly the same moments related to exporters as our calibration of the model with MNEs - in particular, the parametrization of the productivity process is the same..$^{27}$

\footnotetext{
27 The calibrated model with only exporters matches the export-related targeted and non-targeted moments equally well as the model with MNEs (not shown). Appendix Table E.6 shows the calibrated values of per-period and sunk export costs for the model without MNEs.
} 
Table 2: Additional non-targeted moments, data and model.

\begin{tabular}{lcc||cc}
\hline & \multicolumn{2}{c}{ Data } & \multicolumn{2}{c}{ Model } \\
& France & Norway & France & Norway \\
\hline Elasticity of first-year exit rates to size-adjusted iceberg costs, OLS & & & & \\
$\quad$ exporters & $-0.057^{* *}$ & -0.016 & $-0.028^{* * *}$ & -0.033 \\
MNEs & 0.035 & 0.062 & 0.079 & 0.047 \\
\hline Elasticity of entry rates to size-adjusted iceberg costs, OLS & & & & \\
exporters & $0.143^{* * *}$ & 0.226 & $0.253^{* * *}$ & $0.843^{* * *}$ \\
MNEs & $0.554^{* * *}$ & $0.237^{* *}$ & $0.414^{* * *}$ & 0.212 \\
\hline Share of experienced MNEs & 0.60 & 0.47 & 0.99 & 0.99 \\
\hline Exit rates at age zero, experienced MNEs & 0.21 & 0.16 & 0.24 & 0.15 \\
Exit rates at age zero, non-experienced MNEs & 0.29 & 0.21 & 0.29 & 0.19 \\
\hline Starter rate & & & & \\
$\quad$ exporters & 0.020 & 0.035 & 0.019 & 0.019 \\
MNEs & $5.4 \mathrm{e}-04$ & $5.0 \mathrm{e}-04$ & 0.002 & 0.001 \\
Probability of: & & & & \\
exporter to MNE & 0.003 & 0.002 & 0.017 & 0.013 \\
exporter to domestic & 0.188 & 0.275 & 0.237 & 0.239 \\
domestic to MNE & $1.8 \mathrm{e}-04$ & $9.4 \mathrm{e}-05$ & $2.0 \mathrm{e}-04$ & $1.4 \mathrm{e}-06$ \\
domestic to exporter & 0.019 & 0.038 & 0.018 & 0.019 \\
MNE to exporter & 0.059 & 0.069 & 0.142 & 0.110 \\
MNE to domestic & 0.043 & 0.057 & 0.052 & 0.058 \\
\hline
\end{tabular}

Notes: The elasticity of first-year exit rates (entry rates) to size-adjusted iceberg costs $\left(r_{n}^{x}\right.$ and $r_{n}^{m}$, for exporters and MNEs, respectively) is the OLS coefficient of a bivariate regression (with a constant), using the 16 countries included in the calibration, for France and Norway. The fraction of experienced MNEs is calculated as the number of new MNEs of age zero with previous export experience in a market, relative to all new MNEs of age zero entering that market. Starter rates for exporters are calculated as the number of firms that export to $j$ in $t$, but not in $t-1$, relative to the number of Home firms at $t-1$. Starter rates for MNEs are calculated as the number of MNEs that have an affiliate $j$ in $t$, but not in $t-1$, relative to the number of Home firms at $t-1$. The transition probabilities are calculated for all firms, a weighted average across destinations: exporter to MNE (domestic) is relative to the number of non-MNE exporters; domestic to MNE (exporter) is relative to the number of domestic firms; and MNE to exporter (domestic) is relative to the number of MNEs. Observations are at the firm-destination-year level. Averages across destinations included in the calibration are weighted by each destination's share of export (MNE) firms, except for starter rates, and transitions from domestic status, which are weighted by (the inverse of) the number of destinations. Weights are data-based (model-based) for data (model) variables. Exporters in the data refers to non-MNE exporters. Levels of significance denoted by ${ }^{* * *}$ $\mathrm{p}<0.01,{ }^{* *} \mathrm{p}<0.05$, and ${ }^{*} \mathrm{p}<0.1$. Standard errors in parenthesis. 
Appendix Figure D.10a compares exit rates for exporters, averaged across destination markets, in the data and in the calibrated model with and without MNEs, for France. While the model with MNEs does slightly better in matching exit of young exporters, the model with only exporters does better for older exporter. ${ }^{28}$ In contrast with the results in Ruhl and Willis (2017), both our calibrated models feature a monotonic decrease in exit rates with age. This is entirely driven by targeting first-year exit rates. This moment is responsible for calibrated sunk export costs that are close to zero, and hence, for an extremely small band of inaction for exporters.

Appendix Figure D.10b shows that the model with MNEs produces sales profiles for exporters that are slightly flatter (three percentage-points lower) and closer to the data than the model with only exporters. ${ }^{29}$ This finding reflects the result that a model with left and right truncation can yield exporters that grow more slowly than exporters in a model with only left truncation. Yet, demand-side frictions, as the ones considered by Arkolakis (2016) and Ruhl and Willis (2017) would be needed to fully match the data on new exporters' growth.

As we described in Section 4, at the core of the model's mechanism is the self-selection of fast-growing exporters into MNE activities. Appendix Figure D.11 compares growth profiles for ever-MNE and never-MNE exporters in the two models and the data. This figure reveals that the difference in growth rates between the two models is mainly due to the never-MNE exporters. The model with MNEs predicts better the growth profile of new exporters that never switch to MNE status-the bulk of exporters in the data. The two models perform similarly well in capturing the observed dynamics of exporters that later in life become MNEs.

In the next section, we turn to the effects of trade liberalization episodes on aggregate and life-cycle dynamics of exporters and MNEs. We compare the predictions of the model with MNEs to the predictions of the model with only exporters.

\section{The effects of trade liberalization}

Armed with the calibrated model, we analyze the effects of trade liberalization on aggregate dynamics and life-cycle dynamics of MNEs and exporters. For exporters, we further show the effects predicted by the calibrated model without MNEs. Even though the differences between the calibrated model with and without MNEs in fitting the data are not very

\footnotetext{
${ }^{28}$ Appendix Figure D.8 shows results by destination.

${ }^{29}$ Differences become more pronounced when one considers exporters that survive longer in the market (not shown).
} 
large, the two models can deliver different predictions regarding counterfactual exercises. We simulate a 20-percent change in the iceberg-trade cost, $\tau_{n}$, for all destinations $n$, keeping the foreign demand, $E_{n}$, in the destinations unchanged (partial equilibrium).

\subsection{Aggregate dynamics}

Figure 9 shows the evolution from the old to the new steady state of average sales and participation rates for MNEs and exporters. The average MNE sales increase by around 30 percent when trade costs decrease, while participation rates for MNEs decrease by half. The transition is rather fast, with most of the adjustment taking place within three periods. Given that sunk export costs are very low, most of the transition to the new steady state for exporters occurs in one period: for the case of decreasing trade costs, average export sales and participation rates are both about 30-percent higher than in the initial steady state. Interestingly, the model without MNEs predicts smaller effects for exporters: average sales increase by less than 25 percent and the participation rates increase by only around 24-percent, when trade costs decrease by 20 percent. At the heart of these differences is the self-selection of exporters into MNE activities when that option is included in the model.

It is worth noting that increases and decreases in trade costs from the calibrated values do not produce symmetric changes in the aggregate variables under consideration. For instance, participation rates for exporters drop by 60 percent when trade costs increase, but increase by 30 percent when trade costs decrease.

\subsection{Life-cycle dynamics}

In Figure 10 we show the steady-state exit rates and sales profiles, by age, for MNEs and for exporters for the baseline economy, an economy with 20 percent higher trade costs, and an economy with 20 percent lower trade costs. ${ }^{30}$

While life-cycle exit patterns of MNEs do not change much with trade-costs changes, life-cycle growth becomes slower in an environment with lower trade costs: by age four, new MNE sales (relative to entry) are five-percentage points lower than in our calibrated baseline.

For exporters, including MNEs matters for the effects of moving from an environment

\footnotetext{
${ }^{30}$ Because we only use data from the calibrated model, in Figure 10, we normalize sales relative to sales at age 0 rather than age 1 as in Figures 3, 4 and 8.
} 
Figure 9: Aggregate effects of a 20-percent change in trade costs.

Decrease in trade costs

(a) Average sales

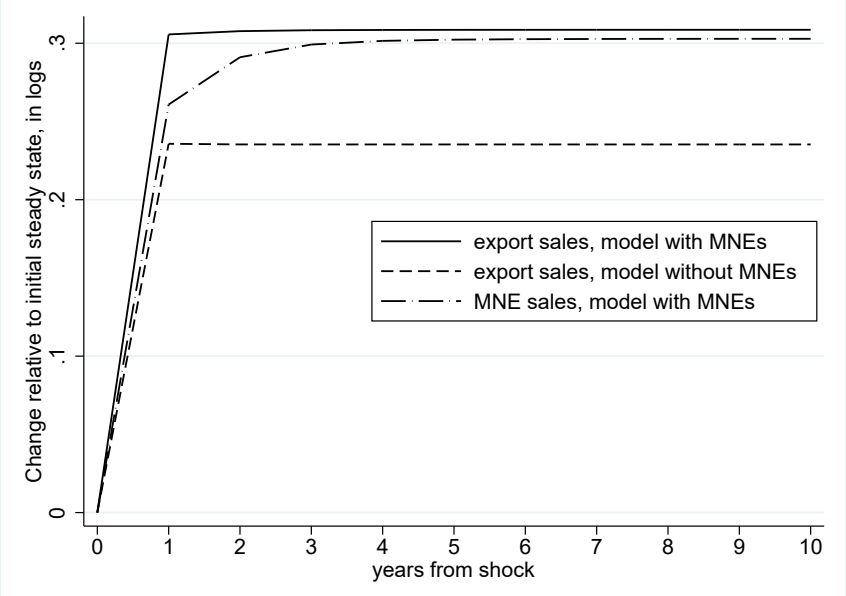

(b) Participation rates

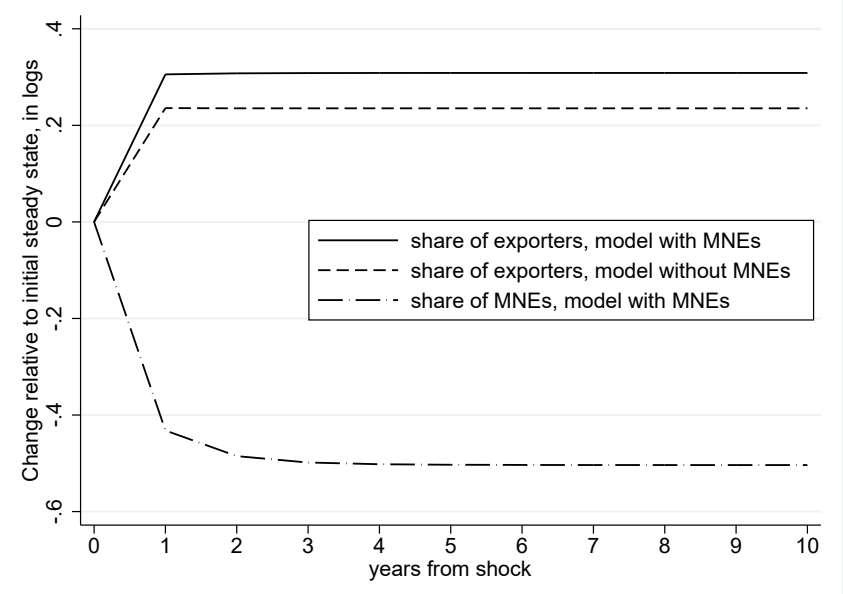

\section{Increase in trade costs}

(c) Average sales

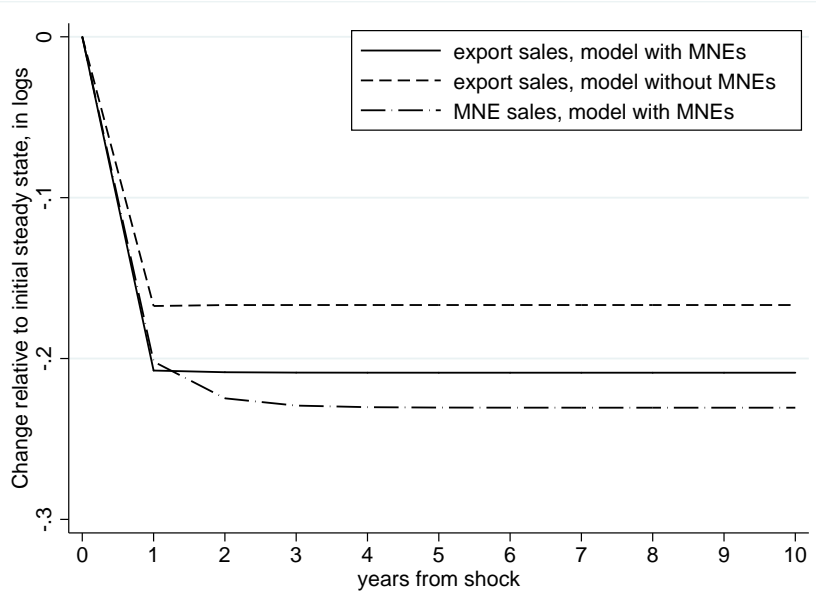

(d) Participation rates

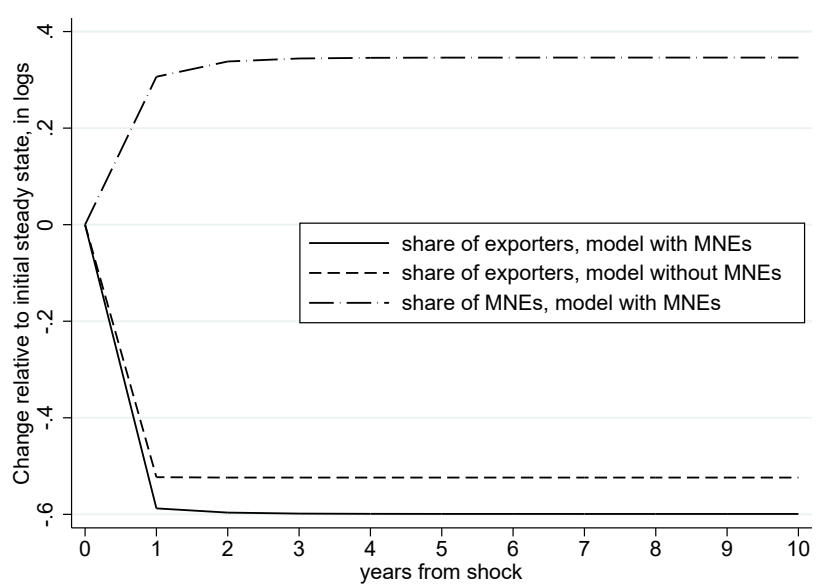

Notes: Models calibrated to French data. The y-axis is log change with respect to the initial steady state. Observations are at the firm-destination-year level. We show averages across destinations included in the calibration, weighted by each destination's share of export (MNE) firms. 
with high trade costs to one with low trade costs. The model with MNEs predicts that new exporters decrease their life-cycle exit rates by seven percentage points by age nine and experience higher sales growth (eight percentage points by age four). The model without MNEs, however, predicts that new exporters have very similar exit and growth patterns before and after the change. These differences between the two models translate into differences in the dynamic behavior of aggregate exports after a shock shown in Figure 9.

A lower $\tau$ decreases the likelihood of becoming an MNE, but increases the one of becoming (or staying) an exporter; in the limit, for $\tau=1$, MNEs disappear and the model collapses to one without MNEs. This implies that exporters' life-cycle profiles are, on average, less similar between the model with and without MNEs as $\tau$ increases. At the same time, a change in trade costs produces a larger change in the life-cycle patterns of exit and growth rates of the average exporter in the model with MNEs than in the model without MNEs. This is because the model with MNEs has two (left and right) margins changing at the same time, which results in a larger change in the number of fast-growing exporters.

Finally, Figure 10 naturally relates to the effects of liberalizing MNE activities on new exporters' dynamics. Since the differences in new exporters dynamics between the model with and without MNEs is larger in an environment with high iceberg trade costs, moving from a scenario without MNEs to one with MNEs leads to small changes in new exporters' dynamics if trade costs are already low, but large changes if trade costs are high.

\section{Conclusions}

This paper studies the life-cycle dynamics of exporters and MNEs. We provide a comprehensive set of facts on the life-cycle dynamics of new exporters and new MNEs that are informative about the features to be included in dynamic models of exporters' and MNEs' behavior. We show that a dynamic model of the proximity-concentration trade-off in Helpman et al. (2004) is qualitatively consistent with the documented facts. Our calibrated version of the model also includes heterogenous sunk and fixed costs at the firm-destination level, similar to Roberts and Tybout (1997). We show that, quantitatively, the standard model of exports dynamics augmented to include MNEs goes far in matching cross-sectional and dynamic moments of the data on both exporters and MNEs.

Comparing the predictions of our calibrated model with both exporters and MNEs and a dynamic model with only exporters, we find that enriching the canonical dynamic model of trade to include MNEs-a first-order feature of the data-has consequences 
Figure 10: Life-cycle effects of a 20-percent change in trade costs.

New MNEs dynamics

(a) Exit rates

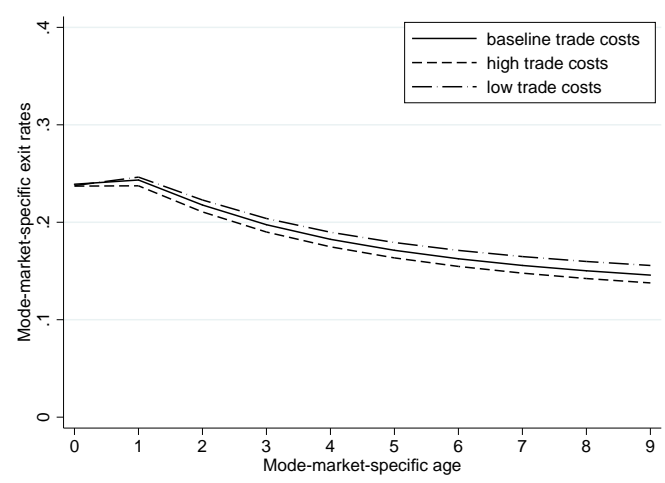

(b) Sales growth

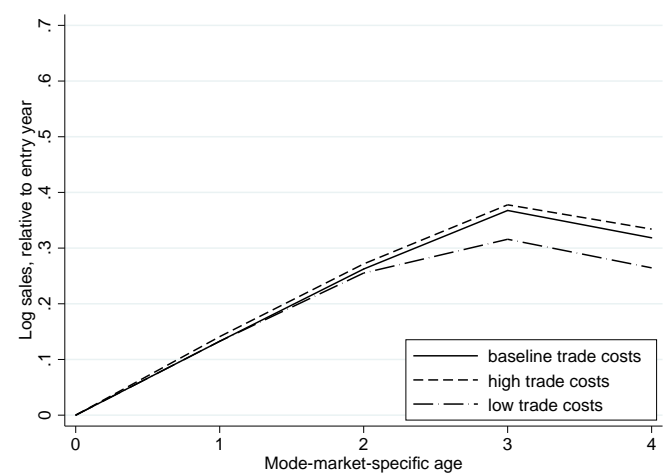

New exporters dynamics, model with MNEs

(c) Exit rates

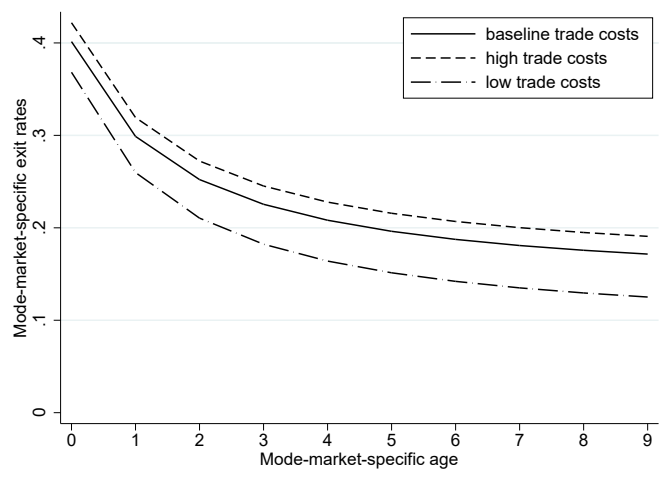

(d) Sales growth

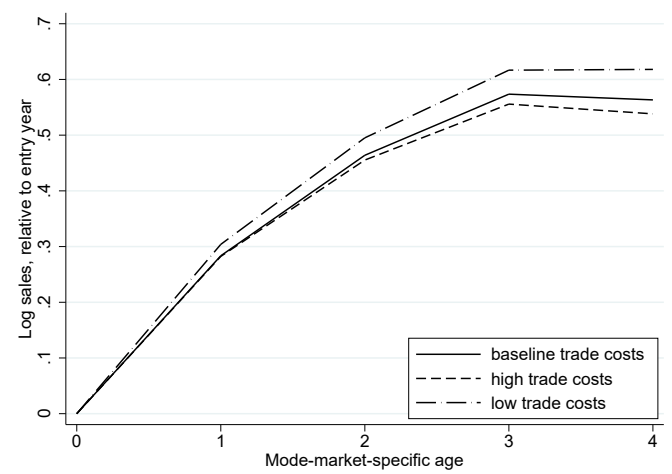

New exporters dynamics, model without MNEs

(e) Exit rates

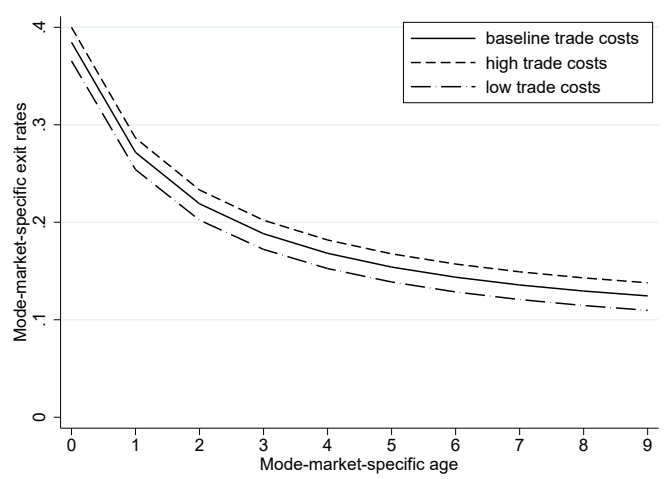

(f) Sales growth

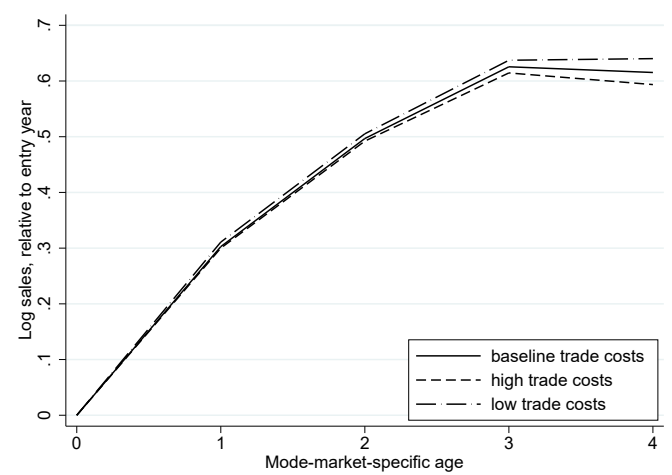

Notes: Models calibrated to French data. High, low, and baseline trade costs refer, respectively, to iceberg trade costs, $\tau_{n}$, which are 20 percent higher, lower, and equal to the baseline values, for each destination $n$. Number of exits from a mode-market relative to the number of firms active in a mode-market, by mode-market-specific age. Log of firm-destination export (affiliate) sales with respect to firm-destination export (affiliate) sales in the year after entry, for firms with five or more years in the market. Observations are at the firm-destination-year level. We show averages across destinations included in the calibration, weighted by each destination's share of export (MNE) firms. 
for the life-cycle and aggregate dynamic behavior of exporters after a trade-liberalization episode. The different response of the exporters between the two models hinge on the right truncation of fast-growing exporters induced by the inclusion of the MNE choice. 


\section{References}

Albornoz, F., S. Fanelli, and J. C. Hallak (2016). Survival in export markets. Journal of International Economics 102, 262-281.

Albornoz, F., H. F. C. Pardo, G. Corcos, and E. Ornelas (2012). Sequential exporting. Journal of International Economics $88(1), 17-31$.

Alessandria, G. and H. Choi (2007). Do sunk costs of exporting matter for new exports dynamics? Quarterly Journal of Economics 122(1), 289-336.

Antrás, P. and S. R. Yeaple (2014). Multinational firms and the structure of international trade. Handbook of International Economics 4 4 ,55-130.

Araujo, L., G. Mion, and E. Ornelas (2016). Institutions and export dynamics. Journal of International Economics 92, 2-20.

Arkolakis, C. (2016). A unified theory of firm selection and growth. Quarterly Journal of Economics 131(1), 89-155.

Baldwin, R. (1989). Sunk-cost hysteresis. NBER Working Paper 2911.

Baldwin, R. and P. Krugman (1989). Persistent trade effects of large exchange rate shocks. Quarterly Journal of Economics 104(4), 635-654.

Belderbos, R. and L. Sleuwaegen (1998). Tariff jumping DFI and export substitution: Japanese electronics firms in Europe. International Journal of Industrial Organization 16(5), 601-38.

Bernard, A. B., E. A. Boler, R. Massari, J.-D. Reyes, and D. Taglioni (2017). Exporter dynamics and partial-year effects. American Economic Review 107(10), 3211-28.

Bloningen, B. (2001). In search of substitution between foreign production and exports. Journal of International Economics 53(1), 81-104.

Buch, C., J. Kleiner, A. Lipponer, and F. Toubal (2005). Determinants and Effects of Foreign Direct Investment: Evidence from German Firm-Level Data. Economic Policy 20(41), $52-110$.

Conconi, P., A. Sapir, and M. Zanardi (2016). The internationalization process of firms: from exports to FDI. Journal of International Economics 99(C), 16-30.

Das, S., M. J. Roberts, and J. R. Tybout (2007). Market entry costs, producer heterogeneity, and export dynamics. Econometrica 75(3), 837-873.

Dixit, A. (1989). Entry and exit decisions under uncertainty. Journal of Political Economy 97(3), 630-638.

Eaton, J., M. Eslava, C. J. Krizan, M. Kugler, and J. Tybout (2014). A search and learning model of export dynamics. Mimeo, Pennsylvania State University. 
Eaton, J., M. Eslava, M. Kugler, and J. Tybout (2008). The margins of entry into export markets: Evidence from Colombia. In E. Helpman, D. Marin, and T. Verdier (eds.), The Organization of Firms in a Global Economy. Cambridge, MA: Harvard University Press.

Feenstra, R. C., R. Inklaar, and M. P. Timmer (2015). The next generation of the Penn World Table. American Economic Review 105(10), 3150-3182.

Fillat, J. L. and S. Garetto (2015). Risk, returns, and multinational production. Quarterly Journal of Economics 130(4), 2027-2073.

Fitzgerald, D., S. Haller, and Y. Yedid-Levi (2017). How exporters grow. Mimeo, Federal Reserve Bank of Minneapolis.

Foster, L., J. Haltiwanger, and C. Syverson (2016). The slow growth of new plants: Learning about demand? Economica 83(329), 91-129.

Ghironi, F. and M. J. Melitz (2005). International trade and macroeconomic dynamics with heterogeneous firms. The Quarterly Journal of Economics 120(3), 865-915.

Haltiwanger, J., R. Jarmin, and J. Miranda (2013). Who creates jobs? small vs. large vs. young. Review of Economics and Statistics 95(2), 347-361.

Head, K. and J. Ries (2001). Overseas investment and firm exports. Review of International Economics 9(1), 108-122.

Helpman, E., M. J. Melitz, and S. R. Yeaple (2004). Export versus FDI with Heterogeneous Firms. American Economic Review 94(1), 300-316.

Hopenhayn, H. A. (1992). Entry, exit, and firm dynamics in long run equilibrium. Econometrica 60(5), 1127-1150.

Impullitti, G., A. A. Irarrazabal, and L. D. Opromolla (2013). A theory of entry and exit into exports markets. Journal of International Economics 90(1), 75-90.

Kleinert, J., J. Martin, and F. Toubal (2015). The few leading the many: Foreign affiliates and business cycle co-movement. American Economic Journal: Macroeconomics 7(4), $134-59$.

Mayer, T. and S. Zignago (2011). Notes on cepii distances measures : the geodist database. CEPII Working Paper 2011(25).

Melitz, M. J. (2003). The impact of trade on intra-industry reallocations and aggregate industry productivity. Econometrica 71(6), 1695-1725.

Morales, E., G. Sheu, and A. Zahler (2017). Extended gravity. Mimeo Princeton University.

Ramondo, N., V. Rappoport, and K. J. Ruhl (2013). The proximity-concentration tradeoff under uncertainty. Review of Economic Studies 80(4), 1582-1621. 
Ramondo, N., V. Rappoport, and K. J. Ruhl (2016). Intra-firm Trade and Vertical Fragmentation in U.S. Multinational Corporations. Journal of International Economics 98(1), 51-59.

Ramondo, N. and A. Rodríguez-Clare (2013). Trade, multinational production, and the gains from openness. Journal of Political Economy 121(2), 273-322.

Rob, R. and N. Vettas (2003). Foreign direct investment and exports with growing demand. Review of Economic Studies 70(3), 629-648.

Roberts, M. J. and J. R. Tybout (1997). The decision to export in Colombia: An empirical model of entry with sunk costs. The American Economic Review 87(4), 545-564.

Ruhl, K. J. and J. Willis (2017). New exporter dynamics. International Economics Review 58(3), 703-726.

Schild, C.-J. and F. Walter (2015). Microdatabase direct investment 1999-2013, data report 2015-01 - metadata version 2-2. Deutsche Bundesbank Research Data and Service Centre.

Tintelnot, F. (2017). Global production with export platforms. Quarterly Journal of Economics 132(1), 157-209. 


\section{A Computations}

\section{A.1 Expected productivity growth for the average exporter}

Assume that firm productivity follows a first-order autoregressive process, $z_{t}=\rho z_{t-1}+$ $\sigma_{\epsilon} \epsilon_{t}$, with $\epsilon_{t} \sim N(0,1)$, and $0 \leq \rho<1$. The expected value of $z_{t}$ is zero with variance given by $\sigma_{z}^{2} \equiv \sigma_{\epsilon}^{2} /\left(1-\rho^{2}\right)$.

Conditional on a starting productivity value of $k$, the expected growth for an exporter in $t$ in the model with only left truncation is given by

$$
G^{L}(k) \equiv \mathbb{E}\left(z_{t}-z_{t-1} \mid z_{t}>\underline{z}, z_{t-1}=k\right),
$$

while in a model with left and right truncation, we have that

$$
G^{L R}(k) \equiv \mathbb{E}\left(z_{t}-z_{t-1} \mid \underline{z}<z_{t}<\bar{z}, \underline{z}=k\right),
$$

with $\underline{z}$ and $\bar{z}$ denoting the left and right truncation points, respectively.

After some algebra, we get that

$$
G^{L}(k)=\sigma_{\epsilon} \frac{\phi(\underline{c}(k))}{1-\Phi(\underline{c}(k))}-k(1-\rho)
$$

and

$$
G^{L R}(k)=\sigma_{\epsilon} \frac{\phi(\underline{c}(k))-\phi(\bar{c}(k))}{\Phi(\bar{c}(k))-\Phi(\underline{c}(k))}-k(1-\rho),
$$

with $\bar{c}(k) \equiv(\bar{z}-\rho k) / \sigma_{\epsilon}, \underline{c}(k) \equiv(\underline{z}-\rho k) / \sigma_{\epsilon}$, and $\phi(\cdot)$ and $\Phi(\cdot)$ denoting the p.d.f. and c.d.f., respectively, of a standard normal distribution.

Taking expectations over all exporters yields

$$
G^{L}=\frac{1}{1-F(\underline{z})} \int_{\underline{z}}^{\infty}\left(\sigma_{\epsilon} \frac{\phi(\underline{c}(k))}{1-\Phi(\underline{c}(k))}-k(1-\rho)\right) d F(k)
$$

and

$$
G^{L R}=\frac{1}{F(\bar{z})-F(\underline{z})} \int_{\underline{z}}^{\bar{z}}\left(\sigma_{\epsilon} \frac{\phi(\underline{c}(k))-\phi(\bar{c}(k))}{\Phi(\bar{c}(k))-\Phi(\underline{c}(k))}-k(1-\rho)\right) d F(k) .
$$

The average exporter grows faster in the model with only left truncation if and only if $G^{L}>G^{L R}$, which is equivalent to

$$
\begin{gathered}
\sigma_{\epsilon}\left(\int_{\underline{z}}^{\infty} \frac{\phi(\underline{c}(k))}{1-\Phi(\underline{c}(k))} \frac{d F(k)}{1-F(\underline{z})}-\int_{\underline{z}}^{\bar{z}} \frac{\phi(\underline{c}(k))-\phi(\bar{c}(k))}{\Phi(\bar{c}(k))-\Phi(\underline{c}(k))} \frac{d F(k)}{F(\bar{z})-F(\underline{z})}\right)> \\
(1-\rho)\left(\int_{\underline{z}}^{\infty} k \frac{d F(k)}{1-F(\underline{z})}-\int_{\underline{z}}^{\bar{z}} k \frac{d F(k)}{F(\bar{z})-F(\underline{z})}\right) .
\end{gathered}
$$


The r.h.s is simply

$$
(1-\rho) \sigma_{z}\left(\frac{\phi\left(\underline{z} / \sigma_{z}\right)}{1-\Phi\left(\underline{z} / \sigma_{z}\right)}-\frac{\phi\left(\underline{z} / \sigma_{z}\right)-\phi\left(\bar{z} / \sigma_{z}\right)}{\Phi\left(\bar{z} / \sigma_{z}\right)-\Phi\left(\underline{z} / \sigma_{z}\right)}\right) .
$$

Hence,

$$
\begin{gathered}
\int_{\underline{z}}^{\infty} \frac{\phi(\underline{c}(k))}{1-\Phi(\underline{c}(k))} \frac{d F(k)}{1-F(\underline{z})}-\int_{\underline{z}}^{\bar{z}} \frac{\phi(\underline{c}(k))-\phi(\bar{c}(k))}{\Phi(\bar{c}(k))-\Phi(\underline{c}(k))} \frac{d F(k)}{F(\bar{z})-F(\underline{z})}> \\
\sqrt{\frac{1-\rho}{1+\rho}}\left(\frac{\phi\left(\underline{z} / \sigma_{z}\right)}{1-\Phi\left(\underline{z} / \sigma_{z}\right)}-\frac{\phi\left(\underline{z} / \sigma_{z}\right)-\phi\left(\bar{z} / \sigma_{z}\right)}{\Phi\left(\bar{z} / \sigma_{z}\right)-\Phi\left(\underline{z} / \sigma_{z}\right)}\right) .
\end{gathered}
$$

\section{B Proofs}

\section{B.1 Proof of Proposition 1}

Firm-productivity $z$ follows a first-order autoregressive process, $z^{\prime}=\rho z+\sigma_{\epsilon} \epsilon^{\prime}$ with $\epsilon^{\prime} \sim$ $N(0,1)$ and $0 \leq \rho \leq 1$. Let $\log \bar{\phi}_{e}^{m} \equiv \bar{z}_{e}^{m}, \log \bar{\phi}^{m} \equiv \bar{z}^{m}$, and $\log \bar{\phi}^{x} \equiv \bar{z}^{x}$, with $\bar{z}_{e}^{m}>\bar{z}^{m}>\bar{z}^{x}$. Let $f^{m}(a)$ denote the probability of exit from MNE status in $t+1$ for a firm that was not an MNE in $t-1$ and had productivity $a$ in $t-1$,

$$
f^{m}(a)=\frac{\int_{\bar{z}_{e}^{m}}^{\infty} \operatorname{Pr}\left(\rho x+\sigma_{\epsilon} \epsilon \leq \bar{z}^{m} \mid x\right) g(x-\rho a) d x}{1-G\left(\bar{z}_{e}^{m}-\rho a\right)},
$$

where $g(\cdot)$ and $G(\cdot)$ denote, respectively, the probability and cumulative density functions of a normal distribution with mean zero and dispersion parameter $\sigma_{\epsilon}$. Let $f^{x}(a)$ denote the probability of exit from export status in $t+1$ for a firm that was only domestic in $t-1$ and had $a$ in $t-1$,

$$
f^{x}(a)=\frac{\int_{\bar{z}^{x}}^{\bar{z}_{e}^{m}} \operatorname{Pr}\left(\rho x+\sigma_{\epsilon} \epsilon \leq \bar{z}^{x} \mid x\right) g(x-\rho a) d x}{G\left(\bar{z}_{e}^{m}-\rho a\right)-G\left(\bar{z}^{x}-\rho a\right)} .
$$

Under which conditions $f^{m}(a)<f^{x}(a)$ ? First, notice that if $\bar{z}^{x}=\bar{z}^{m}=\bar{z}$, then

$$
\int_{\bar{z}_{e}^{m}}^{\infty} \operatorname{Pr}\left(\rho x+\sigma_{\epsilon} \epsilon \leq \bar{z} \mid x\right) g(x-\rho a) d x \leq \int_{\bar{z}}^{\bar{z}_{e}^{m}} \operatorname{Pr}\left(\rho x+\sigma_{\epsilon} \epsilon \leq \bar{z} \mid x\right) g(x-\rho a) d x .
$$

Let $\bar{z}^{m}=\bar{z}^{x}+\xi$, with $\xi>0$. Then,

$$
\lim _{\xi \rightarrow 0} \int_{\bar{z}_{e}^{m}}^{\infty} \operatorname{Pr}\left(\rho x+\sigma_{\epsilon} \epsilon \leq \bar{z}^{x}+\xi \mid x\right) g(x-\rho a) d x=\int_{\bar{z}_{e}^{m}}^{\infty} \operatorname{Pr}\left(\rho x+\sigma_{\epsilon} \epsilon \leq \bar{z}^{x} \mid x\right) g(x-\rho a) d x,
$$


which implies the inequality in (B.3). This means that the numerator in (B.1) is lower than in (B.2). If

$$
1-G\left(\bar{z}_{e}^{m}-\rho a\right)>G\left(\bar{z}_{e}^{m}-\rho a\right)-G\left(\bar{z}^{x}-\rho a\right),
$$

then $f^{m}(a)<f^{x}(a)$. Clearly, the inequality is true if $\bar{z}_{e}^{m}=\bar{z}^{x}$. Let $\bar{z}_{e}^{m}=\bar{z}^{x}+\varphi$, with $\varphi>0$. When $\varphi \rightarrow 0$, then $1-2 G\left(\bar{z}^{x}+\varphi-\rho a\right)>-G\left(\bar{z}^{x}-\rho a\right)$. More generally, there exists $\varphi^{*}$ such that for $0 \leq \varphi<\varphi^{*}$, the inequality in (B.4) holds and $f^{m}(a)<f^{x}(a)$.

\section{B.2 Proof of Proposition 2}

Firm productivity $z$ follows a first-order autoregressive process, $z^{\prime}=\rho z+\sigma_{\epsilon} \epsilon^{\prime}$ with $\epsilon^{\prime} \sim$ $N(0,1)$ and $0 \leq \rho \leq 1$. Let $\bar{z}_{e}^{m}$ and $\bar{z}^{m}$ be the productivity entry and exit thresholds, respectively. Let $f(a)$ denote the probability of exit from multinational status in $t+1$ for a firm that was not a multinational in $t-1$, and with productivity $a$ in $\mathrm{t}-1$, defined by

$$
f(a)=\frac{\int_{\bar{z}_{e}^{m}}^{\infty} \operatorname{Pr}\left(\rho x+\sigma_{\epsilon} \epsilon \leq \bar{z}^{m} \mid x\right) g(x-\rho a) d x}{1-G\left(\bar{z}_{e}^{m}-\rho a\right)},
$$

where $g(\cdot)$ and $G(\cdot)$ denote, respectively, the probability and cumulative density functions of a normal distribution with mean zero and dispersion parameter $\sigma_{\epsilon}$.

Let $\xi \rightarrow 0$, with $\xi>0$. We will show that $f($.$) is a decreasing function-i.e., f(a)-f(a-$ $\xi)<0$. Replacing, we get that

$$
f(a)-f(a-\xi)=\frac{\int_{z_{e}^{m}}^{\infty} \operatorname{Pr}\left(\rho x+\sigma_{\epsilon} \epsilon \leq \bar{z}^{m} \mid x\right) g(x-\rho a) d x}{1-G\left(\bar{z}_{e}^{m}-\rho a\right)}-\frac{\int_{\bar{z}_{e}^{m}}^{\infty} \operatorname{Pr}\left(\rho x+\sigma_{\epsilon} \epsilon \leq \bar{z}^{m} \mid x\right) g(x-\rho a+\rho \xi) d x}{1-G\left(\bar{z}_{e}^{m}-\rho a+\rho \xi\right)},
$$

which, after some algebra, becomes

$f(a)-f(a-\xi)=\frac{\int_{\bar{z}_{e}^{m}}^{\infty} \operatorname{Pr}\left(\rho x+\sigma_{\epsilon} \epsilon \leq \bar{z}^{m} \mid x\right)\left[g(x-\rho a)\left(1-G\left(\bar{z}_{e}^{m}-\rho a+\rho \xi\right)-g(x-\rho a+\rho \xi)\left(1-G\left(\bar{z}_{e}^{m}-\rho a\right)\right)\right] d x\right.}{\left[1-G\left(\bar{z}_{e}^{m}-\rho a\right)\right]\left[1-G\left(\bar{z}_{e}^{m}-\rho a+\rho \xi\right)\right]}$.

Since the denominator is always positive, we need to show that the numerator is negative. Note that $\operatorname{Pr}\left(\rho x+\sigma_{\epsilon} \epsilon \leq \bar{z}^{m} \mid x\right)$ is decreasing in $x$ and that

$$
\frac{\int_{\bar{z}_{e}^{m}}^{\infty} g(x-\rho a) d x}{1-G\left(\bar{z}_{e}^{m}-\rho a\right)}-\frac{\int_{\bar{z}_{e}^{m}}^{\infty} g(x-\rho a+\rho \xi) d x}{1-G\left(\bar{z}_{e}^{m}-\rho a+\rho \xi\right)}=0 .
$$

We then need to show that there exists only one point $m \in[c, \infty]$ such that for $x<m$,

$$
g(x-\rho a)\left[1-G\left(\bar{z}_{e}^{m}-\rho a+\rho \xi\right)\right]-g(x-\rho a+\rho \xi)\left[1-G\left(\bar{z}_{e}^{m}-\rho a\right)\right]<0,
$$


and for $x>m$,

$$
g(x-\rho a)\left[1-G\left(\bar{z}_{e}^{m}-\rho a+\rho \xi\right)\right]-g(x-\rho a+\rho \xi)\left[1-G\left(\bar{z}_{e}^{m}-\rho a\right)\right]>0 .
$$

Since for $\xi>0$ and $\xi \rightarrow 0, G(x-\xi)=G(x)-\xi g(x)$ and $g(x-\xi)=g(x)-\xi g^{\prime}(x)$, replacing, we get that

$$
\begin{aligned}
& g(x-\rho a)\left[1-G\left(\bar{z}_{e}^{m}-\rho a+\rho \xi\right)\right]-g(x-\rho a+\rho \xi)\left[1-G\left(\bar{z}_{e}^{m}-\rho a\right)\right] \\
= & g(x-\rho a)\left[1-G\left(\bar{z}_{e}^{m}-\rho a\right)-\rho \xi g\left(\bar{z}_{e}^{m}-\rho a\right)\right]-\left[g(x-\rho a)+\rho \xi g^{\prime}(x-\rho a)\right]\left[1-G\left(\bar{z}_{e}^{m}-\rho a\right)\right] \\
= & -\rho \xi g(x-\rho a) g\left(\bar{z}_{e}^{m}-\rho a\right)-\rho \xi g^{\prime}(x-\rho a)\left[1-G\left(\bar{z}_{e}^{m}-\rho a\right)\right] \\
= & \rho \xi g(x-\rho a)\left\{-g\left(\bar{z}_{e}^{m}-\rho a\right)+\frac{x-\rho a}{\sigma_{\epsilon}^{2}}\left[1-G\left(\bar{z}_{e}^{m}-\rho a\right)\right]\right\},
\end{aligned}
$$

where, in the last equality, we use that $g^{\prime}(x-\rho a)=-g(x-\rho a)(x-\rho a) / \sigma_{\epsilon}^{2}$.

Denote the function inside the curly brackets in (B.5) as

$$
k(x) \equiv-g\left(\bar{z}_{e}^{m}-\rho a\right)+\frac{x-\rho a}{\sigma_{\epsilon}^{2}}\left[1-G\left(\bar{z}_{e}^{m}-\rho a\right)\right] .
$$

For $x=m, k(m)=0$, with $m=c \sigma_{\epsilon}^{2}+\rho a$ where $c \equiv g\left(\bar{z}_{e}^{m}-\rho a\right) /\left[1-G\left(\bar{z}_{e}^{m}-\rho a\right)\right]>0$ (since $\left[1-G\left(\bar{z}_{e}^{m}-\rho a\right)\right]$ and $g\left(\bar{z}_{e}^{m}-\rho a\right)$ are positive constants). It remains to show that for $x<m$, $k(x)$ is negative, and for $x>m, k(x)$ is positive. Taking the derivative of $k(\cdot)$ with respect to $x$ yields

$$
k^{\prime}(x)=\frac{1-G\left(\bar{z}_{e}^{m}-\rho a\right)}{\sigma_{\epsilon}^{2}},
$$

which is positive for all $x$. Thus, $k(x)<k(m)$, for $x<m$, and $k(x)>k(m)$, for $x>m$, which implies that the expression in (B.5) is decreasing, proving that $f(a)$ is a decreasing function.

\section{B.3 Proof of Proposition 3}

Firm-productivity $z$ follows a first-order autoregressive process, $z^{\prime}=\rho z+\sigma_{\epsilon} \epsilon^{\prime}$ with $\epsilon^{\prime} \sim$ $N(0,1)$ and $0 \leq \rho \leq 1$. Let $\bar{z}$ denote the exit cutoff and $\bar{z}_{e}$ the entry cutoff into an international activity. Let $c$ be a constant in the interval $\left[\bar{z}_{e}, \infty\right)$. Let

$$
f(a)=\frac{\int_{\bar{z}_{e}}^{c} \operatorname{Pr}\left(\rho x+\sigma_{\epsilon} \epsilon \leq \bar{z} \mid x\right) g(x-\rho a) d x}{G(c)-G\left(\bar{z}_{e}-\rho a\right)}
$$

denote the probability of exit from status $i$ in $\mathrm{t}+1$ for a firm that is not yet in status $i$ in $\mathrm{t}-1$ and that has a productivity level of $a$ in $\mathrm{t}-1$. The functions $g(\cdot)$ and $G(\cdot)$ denote, respectively, the probability and cumulative density functions of a normal distribution with mean zero and dispersion parameter $\sigma_{\epsilon}$.

Let $\xi$ and $\varphi$ be two positive constants, with $\xi \leq \varphi$. Without loss of generality, the entry cutoff is $\bar{z}_{e}=\bar{z}+\varphi$. We want to show that when we increase the exit cutoff from $\bar{z}$ to $\bar{z}+\xi$, 
the exit probability increases more when sunk costs are zero-i.e., $\varphi=0$,

$$
f(a ; \xi>0 ; \varphi=0)-f(a ; \xi=0 ; \varphi=0)>f(a ; \xi>0 ; \varphi>0)-f(a ; \xi=0 ; \varphi>0) .
$$

The first term is given by

$$
\begin{aligned}
f(a ; \xi>0 ; \varphi=0)-f(a ; \xi=0 ; \varphi=0) & =\frac{\int_{\bar{z}}^{c} \operatorname{Pr}\left(\rho x+\sigma_{\epsilon} \epsilon \leq \bar{z}+\xi \mid x\right) g(x-\rho a) d x}{G(c)-G(\bar{z}-\rho a)} \\
& -\frac{\int_{\bar{z}}^{c} \operatorname{Pr}\left(\rho x+\sigma_{\epsilon} \epsilon \leq \bar{z} \mid x\right) g(x-\rho a) d x}{G(c)-G(\bar{z}-\rho a)},
\end{aligned}
$$

while the second one is

$$
\begin{aligned}
f(a ; \xi>0 ; \varphi>0)-f(a ; \xi=0 ; \varphi>0) & =\frac{\int_{\bar{z}+\varphi}^{c} \operatorname{Pr}\left(\rho x+\sigma_{\epsilon} \epsilon \leq \bar{z}+\xi \mid x\right) g(x-\rho a) d x}{G(c)-G(\bar{z}+\varphi-\rho a)} \\
& -\frac{\int_{\bar{z}+\varphi}^{c} \operatorname{Pr}\left(\rho x+\sigma_{\epsilon} \epsilon \leq \bar{z} \mid x\right) g(x-\rho a) d x}{G(c)-G(\bar{z}+\varphi-\rho a)} .
\end{aligned}
$$

Rearranging, we get that

$$
f(a ; \xi>0 ; \varphi=0)-f(a ; \xi>0 ; \varphi>0)>f(a ; \xi=0 ; \varphi=0)-f(a ; \xi=0 ; \varphi>0),
$$

which, after some algebra, yields

$$
\begin{gathered}
\frac{\int_{\bar{z}}^{c} \operatorname{Pr}\left(\rho x+\sigma_{\epsilon} \epsilon \leq \bar{z}+\xi \mid x\right) g(x-\rho a) d x-\int_{\bar{z}+\varphi}^{c} \operatorname{Pr}\left(\rho x+\sigma_{\epsilon} \epsilon \leq \bar{z}+\xi \mid x\right) g(x-\rho a) d x}{(G(c)-G(\bar{z}-\rho a))(G(c)-G(\bar{z}+\varphi-\rho a))} \\
>\frac{\int_{\bar{z}}^{c} \operatorname{Pr}\left(\rho x+\sigma_{\epsilon} \epsilon \leq \bar{z} \mid x\right) g(x-\rho a) d x-\int_{\bar{z}+\varphi}^{c} \operatorname{Pr}\left(\rho x+\sigma_{\epsilon} \epsilon \leq \bar{z} \mid x\right) g(x-\rho a) d x}{(G(c)-G(\bar{z}-\rho a))(G(c)-G(\bar{z}+\varphi-\rho a))} .
\end{gathered}
$$

Denominators are always positive and simplify. The numerators can be written as

$$
\begin{gathered}
\int_{\bar{z}}^{\bar{z}+\varphi} \operatorname{Pr}\left(\rho x+\sigma_{\epsilon} \epsilon \leq \bar{z}+\xi \mid x\right) g(x-\rho a) d x+\int_{\bar{z}+\varphi}^{c} \operatorname{Pr}\left(\rho x+\sigma_{\epsilon} \epsilon \leq \bar{z}+\xi \mid x\right) g(x-\rho a) d x \\
-\int_{\bar{z}+\varphi}^{c} \operatorname{Pr}\left(\rho x+\sigma_{\epsilon} \epsilon \leq \bar{z}+\xi \mid x\right) g(x-\rho a) d x=\int_{\bar{z}}^{\bar{z}+\varphi} \operatorname{Pr}\left(\rho x+\sigma_{\epsilon} \epsilon \leq \bar{z}+\xi \mid x\right) g(x-\rho a) d x,
\end{gathered}
$$


and analogously for the numerator in the right-hand side of the inequality. Hence,

$$
\int_{\bar{z}}^{\bar{z}+\varphi} \operatorname{Pr}\left(\rho x+\sigma_{\epsilon} \epsilon \leq \bar{z}+\xi \mid x\right) g(x-\rho a) d x>\int_{\bar{z}}^{\bar{z}+\varphi} \operatorname{Pr}\left(\rho x+\sigma_{\epsilon} \epsilon \leq \bar{z} \mid x\right) g(x-\rho a) d x .
$$

Because $\operatorname{Pr}\left(\rho x+\sigma_{\epsilon} \epsilon \leq \bar{z}+\xi \mid x\right)>\operatorname{Pr}\left(\rho x+\sigma_{\epsilon} \epsilon \leq \bar{z} \mid x\right)$, we show that when we increase the exit cutoff, the probability of exit upon entry increases by less with the presence of sunk costs.

\section{B.4 Proof of Proposition 4}

Let $\phi(\cdot)$ and $\Phi(\cdot)$ denote the p.d.f. and c.d.f., respectively, of a standard normal distribution. Then,

$$
\begin{aligned}
G^{L} & \equiv \mathbb{E}\left(z_{t}-z_{t-1} \mid z_{t}>\underline{z}, z_{t-1}=\underline{z}\right)=\mathbb{E}\left(z_{t} \mid z_{t}>\underline{z}, z_{t-1}=\underline{z}\right)-\underline{z} \\
& =\mathbb{E}\left(\rho z_{t-1}+\sigma_{\epsilon} \epsilon_{t} \mid z_{t}>\underline{z}, z_{t-1}=\underline{z}\right)-\underline{z}=\rho \underline{z}+\mathbb{E}\left(\sigma_{\epsilon} \epsilon_{t} \mid z_{t}>\underline{z}, z_{t-1}=\underline{z}\right)-\underline{z} \\
& =\rho \underline{z}+\sigma_{\epsilon} \mathbb{E}\left(\epsilon_{t} \mid \epsilon_{t}>\underline{z}(1-\rho) / \sigma_{\epsilon}\right)-\underline{z}=\sigma_{\epsilon} \mathbb{E}\left(\epsilon_{t} \mid \epsilon_{t}>\underline{c}\right)-\sigma_{\epsilon} \underline{c} \\
& =\sigma_{\epsilon}\left(\frac{\phi(\underline{c})}{1-\Phi(\underline{c})}-\underline{c}\right),
\end{aligned}
$$

where $\underline{c} \equiv(1-\rho) \underline{z} / \sigma_{\epsilon}$. Similar calculations yield

$$
G^{L R} \equiv \mathbb{E}\left(z_{t}-z_{t-1} \mid \underline{z}<z_{t}<\bar{z}, z_{t-1}=\underline{z}\right)=\sigma_{\epsilon}\left(\frac{\phi(\underline{c})-\phi(\bar{c})}{\Phi(\bar{c})-\Phi(\underline{c})}-\underline{c}\right)
$$

where $\bar{c} \equiv(1-\rho) \bar{z} / \sigma_{\epsilon}$.

Growth is higher with left (L) than with left and right (LR) truncation when

$$
\frac{\phi(\underline{c})}{1-\Phi(\underline{c})}>\frac{\phi(\underline{c})-\phi(\bar{c})}{\Phi(\bar{c})-\Phi(\underline{c})}
$$

or equivalently,

$$
\frac{\Phi(\bar{c})-\Phi(\underline{c})}{1-\Phi(\underline{c})}>\frac{\phi(\underline{c})-\phi(\bar{c})}{\phi(\underline{c})}
$$

The expression on the left-hand side (1.h.s.) of the inequality has the following properties:

$$
\lim _{\bar{c} \rightarrow \underline{c}} \frac{\Phi(\bar{c})-\Phi(\underline{c})}{1-\Phi(\underline{c})}=0 ; \quad \lim _{\bar{c} \rightarrow \infty} \frac{\Phi(\bar{c})-\Phi(\underline{c})}{1-\Phi(\underline{c})}=1 ; \quad \frac{d l . h . s .}{d \bar{c}}=\frac{\phi(\bar{c})}{1-\Phi(\underline{c})} \cdot>0 .
$$

With $\bar{z}>\underline{z}$, and $\bar{c}>0$, the expression on the right-hand side (r.h.s.) of the inequality has 
the following properties:

$$
\lim _{\bar{c} \rightarrow \underline{c}} \frac{\phi(\underline{c})-\phi(\bar{c})}{\phi(\underline{c})}=0 ; \quad \lim _{\bar{c} \rightarrow \infty} \frac{\phi(\underline{c})-\phi(\bar{c})}{\phi(\underline{c})}=1 ; \quad \frac{d r . h . s .}{d \bar{c}}=\bar{c} \frac{\phi(\bar{c})}{\phi(\underline{c})}>0 .
$$

Both functions have the same limits and both are increasing with $\bar{c}$. The left-hand side, however, grows faster than the right-hand side when

$$
\bar{c}<\frac{\phi(\underline{c})}{1-\Phi(\underline{c})} .
$$

Therefore, there exits $\bar{c}^{*}$-and consequently, $\bar{z}^{*}$-such that for all $\underline{c}<\bar{c}<\bar{c}^{*}, G^{L}>G^{L R}$, with $G^{L}=G^{L R}$ for $\bar{c}=\bar{c}^{*}$.

\section{Quantitative model}

We extend the model in Section 4 to include sunk export costs, $F^{x}>0$, paid in units of labor and $F^{m}>F^{x}$. Additionally, we assume that all fixed and sunk costs are heterogeneous across firms, but fixed over time for each firm. Fixed and sunk costs distributions are independent of the firm productivity distribution, and follow a log-normal distribution,

$$
\log \left(F_{e}^{s}\right) \sim N\left(\mu_{e}^{s},\left(\sigma_{e}^{s}\right)^{2}\right) \text { and } \log \left(f^{s}\right) \sim N\left(\mu^{s},\left(\sigma^{s}\right)^{2}\right),
$$

where $s=m, x$.

Firms have three possible states: producing in the domestic market for home consumers only $(D)$; producing in the domestic market for home and foreign consumers $(X)$; or producing in the domestic market for home consumers and in the foreign market for foreign consumers $(M)$.

The value of being an MNE with productivity $\phi$ is given by

$$
\begin{array}{r}
V\left(\phi, F_{e}^{m}, F_{e}^{x}, f^{m}, f^{x}, M\right)=\frac{X^{d}(\phi)}{\sigma}+\max \left\{\frac{X^{m}(\phi)}{\sigma}-f^{m}+\beta E_{\phi^{\prime}} V\left(\phi^{\prime}, F_{e}^{m}, F_{e}^{x}, f^{m}, f^{x}, M \mid \phi\right),\right. \\
\left.\beta E_{\phi^{\prime}} V\left(\phi^{\prime}, F_{e}^{m}, F_{e}^{x}, f^{m}, f^{x}, D \mid \phi\right), \frac{X^{x}(\phi)}{\sigma}-f^{x}-F_{e}^{x}+\beta E_{\phi^{\prime}} V\left(\phi^{\prime}, F_{e}^{m}, F_{e}^{x}, f^{m}, f^{x}, X \mid \phi\right)\right\} .
\end{array}
$$

An MNE chooses among continuing its operations abroad and incurring the per-period fixed cost $f^{m}$; shutting down the affiliate and becoming an exporter into the foreign market, incurring a per-period fixed cost $f^{x}$ and sunk cost $F^{x}$; or abandoning the foreign market altogether. 
The value of being an exporter with productivity $\phi$ is given by

$$
\begin{gathered}
V\left(\phi, F_{e}^{m}, F_{e}^{x}, f^{m}, f^{x}, X\right)=\frac{X^{d}(\phi)}{\sigma}+\max \left\{\frac{X^{x}(\phi)}{\sigma}-f^{x}+\beta E_{\phi^{\prime}} V\left(\phi^{\prime}, F_{e}^{m}, F_{e}^{x}, f^{m}, f^{x}, X \mid \phi\right),\right. \\
\left.\beta E_{\phi^{\prime}} V\left(\phi^{\prime}, F_{e}^{m}, F_{e}^{x}, f^{m}, f^{x}, D \mid \phi\right), \frac{X^{m}(\phi)}{\sigma}-f^{m}-F_{e}^{m}+\beta E_{\phi^{\prime}} V\left(\phi^{\prime}, F_{e}^{m}, F_{e}^{x}, f^{m}, f^{x}, M \mid \phi\right)\right\} .
\end{gathered}
$$

An exporter can choose to become an MNE in the foreign market and pay the per-period fixed cost $f^{m}$ and the entry sunk cost $F^{m}$; continue exporting to the foreign market, and pay the per-period fixed cost $f^{x}$; or operate in and serve only its home market.

The value of being a domestic firm with productivity $\phi$ is given by

$$
\begin{array}{r}
V\left(\phi, F_{e}^{m}, F_{e}^{x}, f^{m}, f^{x}, D\right)=\frac{X^{d}(\phi)}{\sigma}+\max \left\{\frac{X^{m}(\phi)}{\sigma}-f^{m}-F_{e}^{m}+\beta E_{\phi^{\prime}} V\left(\phi^{\prime}, F_{e}^{m}, F_{e}^{x}, f^{m}, f^{x}, M \mid \phi\right),\right. \\
\left.\beta E_{\phi^{\prime}} V\left(\phi^{\prime}, F_{e}^{m}, F_{e}^{x}, f^{m}, f^{x}, D \mid \phi\right), \frac{X^{x}(\phi)}{\sigma}-f^{x}-F_{e}^{x}+\beta E_{\phi^{\prime}} V\left(\phi^{\prime}, F_{e}^{m}, F_{e}^{x}, f^{m}, f^{x}, X \mid \phi\right)\right\} .
\end{array}
$$

A domestic firm can choose to become an MNE in the foreign market and pay the perperiod fixed cost $f^{m}$ and the entry sunk cost $F^{m}$; export to the foreign market, and pay the per-period fixed cost $f^{x}$ and sunk cost $F^{x}$; or operate in and serve only its home market. 


\section{Additional figures}

Figure D.1: Life-cycle dynamics of exports for new MNEs.

(a) Export-to-foreign sales ratio

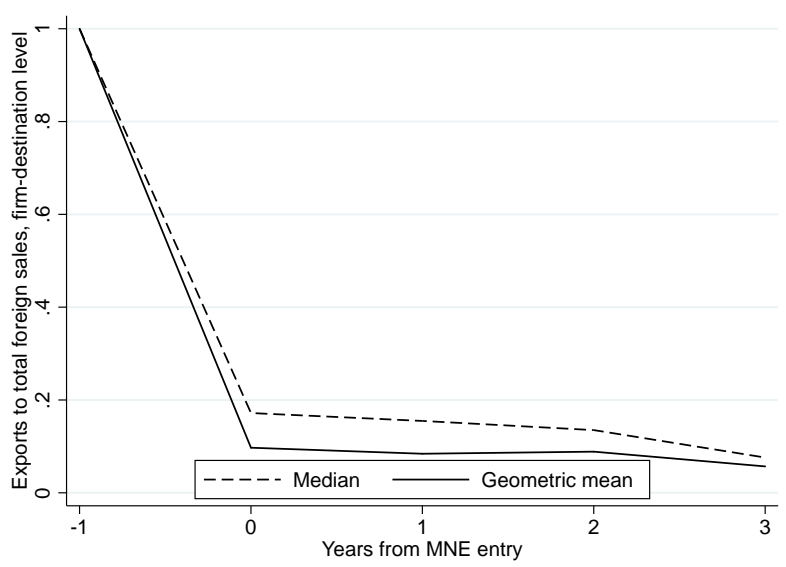

(b) Share of exporters, MNEs with export experience

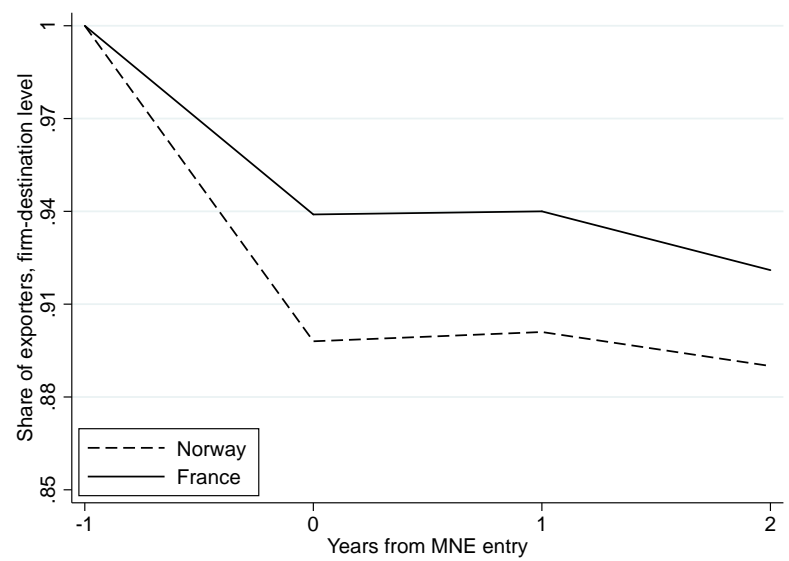

Notes: Data on MNE sales are available only for Norway. (D.1a): ratio of exports-to-foreign sales, by years from MNE entry, at the firm-destination-year level, average over MNE-destination pairs with at least four years in the market and with positive exports before MNE entry. (D.1b): share of exporters among MNEs that export (to the market of the affiliate) in the year before MNE entry, by years from MNE entry, for firm-destination pairs that survive at least four years as MNEs in a market. 


\section{Figure D.2: Exit rates by age: MNEs versus exporters, OLS.}

(a) France

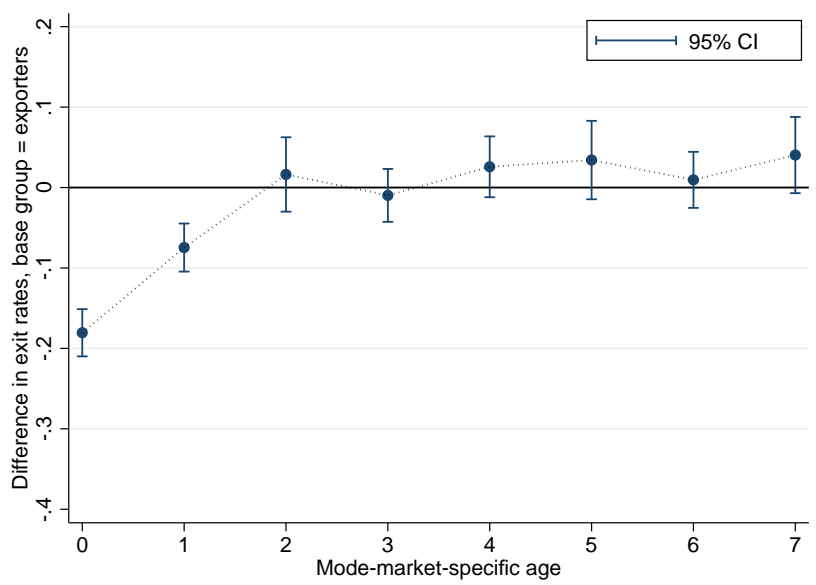

(b) Norway

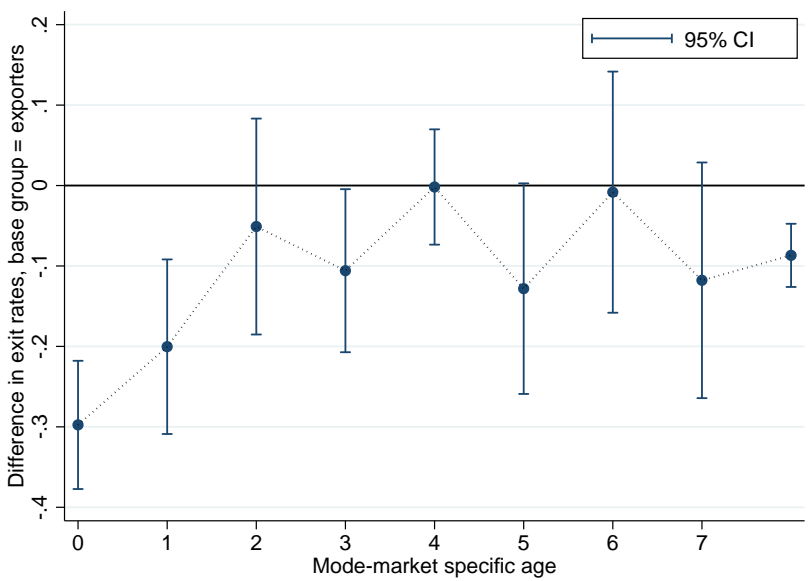

Notes: Difference in coefficients and 95\%-confidence bands from estimating, by OLS,

$$
D\left(\text { Exit }_{\text {inmta }}\right)=\beta_{0} M N E_{\text {inta }}+\sum_{a} \beta_{1}^{a} D\left(a g e_{i n m t}=a\right)+\sum_{a} \beta_{2}^{a} M N E_{\text {inta }} \times D\left(a g e_{i n m t}=a\right)+\epsilon_{i n m t a},
$$

where $D\left(\right.$ Exit $\left._{\text {inmta }}\right)$ is a dummy equal to one in the year $t$ in which firm $i$ of age $a$ exits mode $m$ in market $n$, and zero otherwise; $M N E_{\text {inta }}$ is one if firm $i$ at age $a$ is active in market $n$ and year $t$ as an MNE, and zero otherwise; and $D\left(a g e_{\text {inmt }}=a\right)$ equals one if firm $i$ in market $n$ and mode $m$ at time $t$ is of age $a$, and zero otherwise. We include year, industry, country fixed effects, and the log of home sales as a control. Standard errors are clustered by industry. Exporters are the base group. Observations are at the firm-destination-year level. Exporters refers to non-MNE exporters. 
Figure D.3: Exit rates by age: experienced versus non-experienced MNEs, OLS.

(a) France

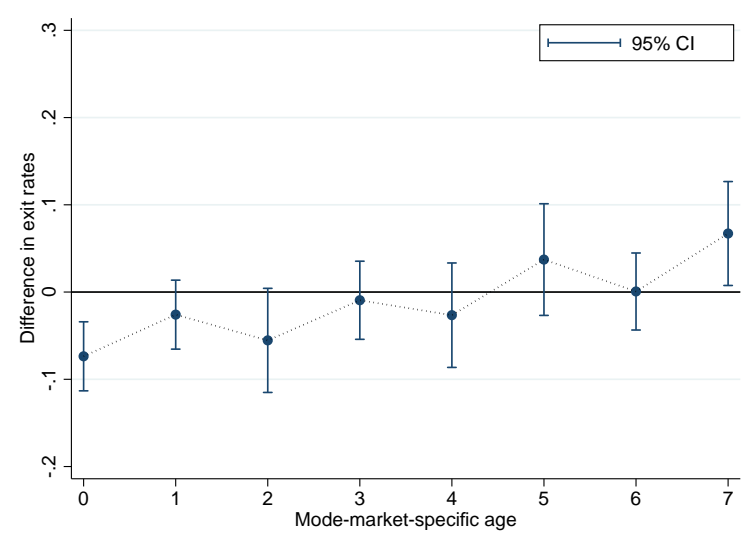

(b) Norway

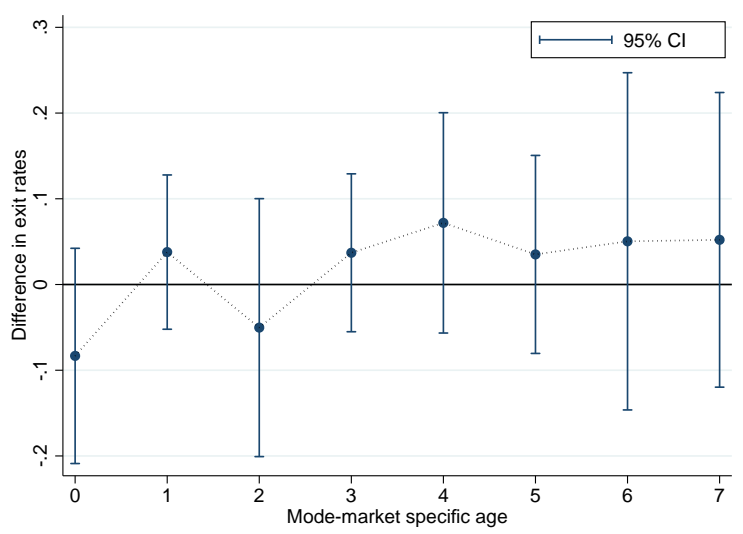

Notes: Number of exits from a mode-market relative to the number of firms active in a mode-market, by modemarket-specific age. Experienced MNEs are new affiliates of MNEs that exported to a foreign market for one or more years before opening an affiliate there.Difference in coefficients and 95\%-confidence bands from estimating, by OLS,

$$
\begin{array}{r}
D\left(\text { Exit }_{\text {inmta }}\right)=\beta_{0} M N E_{\text {inta }}+\sum_{a} \beta_{1}^{a} D\left(\text { age }_{\text {inmt }}=a\right)+\sum_{a} \beta_{2}^{a} M N E_{\text {inta }} \times D\left(\text { age }_{\text {inmt }}=a\right) \\
+\beta_{3} \text { exp.mne }_{i n m t a}+\sum_{a} \beta_{4}^{a} \text { exp.mne } e_{\text {inmta }} \times D\left(a g e_{\text {inmt }}=a\right)+\beta_{5} \text { exp.mne } e_{\text {inmta }} \times M N E_{\text {inta }} \\
+\sum_{a} \beta_{6}^{a} D\left(\text { age }_{\text {inmt }}=a\right) \times M N E_{\text {inta }} \times \text { exp.mne }_{\text {inmta }}+\epsilon_{\text {inmta }},
\end{array}
$$

where $D\left(\right.$ Exit $\left._{\text {inmta }}\right)$ is a dummy equal to one in the year $t$ in which firm $i$ of age $a$ exits mode $m$ in market $n$, and zero otherwise; $M N E_{\text {inta }}$ is one if firm $i$ at age $a$ is active in market $n$ and year $t$ as an MNE, and zero otherwise; and $D\left(a_{\text {age }}\right.$ inmt $\left.=a\right)$ equals one if firm $i$ in market $n$ and mode $m$ at time $t$ is of age $a$, and zero otherwise. exp.mne inmta indicates the years of export experience before MNE entry in market $n$, for firm $i$ at age $a$ and year $t$. We include year, industry, country fixed effects, and the log of home sales as a control. Standard errors are clustered by industry. Non-experienced MNEs are the base group. Observations at the firm-destination-year level.

Figure D.4: Sales growth by age and cohort.

(a) Exporters, France

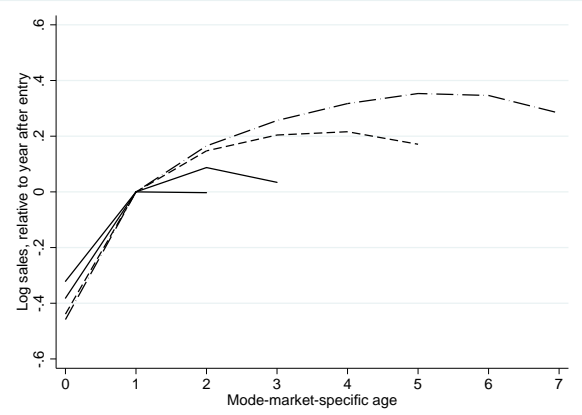

(b) Exporters, Norway

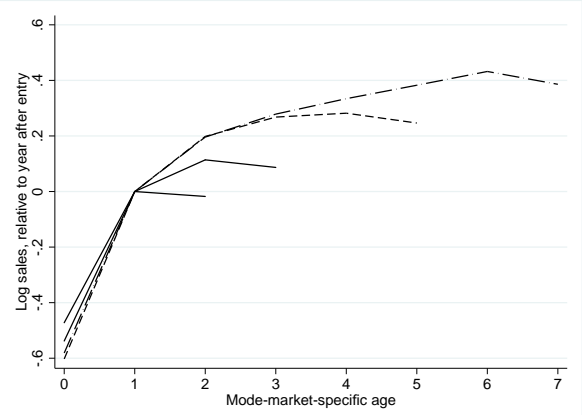

(c) MNEs, Norway

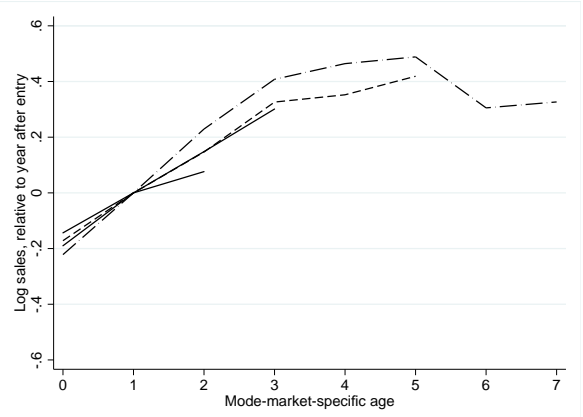

Notes: Log of firm-destination export (affiliate) sales with respect to firm-destination export (MNE) sales in the year after entry, firms with at least $t$ years in the market, selected cohorts in each mode. Observations are at the firmdestination-year level. We show averages across destinations weighted by each destination's share of export (MNE) firms. Log of sales first demeaned by industry, year, and destination fixed effects. Exporters refers to non-MNE exporters. 


\section{Figure D.5: Greenfield versus M\&A FDI, Germany.}

(a) Exit rates by age

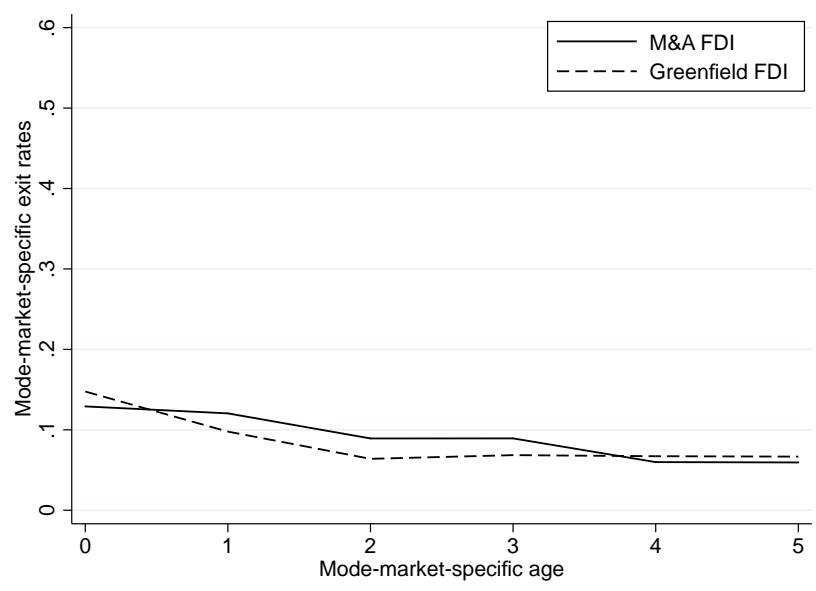

(b) Sales growth by age

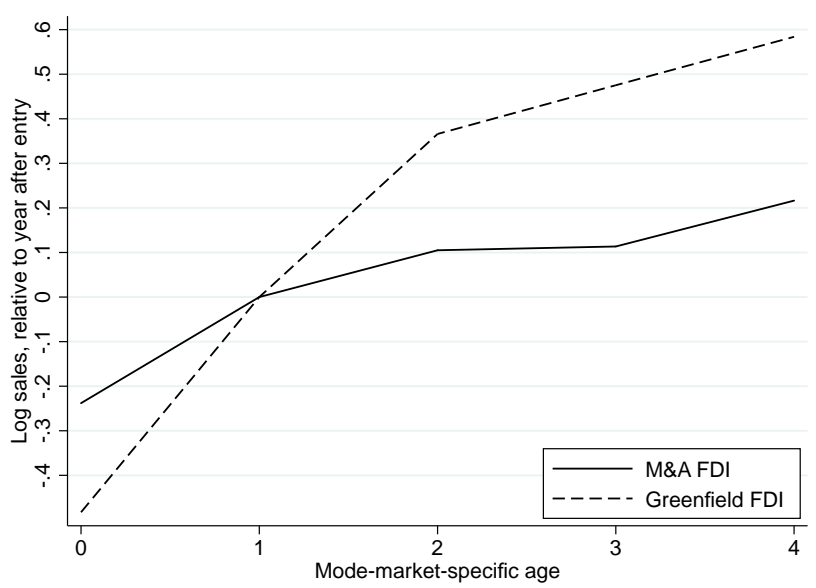

Notes: (D.5a): number of exits from a mode-market relative to the number of firms active in a mode-market, by mode-market-specific age. (D.5b): log of firm-destination MNE sales with respect to firm-destination MNE sales in the year after entry, firms with five or more years in the market. Observations are at the firm-destination-year level. We show averages across destinations weighted by each destination's share of MNE firms. Log of sales first demeaned by industry, year, and destination fixed effects. The sample period is 2005-2011 (no information on FDI entry mode available before 2005). Source: Deutsche Bundesbank Research Data and Service Centre, Microdatabase Direct investment, own calculations. 


\section{Figure D.6: First-year exit rates and market characteristics, Norway.}

(a) Exporters - market size

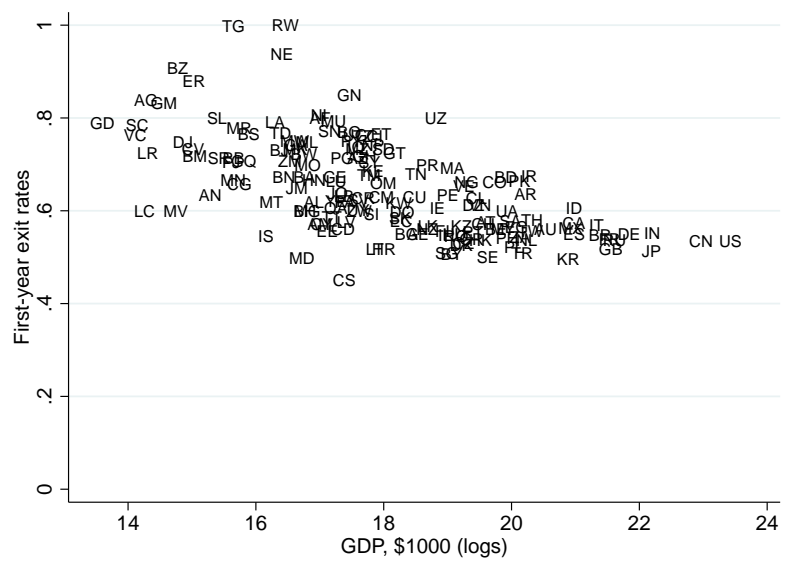

(c) Exporters - distance

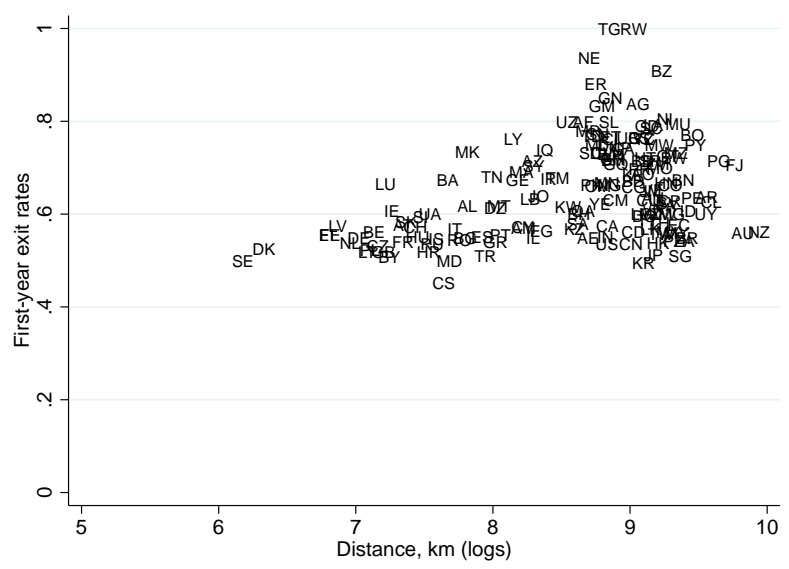

(b) MNEs - market size

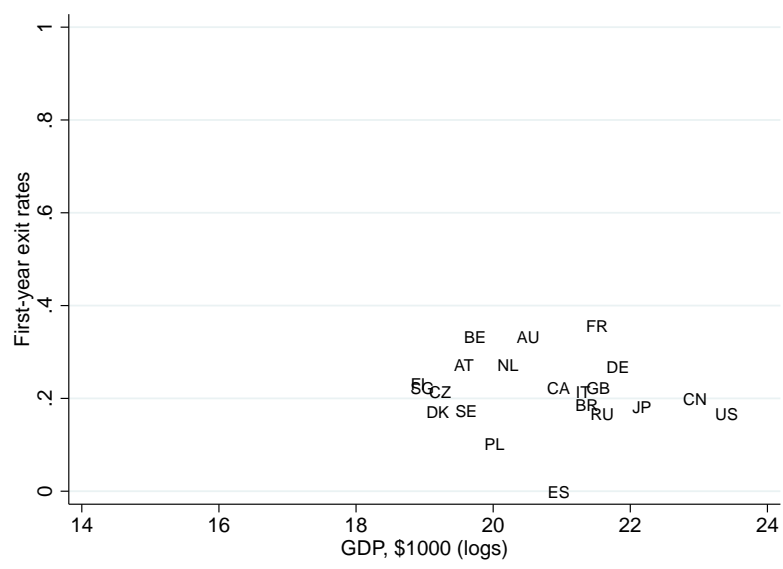

(d) MNEs - distance

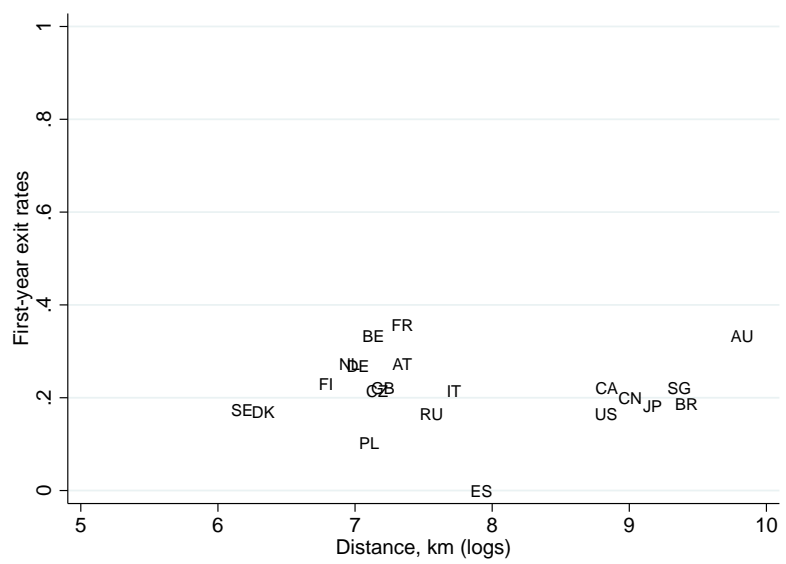

Notes: Number of exits from a mode-market relative to the number of firms active in a mode-market, for exporters and MNEs, in the first year upon market-mode entry. Destinations with ten or more firmyear observations and with available GDP data. Exporters refers to non-MNE exporters. GDP data from International Financial Statistics (IMF). Distance data from CEPII (Mayer and Zignago, 2011). 
Figure D.7: Entry rates and market characteristics, Norway.

(a) Exporters - market size

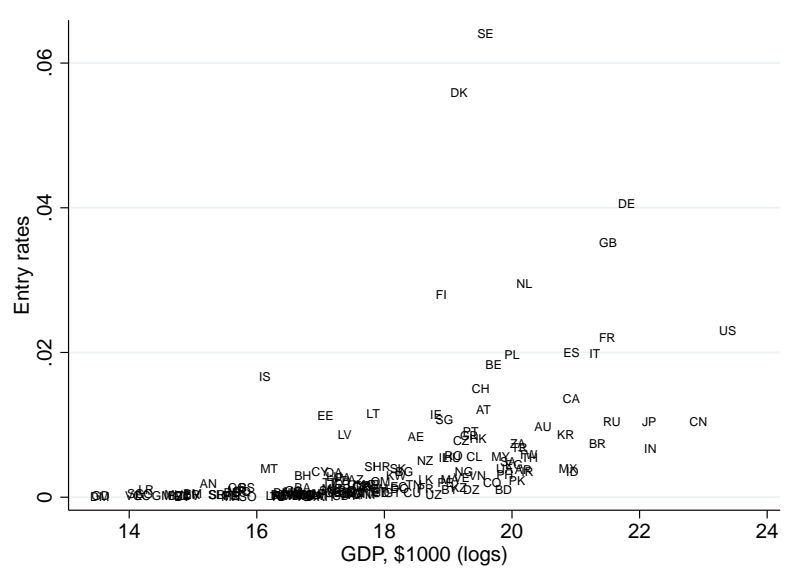

(c) Exporters - distance

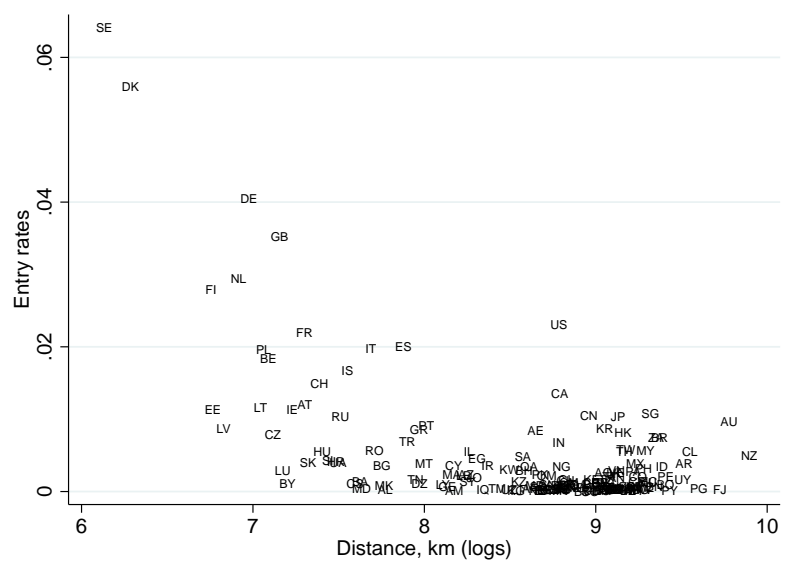

(b) MNEs - market size

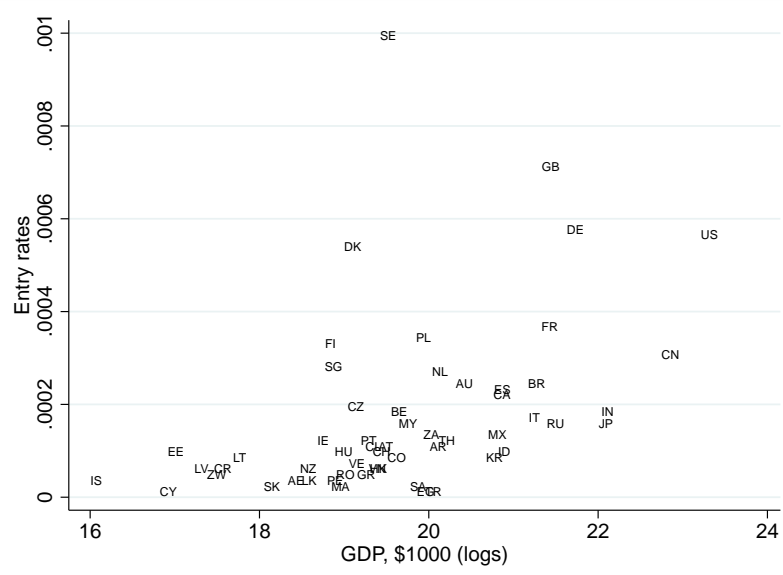

(d) MNEs - distance

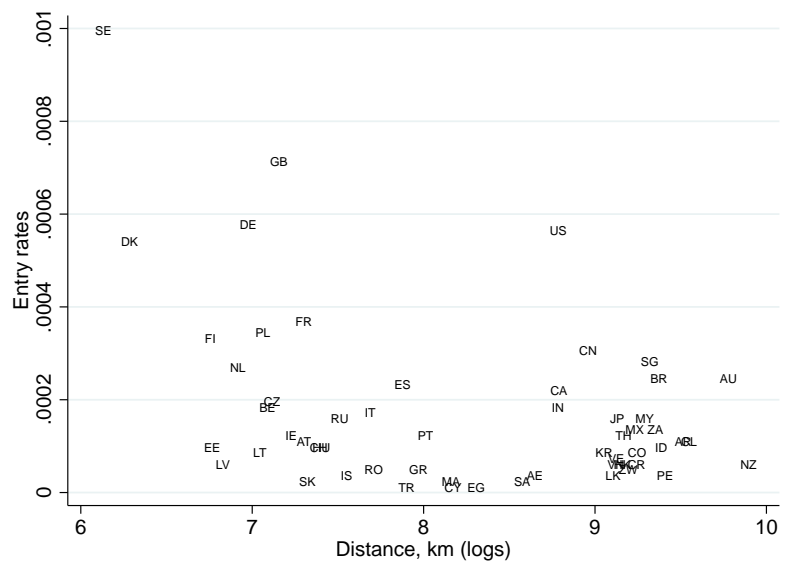

Notes: Number of entries to a mode-market relative to the number of domestic firms (MNEs) active in the home market. Destinations with ten or more firm-year observations and with available GDP data. Exporters refers to non-MNE exporters. GDP data from International Financial Statistics (IMF). Distance data from CEPII (Mayer and Zignago, 2011). 
Figure D.8: Exporters' exit rates by age: calibrated models and data, by country.

(a) Austria

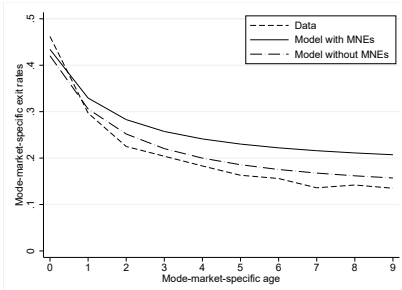

(e) Denmark

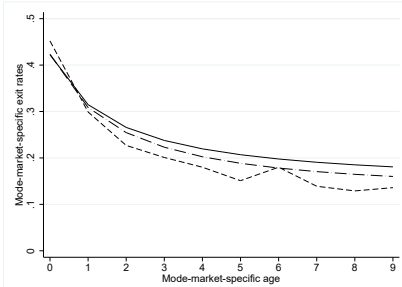

(i) Morocco

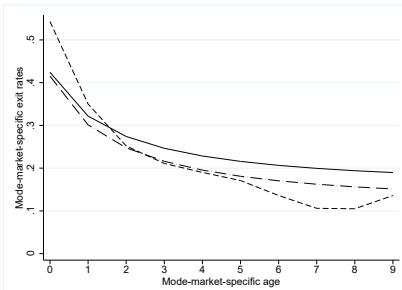

(m) Tunisia

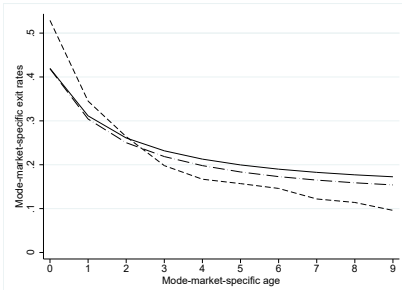

(b) Benelux

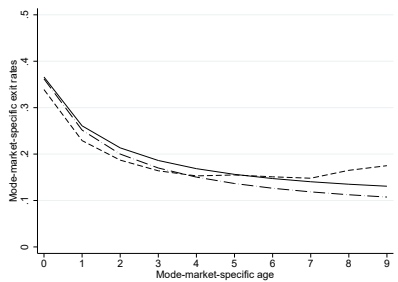

(f) Spain

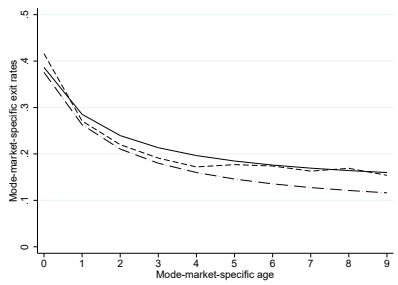

(j) Poland

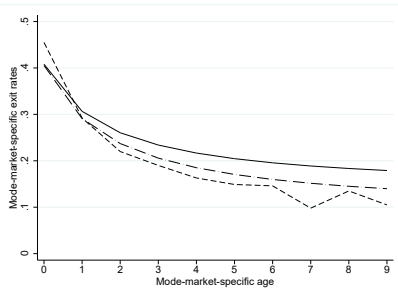

(n) United States

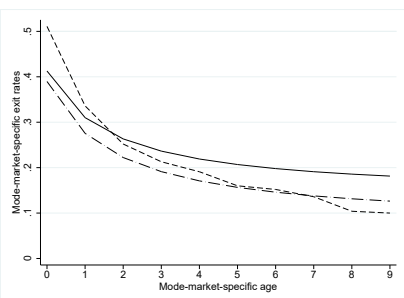

(c) Switzerland

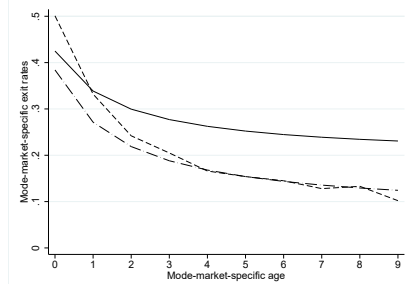

(g) Great Britain

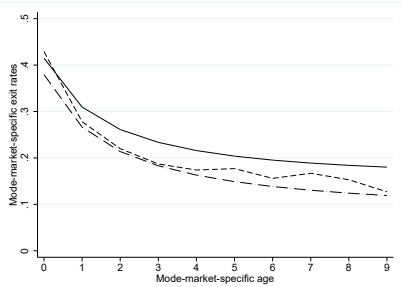

(k) Portugal

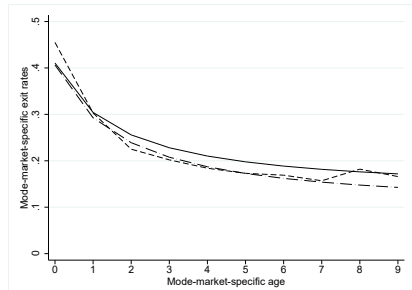

(o) China

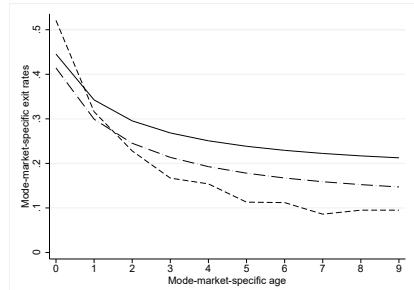

(d) Germany

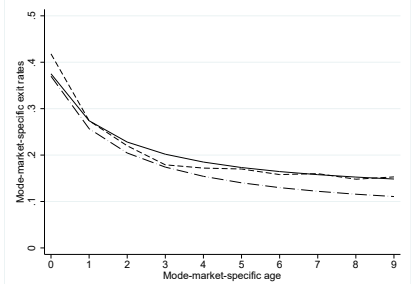

(h) Italy

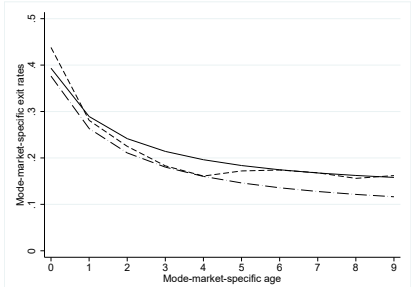

(1) Sweden

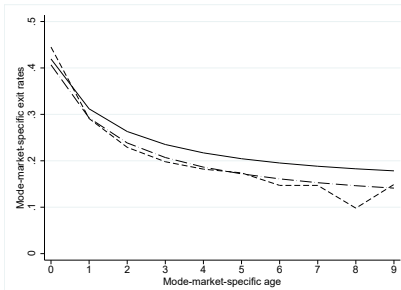

(p) Rest of the World

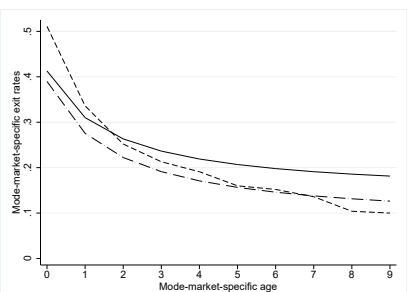

Notes: Models calibrated to French data. Number of exits from a mode-market relative to the number of firms active in a mode-market, for each destination. Rest of the World is a weighted average among the remaining countries in the sample. Exporters in the data refers to non-MNE exporters. Observations are at the firmdestination-year level. 
Figure D.9: Exporters' sales growth by age: calibrated models and data, by country.

(a) Austria

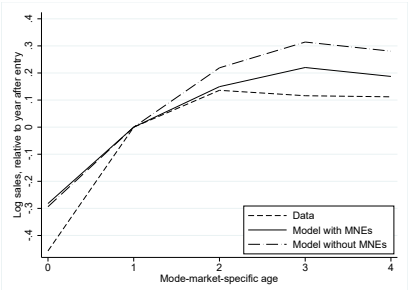

(e) Denmark

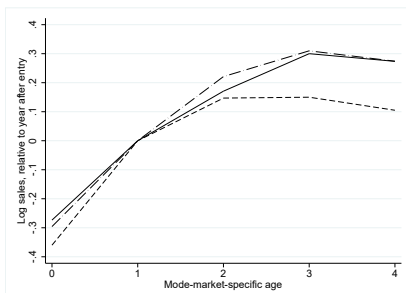

(i) Morocco

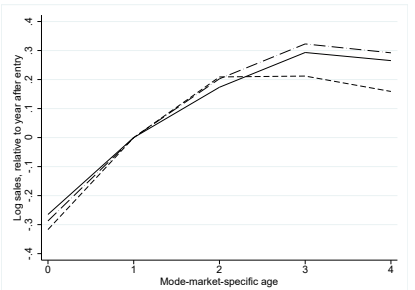

(m) Tunisia

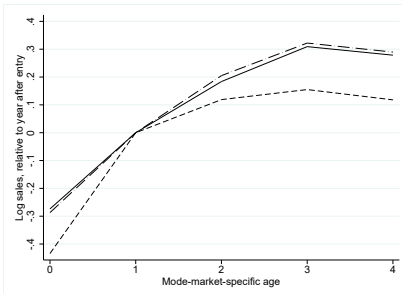

(b) Benelux

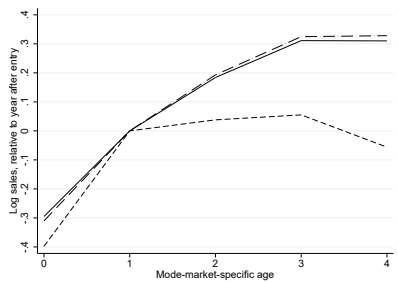

(f) Spain

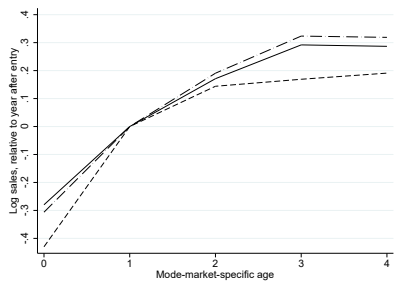

(j) Poland

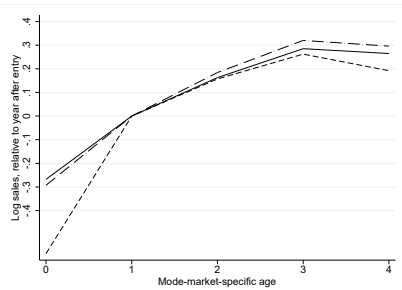

(n) United States

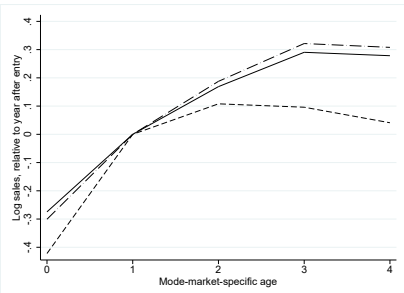

(c) Switzerland

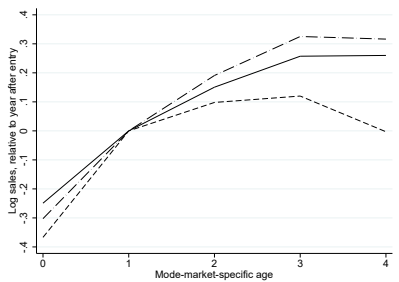

(g) Great Britain

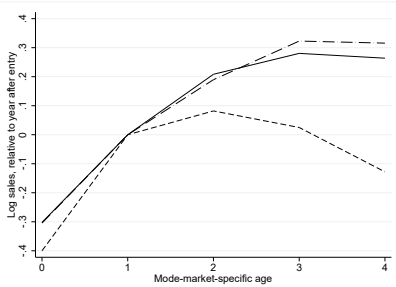

(k) Portugal

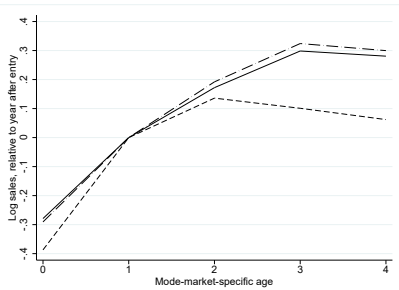

(o) China

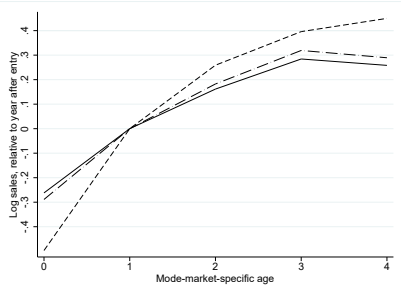

(d) Germany

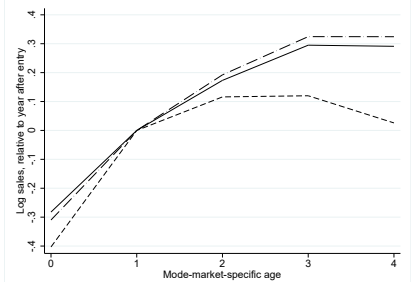

(h) Italy

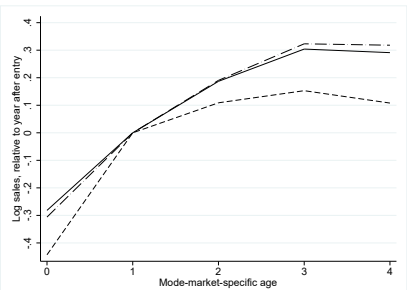

(l) Sweden

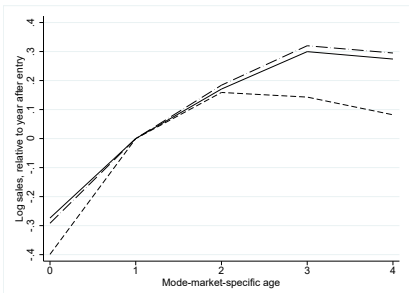

(p) Rest of the World

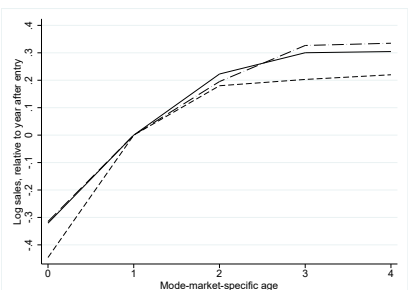

Notes: Models calibrated to French data. Log of firm-destination export sales with respect to firm-destination export sales in the year after entry, average over firms with five or more years in the market, by destination. Rest of the World is a weighted average among the remaining countries in the sample. Exporters in the data refers to non-MNE exporters. Observations are at the firm-destination-year level. 
Figure D.10: Exporters exit rates and sales growth, by age.

(a) New exporters' exit rates

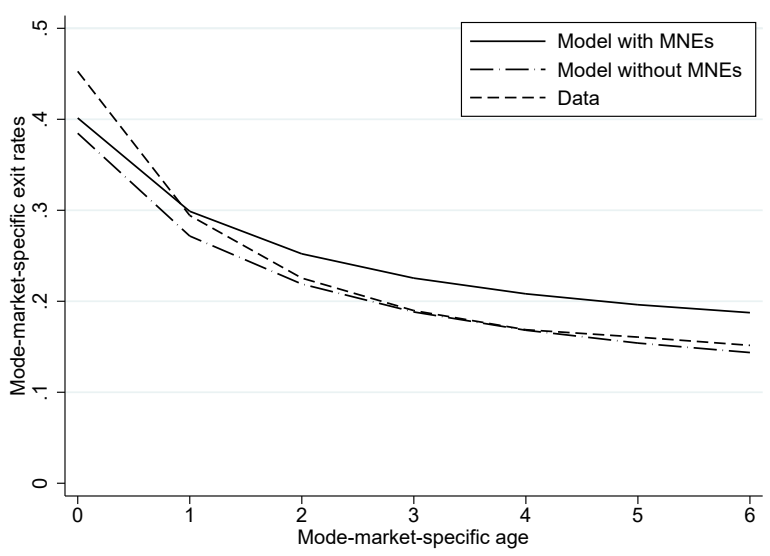

(b) New exporters' sales growth

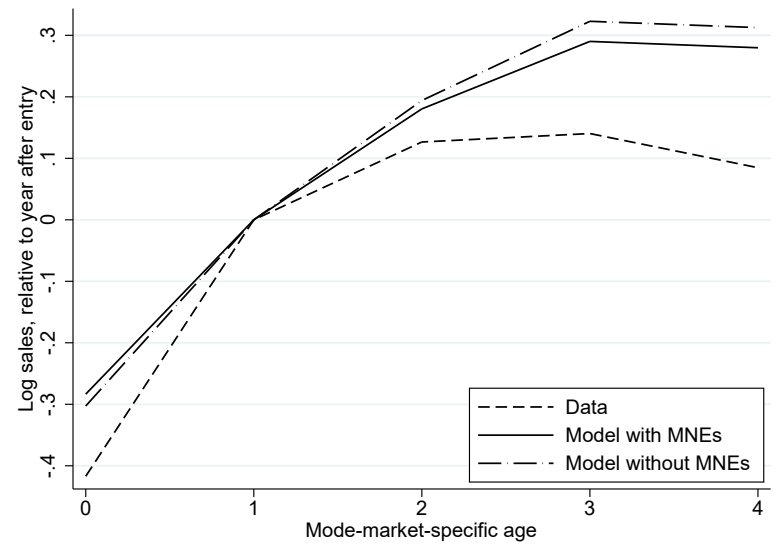

Notes: Models calibrated to French data. (D.10a): number of exits from a mode-market relative to the number of firms active in a mode-market, by mode-market-specific age. (D.10b): log of firm-destination export sales with respect to firm-destination export sales in the year after entry, an average over firms with five or more years in the market. In the data, log of sales are first demeaned by industry, year, and destination fixed effects. Observations are at the firm-destination-year level. We show averages across destinations included in the calibration, weighted by each destination's share of export firms. Weights are data-based (model-based) for data (model) variables. Exporters in the data refers to non-MNE exporters.

Figure D.11: Sales growth, by age and exporter type.

(a) Never-MNE exporters

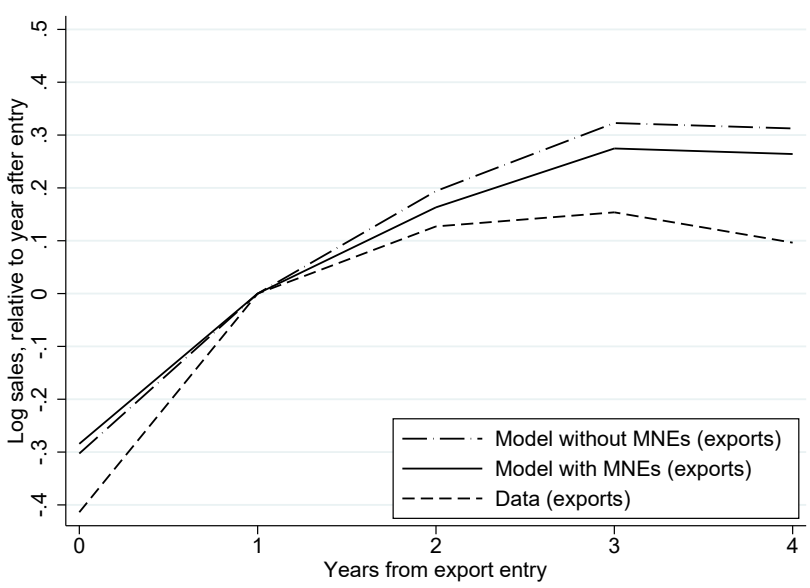

(b) Ever-MNE exporters

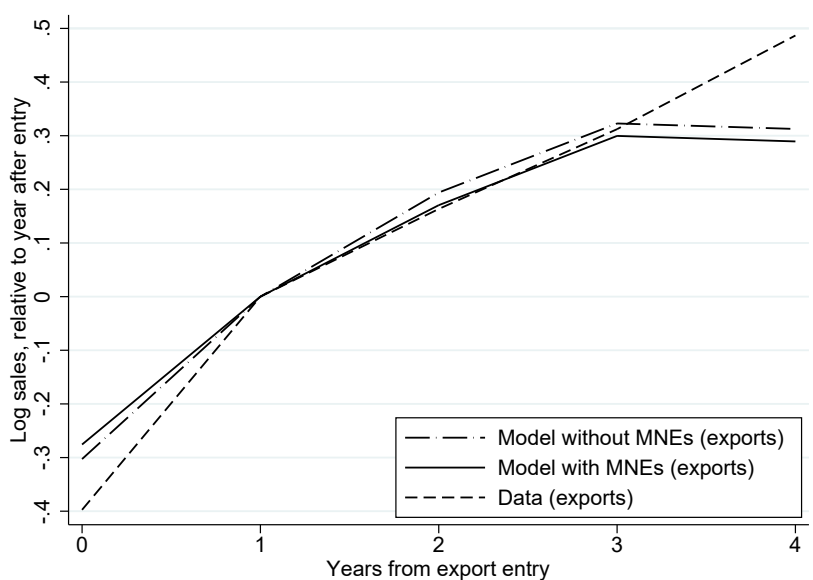

Notes: Models calibrated to French data. Log of firm-destination export sales with respect to firm-destination export sales in the year after export entry, an average over firms with five or more years in the market as exporters. Observations are at the firm-destination-year level. We show averages across destinations included in the calibration, weighted by each destination's share of export firms. Never-MNE exporters are exporters that, in our sample period, do not change to MNE status. Ever-MNE exporters are exporters that become MNEs after export entry. Exports for ever-MNE exporters are computed for the years before MNE entry. Exporters in the data refers to non-MNE exporters. 


\section{E Additional tables}

Table E.1: Summary statistics.

\begin{tabular}{lcccc}
\hline & \multicolumn{3}{c}{ France } & \\
& share of revenues & share of employment & share of firm-year obs & firm-year obs \\
\hline Domestic firms & 0.076 & 0.116 & 0.697 & 671,283 \\
Non-MNE exporters & 0.289 & 0.317 & 0.287 & 276,499 \\
Non-exporter MNEs & 0.005 & 0.010 & 0.001 & 1,007 \\
Exporter MNEs & 0.630 & 0.557 & 0.015 & 14,589 \\
\hline \hline & & \multicolumn{2}{c}{ Norway } & firm-year obs \\
\hline Domestic firms & 0.153 & 0.235 & 0.622 & 55,359 \\
Non-MNE exporters & 0.625 & 0.630 & 0.364 & 32,376 \\
Non-exporter MNEs & 0.002 & 0.002 & 0.002 & 136 \\
Exporter MNEs & 0.220 & 0.133 & 0.013 & 1,147 \\
\hline
\end{tabular}

Notes: Non-MNE exporters are exporters that do not have MNE activities. Non-exporter MNEs are MNEs that are not exporters. Exporter MNEs are MNEs that also export. 
Table E.2: Exit rates and growth rates, OLS.

\begin{tabular}{|c|c|c|c|c|c|c|c|c|c|c|c|}
\hline \multirow[t]{3}{*}{ Dep variable } & \multicolumn{4}{|c|}{$D$ (exit) } & \multicolumn{7}{|c|}{ Sales, relative to age one } \\
\hline & \multicolumn{2}{|c|}{ market-mode } & \multirow{2}{*}{$\begin{array}{c}\text { market } \\
\text { FRA }\end{array}$} & \multirow{2}{*}{$\begin{array}{c}\text { market age } \\
\text { FRA }\end{array}$} & \multicolumn{2}{|c|}{ calendar yr } & \multirow{2}{*}{$\begin{array}{l}12-m o \text { yr } \\
\text { FRA (exp) }\end{array}$} & \multicolumn{2}{|c|}{ "never MNEs" } & \multicolumn{2}{|c|}{ "ever MNEs" } \\
\hline & FRA & NOR & & & FRA (exp) & NOR & & FRA & NOR & FRA & NOR \\
\hline & (1) & (2) & (3) & (4) & (5) & (6) & (7) & (8) & (9) & (10) & (11) \\
\hline$M N E$ & $\begin{array}{c}-0.181^{* * *} \\
(0.015)\end{array}$ & $\begin{array}{c}-0.211^{* * *} \\
(0.038)\end{array}$ & $\begin{array}{c}-0.273^{* * *} \\
(0.014)\end{array}$ & $\begin{array}{c}-0.177^{* * *} \\
(0.016)\end{array}$ & & $\begin{array}{c}-0.079 * * \\
(0.045)\end{array}$ & & & & & \\
\hline$D($ age $=0)$ & $\begin{array}{c}-0.172^{* * *} \\
(0.003)\end{array}$ & $\begin{array}{c}-0.218^{* * *} \\
(0.008)\end{array}$ & $\begin{array}{c}-0.171^{* * *} \\
(0.003)\end{array}$ & $\begin{array}{c}-0.172^{* * *} \\
(0.003)\end{array}$ & $\begin{array}{c}-0.436^{* * *} \\
(0.011)\end{array}$ & $\begin{array}{c}-0.686^{* * *} \\
(0.045)\end{array}$ & $\begin{array}{c}-0.109^{* * *} \\
(0.010)\end{array}$ & $\begin{array}{c}-0.436^{* * *} \\
(0.011)\end{array}$ & $\begin{array}{c}-0.683^{* * * *} \\
(0.045)\end{array}$ & $\begin{array}{c}-0.448^{* * * *} \\
(0.089)\end{array}$ & $\begin{array}{r}-2.540^{* *} \\
(1.059)\end{array}$ \\
\hline$\times M N E$ & $\begin{array}{c}0.106^{* * *} \\
(0.015)\end{array}$ & $\begin{array}{c}0.116^{* * *} \\
(0.039)\end{array}$ & $\begin{array}{c}0.126^{* * *} \\
(0.015)\end{array}$ & $\begin{array}{c}0.106^{* * *} \\
(0.017)\end{array}$ & & $\begin{array}{c}0.469^{* * *} \\
(0.109)\end{array}$ & & & & & \\
\hline$D($ age $=1)$ & $\begin{array}{c}-0.246^{* * *} \\
(0.004)\end{array}$ & $\begin{array}{c}-0.270 \\
(0.011))\end{array}$ & $\begin{array}{c}-0.246^{* * *} \\
(0.004)\end{array}$ & $\begin{array}{c}-0.246^{* * *} \\
(0.004)\end{array}$ & & & & & & & \\
\hline$\times M N E$ & $\begin{array}{c}0.197^{* * *} \\
(0.029)\end{array}$ & $\begin{array}{c}0.257^{* * *} \\
(0.045)\end{array}$ & $\begin{array}{c}0.229^{* * *} \\
(0.029)\end{array}$ & $\begin{array}{c}0.198^{* * *} \\
(0.025)\end{array}$ & & & & & & & \\
\hline$D($ age $=2)$ & $\begin{array}{c}-0.283^{* * *} \\
(0.004)\end{array}$ & $\begin{array}{c}-0.316^{* * *} \\
(0.016)\end{array}$ & $\begin{array}{c}-0.283^{* * *} \\
(0.004)\end{array}$ & $\begin{array}{c}-0.283^{* * *} \\
(0.004)\end{array}$ & $\begin{array}{c}0.154^{* * *} \\
(0.008)\end{array}$ & $\begin{array}{c}0.178^{* * *} \\
(0.024)\end{array}$ & $\begin{array}{c}0.126^{* * *} \\
(0.009)\end{array}$ & $\begin{array}{c}0.154^{* * *} \\
(0.008)\end{array}$ & $\begin{array}{l}0.179 * * * \\
(0.0249)\end{array}$ & $\begin{array}{l}0.204^{* *} \\
(0.080)\end{array}$ & $\begin{array}{c}0.929 \\
(0.972)\end{array}$ \\
\hline$\times M N E$ & $\begin{array}{c}0.171^{* * *} \\
(0.019)\end{array}$ & $\begin{array}{c}0.236^{* * *} \\
(0.044)\end{array}$ & $\begin{array}{c}0.207^{* * *} \\
(0.018)\end{array}$ & $\begin{array}{c}0.179^{* * *} \\
(0.020)\end{array}$ & & $\begin{array}{c}0.021 \\
(0.102)\end{array}$ & & & & & \\
\hline$D($ age $=3)$ & $\begin{array}{c}-0.308^{* * *} \\
(0.006)\end{array}$ & $\begin{array}{c}-0.334^{* * *} \\
(0.013)\end{array}$ & $\begin{array}{c}-0.308^{* * *} \\
(0.006)\end{array}$ & $\begin{array}{c}-0.308^{* * *} \\
(0.006)\end{array}$ & $\begin{array}{c}0.209^{* * *} \\
(0.012)\end{array}$ & $\begin{array}{c}0.277^{* * *} \\
(0.042)\end{array}$ & $\begin{array}{c}0.164^{* * *} \\
(0.014)\end{array}$ & $\begin{array}{c}0.209^{* * *} \\
(0.012)\end{array}$ & $\begin{array}{c}0.280^{* * *} \\
(0.043)\end{array}$ & $\begin{array}{c}0.361^{* * *} \\
(0.086)\end{array}$ & $\begin{array}{c}1.376 \\
(1.509)\end{array}$ \\
\hline$\times M N E$ & $\begin{array}{c}0.207^{* * *} \\
(0.021)\end{array}$ & $\begin{array}{c}0.250^{* * *} \\
(0.044)\end{array}$ & $\begin{array}{c}0.246^{* * *} \\
(0.020)\end{array}$ & $\begin{array}{c}0.214^{* * *} \\
(0.026)\end{array}$ & & $\begin{array}{c}0.071 \\
(0.140)\end{array}$ & & & & & \\
\hline$D($ age $=4)$ & $\begin{array}{c}-0.316^{* * *} \\
(0.008)\end{array}$ & $\begin{array}{c}-0.343^{* * *} \\
(0.015)\end{array}$ & $\begin{array}{c}-0.316^{* * *} \\
(0.008)\end{array}$ & $\begin{array}{c}-0.317^{* * *} \\
(0.008)\end{array}$ & $\begin{array}{c}0.157^{* * *} \\
(0.020)\end{array}$ & $\begin{array}{c}0.241^{* * *} \\
(0.054)\end{array}$ & $\begin{array}{c}0.088^{* * *} \\
(0.020)\end{array}$ & $\begin{array}{c}0.157^{* * *} \\
(0.020)\end{array}$ & $\begin{array}{c}0.245^{* * *} \\
(0.055)\end{array}$ & $\begin{array}{c}0.460^{* * *} \\
(0.125)\end{array}$ & $\begin{array}{c}2.671 \\
(2.166)\end{array}$ \\
\hline$\times M N E$ & $\begin{array}{c}0.214^{* * *} \\
(0.025) \\
(0.008) \\
(0.018) \\
(0.007)\end{array}$ & $\begin{array}{c}0.283^{* * *} \\
(0.050) \\
(0.017) \\
(0.056) \\
(0.019)\end{array}$ & $\begin{array}{c}0.248^{* * *} \\
(0.024) \\
(0.008) \\
(0.017) \\
(0.007)\end{array}$ & $\begin{array}{c}0.216^{* * *} \\
(0.026) \\
(0.008) \\
(0.019) \\
(0.007)\end{array}$ & & $\begin{array}{c}0.132 \\
(0.143)\end{array}$ & & & & & \\
\hline Observations & $1,044,855$ & 74,119 & $1,044,855$ & $1,044,855$ & 405,009 & 25,887 & 297,896 & 405,009 & 24,902 & 2,632 & 104 \\
\hline
\end{tabular}

Notes: Dummy equals one if firm $i$ exits: cols 1-2: mode-market by mode-market age; col 3: market by mode-market age; col 4: mode-market by market age. Cols 5-11: Log of firm-destination export sales with respect to firm-destination export sales in the year after export entry, firms with five or more years in the market-mode. Col 7: adjusted by partialyear effects. Cols 8-9: Never-MNE are exporters that, in our sample period, do not change to MNE status. Cols 10-11: Ever-MNE are exporters that become MNEs after export entry. Exports for ever-MNE exporters computed for the years before MNE entry. All regressions with year, industry, and country fixed effects. Regressions for exit rates include log of Home sales and age dummies (and interactions) till age 6. Standard errors, clustered by industry, are in parentheses. ${ }^{* * *} p<0.01,{ }^{* *} p<0.05,{ }^{*} p<0.1$. Observations are at the firm-destination-year level. Exporters refers to non-MNE exporters. 
Table E.3: Foreign-to-domestic sales ratio, by country.

\begin{tabular}{|c|c|c|c|c|c|}
\hline & \multicolumn{2}{|c|}{ France } & & \multicolumn{2}{|c|}{ Norway } \\
\hline & $r_{n}^{x}$ & $r_{n}^{m}$ & & $r_{n}^{x}$ & $r_{n}^{m}$ \\
\hline Austria & 0.003 & $0.024^{*}$ & Austria & 0.009 & 0.432 \\
\hline Benelux & 0.068 & $0.135^{*}$ & Belgium & 0.029 & 0.086 \\
\hline Switzerland & 0.011 & 0.064 & Canada & 0.010 & 0.130 \\
\hline China & 0.014 & $0.213^{*}$ & Germany & 0.087 & 0.456 \\
\hline Germany & 0.123 & 0.181 & Denmark & 0.030 & 0.501 \\
\hline Denmark & 0.003 & $0.017^{*}$ & Spain & 0.031 & 0.051 \\
\hline Spain & 0.044 & 0.119 & Finland & 0.025 & 0.546 \\
\hline Great Britain & 0.040 & 0.181 & France & 0.045 & 0.231 \\
\hline Italy & 0.054 & 0.100 & Great Britain & 0.069 & 0.193 \\
\hline Morocco & 0.004 & 0.037 & Italy & 0.034 & 0.094 \\
\hline Portugal & 0.006 & $0.019^{*}$ & Netherlands & 0.031 & 0.178 \\
\hline Poland & 0.013 & 0.038 & Poland & 0.016 & 0.088 \\
\hline Sweden & 0.012 & $0.037^{*}$ & Sweden & 0.065 & 0.918 \\
\hline Tunisia & 0.004 & $0.008^{*}$ & Singapore & 0.018 & 0.382 \\
\hline United States & 0.038 & $0.427^{*}$ & United States & 0.056 & 0.749 \\
\hline RoW & 0.067 & 0.074 & RoW & 0.009 & 0.110 \\
\hline
\end{tabular}

Notes: $r_{n}^{x}$ refers to the export-to-domestic sales ratio, while $r_{n}^{m}$ refers to the MNE affiliate-todomestic sales ratio, for market $n .\left({ }^{*}\right)$ imputed values. RoW refers to the rest of the world, a weighted average among the remaining countries in the sample. Observations are at the firmdestination-year level.

Table E.4: Targeted moments, model and data, summary statistics.

\begin{tabular}{lcc||cc}
\hline & \multicolumn{2}{c||}{ Data, avg } & \multicolumn{2}{c}{ Model, avg } \\
& France & Norway & France & Norway \\
\hline Share of MNEs & 0.003 & 0.003 & 0.003 & 0.003 \\
Share of exporters & 0.090 & 0.087 & 0.085 & 0.085 \\
First-year exit rate, MNEs & 0.248 & 0.181 & 0.232 & 0.149 \\
First-year exit rate, exporters & 0.462 & 0.528 & 0.410 & 0.417 \\
Average exit rate, MNEs & 0.182 & 0.149 & 0.194 & 0.169 \\
Average exit rate, exporters & 0.316 & 0.313 & 0.254 & 0.252 \\
\hline
\end{tabular}

Notes: Observations are at the firm-destination-year level. For each variable, we show an unweighted averages across destinations included in the calibration. Share of exporters (MNEs) to market $n$ calculated relative to firms that do not export to (do not have affiliates in) destination $n$. Exporter (MNE) exit rates are calculated relative to exporters (MNEs) that stay in the market. Exporters in the data refers to non-MNE exporters. 
Table E.5: Targeted moments, model and data, by country.

\begin{tabular}{|c|c|c|c|c|c|c|c|c|c|c|c|c|}
\hline & \multicolumn{6}{|c|}{ Data } & \multicolumn{6}{|c|}{ Model } \\
\hline & \multicolumn{2}{|c|}{ shares } & \multicolumn{2}{|c|}{ 1st-yr exit rates } & \multicolumn{2}{|c|}{ avg exit rates } & \multicolumn{2}{|c|}{ shares } & \multicolumn{2}{|c|}{ 1st-yr exit rates } & \multicolumn{2}{|c|}{ avg exit rates } \\
\hline & $\exp$ & MNEs & $\exp$ & MNEs & $\exp$ & MNEs & $\exp$ & MNEs & $\exp$ & MNEs & $\exp$ & MNES \\
\hline \multicolumn{13}{|l|}{ France } \\
\hline Benelux & 0.155 & 0.004 & 0.339 & 0.299 & 0.269 & 0.209 & 0.150 & 0.005 & 0.339 & 0.273 & 0.203 & 0.196 \\
\hline Switzerland & 0.133 & 0.003 & 0.501 & 0.223 & 0.354 & 0.166 & 0.141 & 0.003 & 0.501 & 0.214 & 0.291 & 0.185 \\
\hline Germany & 0.128 & 0.005 & 0.418 & 0.250 & 0.284 & 0.174 & 0.118 & 0.005 & 0.418 & 0.245 & 0.218 & 0.188 \\
\hline Spain & 0.118 & 0.005 & 0.416 & 0.249 & 0.285 & 0.187 & 0.114 & 0.005 & 0.416 & 0.250 & 0.231 & 0.188 \\
\hline Italy & 0.111 & 0.004 & 0.438 & 0.295 & 0.297 & 0.192 & 0.104 & 0.004 & 0.438 & 0.285 & 0.240 & 0.207 \\
\hline G. Britain & 0.105 & 0.004 & 0.429 & 0.297 & 0.291 & 0.194 & 0.105 & 0.004 & 0.429 & 0.276 & 0.263 & 0.212 \\
\hline U. States & 0.078 & 0.006 & 0.511 & 0.238 & 0.362 & 0.175 & 0.077 & 0.006 & 0.511 & 0.222 & 0.261 & 0.189 \\
\hline Portugal & 0.070 & 0.002 & 0.455 & 0.235 & 0.316 & 0.157 & 0.068 & 0.002 & 0.455 & 0.203 & 0.259 & 0.196 \\
\hline Morocco & 0.057 & 0.002 & 0.543 & 0.218 & 0.391 & 0.162 & 0.053 & 0.002 & 0.543 & 0.200 & 0.286 & 0.190 \\
\hline Tunisia & 0.052 & 0.001 & 0.529 & 0.298 & 0.379 & 0.213 & 0.049 & 0.001 & 0.529 & 0.273 & 0.274 & 0.246 \\
\hline Austria & 0.054 & 0.001 & 0.462 & 0.258 & 0.318 & 0.182 & 0.053 & 0.001 & 0.462 & 0.232 & 0.300 & 0.215 \\
\hline Poland & 0.051 & 0.003 & 0.455 & 0.223 & 0.307 & 0.185 & 0.048 & 0.003 & 0.455 & 0.221 & 0.265 & 0.192 \\
\hline Sweden & 0.049 & 0.001 & 0.445 & 0.235 & 0.307 & 0.154 & 0.048 & 0.001 & 0.445 & 0.193 & 0.273 & 0.200 \\
\hline Denmark & 0.050 & 0.001 & 0.452 & 0.195 & 0.311 & 0.137 & 0.047 & 0.001 & 0.452 & 0.154 & 0.277 & 0.186 \\
\hline China & 0.036 & 0.003 & 0.521 & 0.188 & 0.353 & 0.146 & 0.035 & 0.003 & 0.521 & 0.165 & 0.306 & 0.176 \\
\hline RoW & 0.194 & 0.008 & 0.488 & 0.273 & 0.327 & 0.188 & 0.181 & 0.008 & 0.488 & 0.253 & 0.220 & 0.201 \\
\hline \multicolumn{13}{|l|}{ Norway } \\
\hline Austria & 0.031 & 0.001 & 0.527 & 0.263 & 0.282 & 0.180 & 0.031 & 0.001 & 0.527 & 0.201 & 0.298 & 0.229 \\
\hline Belgium & 0.055 & 0.001 & 0.552 & 0.214 & 0.313 & 0.129 & 0.060 & 0.001 & 0.552 & 0.186 & 0.240 & 0.169 \\
\hline Canada & 0.039 & 0.001 & 0.549 & 0.222 & 0.318 & 0.117 & 0.040 & 0.001 & 0.549 & 0.090 & 0.328 & 0.154 \\
\hline Germany & 0.135 & 0.004 & 0.541 & 0.182 & 0.285 & 0.166 & 0.121 & 0.005 & 0.541 & 0.090 & 0.258 & 0.137 \\
\hline Denmark & 0.193 & 0.004 & 0.511 & 0.163 & 0.270 & 0.139 & 0.175 & 0.004 & 0.511 & 0.150 & 0.232 & 0.166 \\
\hline Spain & 0.060 & 0.001 & 0.533 & 0.059 & 0.299 & 0.131 & 0.070 & 0.001 & 0.533 & 0.066 & 0.232 & 0.128 \\
\hline Finland & 0.099 & 0.002 & 0.544 & 0.192 & 0.273 & 0.141 & 0.095 & 0.002 & 0.544 & 0.151 & 0.264 & 0.187 \\
\hline France & 0.073 & 0.003 & 0.524 & 0.310 & 0.276 & 0.168 & 0.071 & 0.003 & 0.524 & 0.258 & 0.278 & 0.209 \\
\hline G. Britain & 0.123 & 0.006 & 0.506 & 0.179 & 0.268 & 0.131 & 0.114 & 0.006 & 0.506 & 0.158 & 0.251 & 0.165 \\
\hline Italy & 0.062 & 0.002 & 0.553 & 0.154 & 0.297 & 0.119 & 0.078 & 0.001 & 0.553 & 0.150 & 0.229 & 0.153 \\
\hline Netherlands & 0.100 & 0.002 & 0.528 & 0.238 & 0.274 & 0.136 & 0.100 & 0.002 & 0.528 & 0.180 & 0.280 & 0.188 \\
\hline Poland & 0.055 & 0.002 & 0.504 & 0.071 & 0.303 & 0.086 & 0.053 & 0.002 & 0.504 & 0.052 & 0.280 & 0.137 \\
\hline RoW & 0.005 & 0.000 & 0.572 & 0.204 & 0.364 & 0.168 & 0.005 & 0.000 & 0.572 & 0.171 & 0.372 & 0.240 \\
\hline Sweden & 0.249 & 0.007 & 0.484 & 0.158 & 0.239 & 0.151 & 0.226 & 0.007 & 0.484 & 0.154 & 0.199 & 0.160 \\
\hline Singapore & 0.035 & 0.002 & 0.505 & 0.150 & 0.280 & 0.120 & 0.035 & 0.002 & 0.505 & 0.118 & 0.298 & 0.167 \\
\hline U. States & 0.077 & 0.004 & 0.519 & 0.130 & 0.262 & 0.128 & 0.077 & 0.004 & 0.519 & 0.116 & 0.270 & 0.157 \\
\hline
\end{tabular}

Notes: Share of exporters (MNEs) to market $n$ calculated relative to firms that do not export to (do not have affiliates in) destination $n$. Exporter (MNE) exit rates are calculated relative to exporters (MNEs) that stay in the market. First-year exit rate refers to exit at age zero. RoW refers to the rest of the world, a weighted average among the remaining countries in the sample. Exporters in the data refers to non-MNE exporters. Observations are at the firm-destination-year level. 
Table E.6: Calibrated parameters, by country.

\begin{tabular}{|c|c|c|c|c|c|c|}
\hline & \multicolumn{4}{|c|}{ Model with MNEs } & \multicolumn{2}{|c|}{ Model without MNEs } \\
\hline & $\log \left(f_{n}^{x}\right)$ & $\log \left(f_{n}^{m}\right)$ & $\log \left(F_{n}^{x}\right)$ & $\log \left(F_{n}^{m}\right)$ & $\log \left(f_{n}^{x}\right)$ & $\log \left(F_{n}^{x}\right)$ \\
\hline \multicolumn{7}{|l|}{ France } \\
\hline Benelux & $-1.53(1.93)$ & $0.11(0.07)$ & $-25.78(32.56)$ & $8.55(5.61)$ & $-1.71(0.80)$ & $-28.02(13.15)$ \\
\hline Switzerland & $2.43(3.16)$ & $-0.01(0.00)$ & $-12.40(16.17)$ & 15.50 & $.87(1.53)$ & $-104.54(55.59)$ \\
\hline Germany & $-0.98(0.44)$ & $0.15(0.10)$ & $-19.97(9.00)$ & 13.17 & $.94(0.42)$ & $-27.19(12.03)$ \\
\hline Spain & $1.91(0.65)$ & $0.06(0.04)$ & $-15.77(5.40)$ & $12.13(7$ & $.75(0.80)$ & $-31.04(14.25)$ \\
\hline Italy & $1.09(1.89)$ & $0.09(0.06)$ & $-30.03(52.16)$ & $6.59(4.5$ & $.52(0.67)$ & $-25.76(11.40)$ \\
\hline Great Britain & $1.18(2.19)$ & $1.10(0.64)$ & $-13.79(25.46)$ & 14.51 & $-1.72(0.79)$ & $-30.81(14.19)$ \\
\hline United States & $1.62(0.56)$ & $1.82(0.93)$ & $-29.09(10.14)$ & $9.17(4.6$ & $-1.45(0.66)$ & $-32.77(14.98)$ \\
\hline Portugal & $-3.16(0.84)$ & $-0.81(0.51)$ & $-41.73(11.09)$ & $13.96(8$ & $-2.72(1.41)$ & $-77.87(40.42)$ \\
\hline Morocco & $-2.89(1.35)$ & $-0.13(0.08)$ & $-36.41(17.00)$ & $11.11(6.77)$ & $-2.82(1.44)$ & $-69.49(35.62)$ \\
\hline Tunisia & $-2.81(1.32)$ & $-1.01(0.72)$ & $-37.41(17.61)$ & $8.59(6.10)$ & $-2.72(1.43)$ & $-85.20(44.63)$ \\
\hline Austria & $2.73(2.01)$ & $-0.01(0.01)$ & $-25.44(18.74)$ & $11.85(7.21)$ & $-2.96(1.56)$ & $-95.74(50.36)$ \\
\hline Poland & $2.29(0.04)$ & $-0.51(0.32)$ & $-44.48(0.83)$ & $17.33(10.78)$ & $-1.97(0.85)$ & $-25.90(11.20)$ \\
\hline Sweden & $-2.06(0.83)$ & $0.21(0.12)$ & $-34.11(13.73)$ & $11.25(6.60)$ & $-2.01(0.87)$ & $-26.16(11.34)$ \\
\hline Denmark & $-3.37(0.91)$ & $-0.43(0.27)$ & $-28.19(7.59)$ & $6.98(4.32)$ & $-2.86(1.54)$ & $-125.00(67.38)$ \\
\hline China & $-1.79(0.54)$ & $1.54(0.76)$ & $-30.73(9.35)$ & $9.38(4.61)$ & $-1.61(0.73)$ & $-28.59(12.95)$ \\
\hline RoW & $-1.61(2.71)$ & $-0.86(0.55)$ & $-14.00(23.58)$ & 18.70 & $-1.95(0.84)$ & $-25.42(10.95)$ \\
\hline \multicolumn{7}{|l|}{ Norway } \\
\hline Austria & $3.07(0.86)$ & $1.51(0.78)$ & $-27.32(7.60)$ & $8.57(4.41)$ & $-3.03(0.88)$ & $-22.87(6.65)$ \\
\hline Belgium & $-2.79(0.13)$ & $2.62(2.37)$ & $-28.26(1.36)$ & $4.70(4.24)$ & $-2.17(0.99)$ & $-27.01(12.34)$ \\
\hline Canada & $-3.14(0.88)$ & $0.35(0.45)$ & $-15.16(4.25)$ & $2.33(2.99)$ & $-2.81(1.14)$ & $-22.20(9.04)$ \\
\hline Germany & $-1.69(1.55)$ & $0.24(0.14)$ & $-43.01(39.47)$ & $5.22(2.98)$ & $-1.94(0.89)$ & $-30.79(14.04)$ \\
\hline Denmark & $-3.00(1.57)$ & $0.58(0.33)$ & $-85.72(44.90)$ & $9.60(5.52)$ & $-2.97(1.61)$ & $-143.57(77.86)$ \\
\hline Spain & $-2.79(0.27)$ & $2.03(2.39)$ & $-19.38(1.84)$ & $2.61(3.08)$ & $-2.23(0.95)$ & $-23.27(9.85)$ \\
\hline Finland & $-2.71(1.18)$ & $1.21(0.63)$ & $-29.55(12.89)$ & $8.74(4.55)$ & $-2.74(1.12)$ & $-23.12(9.47)$ \\
\hline France & $-2.11(0.88)$ & $-0.11(0.07)$ & $-22.05(9.20)$ & 8.83 (5.97) & $-2.03(0.94)$ & -32.66 (15.07) \\
\hline Great Britain & $-2.10(0.93)$ & $-0.66(0.42)$ & $-51.29(22.66)$ & 16.40 (10.27) & $-2.08(0.91)$ & $-25.91(11.35)$ \\
\hline Italy & $-2.78(0.28)$ & $3.09(2.67)$ & $-42.35(4.27)$ & $5.04(4.35)$ & $-2.18(0.93)$ & $-24.67(10.54)$ \\
\hline Netherlands & $-2.36(1.62)$ & $-0.17(0.11)$ & $-24.63(16.94)$ & $10.02(6.31)$ & $-2.57(1.08)$ & $-24.87(10.44)$ \\
\hline Poland & $-2.97(0.80)$ & $-0.86(0.51)$ & $-24.50(6.56)$ & $18.13(10.70)$ & $-2.45(1.30)$ & $-103.41(54.75)$ \\
\hline RoW & $-2.19(0.62)$ & $1.06(0.58)$ & $-31.01(8.74)$ & $10.32(5.64)$ & $-2.00(0.79)$ & $-27.29(10.78)$ \\
\hline Sweden & $-2.94(0.84)$ & $0.94(0.52)$ & $-25.94(7.40)$ & $9.25(5.14)$ & $-2.66(1.41)$ & $-105.98(56.35)$ \\
\hline Singapore & $-2.74(0.55)$ & $0.67(0.36)$ & $-39.35(7.97)$ & $8.15(4.44)$ & $-2.41(0.90)$ & $-27.83(10.43)$ \\
\hline United States & $-2.19(0.55)$ & $1.07(0.56)$ & $-36.72(9.23)$ & $9.38(4.91)$ & $-1.94(0.85)$ & $-26.35(11.48)$ \\
\hline
\end{tabular}

Notes: We report the mean across firms and the standard deviation in parenthesis. $f_{n}^{x}$ are per-period fixed export costs; $f_{n}^{m}$ are per-period fixed MNE costs; $F_{n}^{x}$ are sunk export costs; and $F_{n}^{m}$ are sunk MNE costs. RoW refers to the rest of the world, a weighted average among the remaining countries in the sample. Observations are at the firm-destination-year level. 
Table E.7: The size of calibrated costs, by country.

\begin{tabular}{|c|c|c|c|c|c|c|c|c|}
\hline & \multicolumn{4}{|c|}{ as $\%$ of sales, for median firm } & \multicolumn{4}{|c|}{ in U.S. dollars, for median firm } \\
\hline & $f_{n}^{x}$ & $f_{n}^{m}$ & $F_{n}^{x}$ & $F_{n}^{m}$ & $f_{n}^{x}$ & $f_{n}^{m}$ & $F_{n}^{x}$ & $F_{n}^{m}$ \\
\hline \multicolumn{9}{|l|}{ France } \\
\hline Benelux & 15.09 & 8.71 & 0.00 & 2.40 & 2,818 & 230,473 & 0 & 63,629 \\
\hline Switzerland & 24.51 & 11.84 & 0.00 & 6.10 & 641 & 33,279 & 0 & 17,150 \\
\hline Germany & 12.11 & 6.32 & 0.06 & 1.67 & 4,319 & 99,775 & 22 & 26,360 \\
\hline Spain & 12.72 & 9.59 & 0.02 & 3.24 & 7,693 & 144,395 & 11 & 48,768 \\
\hline Italy & 15.80 & 9.15 & 0.00 & 2.19 & 1,375 & 242,682 & 0 & 57,994 \\
\hline Great Britain & 16.58 & 12.03 & 0.00 & 3.03 & 1,186 & 13,930 & 0 & 3,503 \\
\hline United States & 13.30 & 13.08 & 0.00 & 4.15 & 4,111 & 22,638 & 0 & 7,175 \\
\hline Portugal & 14.17 & 10.40 & 0.00 & 5.45 & 10,552 & 71,844 & 0 & 37,651 \\
\hline Morocco & 15.56 & 12.40 & 0.02 & 7.53 & 6,098 & 52,811 & 8 & 32,075 \\
\hline Tunisia & 15.48 & 8.93 & 0.02 & 2.61 & 6,466 & 82,339 & 9 & 24,107 \\
\hline Austria & 17.51 & 12.88 & 0.00 & 6.91 & 2,516 & 79,248 & 0 & 42,519 \\
\hline Poland & 13.37 & 10.38 & 0.00 & 4.27 & 8,257 & 63,511 & 0 & 26,159 \\
\hline Sweden & 14.67 & 10.29 & 0.00 & 6.97 & 4,126 & 78,653 & 0 & 53,248 \\
\hline Denmark & 14.92 & 11.47 & 0.00 & 10.31 & 11,645 & 93,852 & 0 & 84,357 \\
\hline China & 14.54 & 12.95 & 0.00 & 8.36 & 5,380 & 30,661 & 0 & 19,777 \\
\hline RoW & 16.78 & 2.49 & 0.00 & 0.72 & 735 & 26,913 & 0 & 7,782 \\
\hline \multicolumn{9}{|l|}{ Norway } \\
\hline Austria & 18.27 & 17.20 & 0.00 & 7.12 & 16,692 & 42,167 & 0 & 17,457 \\
\hline Belgium & 16.11 & 14.15 & 0.00 & 4.41 & 14,354 & 223,242 & 0 & 69,587 \\
\hline Canada & 18.83 & 11.99 & 0.02 & 62.59 & 17,744 & 65,864 & 21 & 343,909 \\
\hline Germany & 18.65 & 13.95 & 0.00 & 11.62 & 2,862 & 120,806 & 0 & 100,606 \\
\hline Denmark & 18.28 & 15.20 & 0.01 & 8.39 & 6,336 & 131,619 & 3 & 72,675 \\
\hline Spain & 15.99 & 11.62 & 0.00 & 6.35 & 19,336 & 213,711 & 0 & 116,753 \\
\hline Finland & 18.02 & 15.93 & 0.02 & 9.17 & 9,466 & 50,191 & 10 & 28,891 \\
\hline France & 17.57 & 15.09 & 0.04 & 3.67 & 8,938 & 130,652 & 20 & 31,828 \\
\hline Great Britain & 16.94 & 12.68 & 0.00 & 5.67 & 8,761 & 152,299 & 0 & 68,038 \\
\hline Italy & 15.90 & 13.63 & 0.00 & 5.21 & 19,179 & 593,834 & 0 & 226,801 \\
\hline Netherlands & 19.45 & 14.98 & 0.00 & 7.03 & 5,718 & 191,689 & 0 & 90,032 \\
\hline Poland & 17.62 & 13.24 & 0.00 & 18.49 & 21,330 & 132,818 & 0 & 185,505 \\
\hline Sweden & 19.07 & 15.81 & 0.00 & 10.88 & 6,871 & 65,530 & 0 & 45,103 \\
\hline Singapore & 15.44 & 15.02 & 0.00 & 7.26 & 12,632 & 54,242 & 0 & 26,217 \\
\hline United States & 17.58 & 15.35 & 0.00 & 11.61 & 19,631 & 119,927 & 0 & 90,765 \\
\hline RoW & 16.81 & 15.06 & 0.00 & 10.66 & 11,171 & 89,324 & 0 & 63,235 \\
\hline
\end{tabular}

Notes: $f_{n}^{x}$ are per-period fixed export costs; $f_{n}^{m}$ are per-period fixed MNE costs; $F_{n}^{x}$ are sunk export costs; and $F_{n}^{m}$ are sunk MNE costs. The fixed and sunk export (MNE) cost values are conditional means across random draws, conditional on positive measure of exporters (MNEs). Median firm refers to the firm with median export (MNE) sales in destination $n$. RoW refers to the rest of the world, a weighted average among the remaining countries in the sample. 